RICARDO LEANDRO PIANTOLA DA SILVA

\title{
USO DO CONCEITO DE QUALIDADE DO CONTEÚDO DA MEMÓRIA EM ALGORITMOS DE GERÊNCIA DE MEMÓRIA PAGINADA
}

Tese apresentada a Escola Politécnica da Universidade de São Paulo para obtenção do Título de Doutor em Ciências. 
RICARDO LEANDRO PIANTOLA DA SILVA

\section{USO DO CONCEITO DE QUALIDADE DO CONTEÚDO DA MEMÓRIA EM ALGORITMOS DE GERÊNCIA DE MEMÓRIA PAGINADA}

Tese apresentada a Escola Politécnica da Universidade de São Paulo para obtenção do Título de Doutor em Ciências.

Área de Concentração:

Engenharia de Computação

Orientador:

Dra. Liria Matsumoto Sato 
Este exemplar foi revisado e alterado em relação à versão original, sob responsabilidade única do autor e com a anuência de seu orientador.

São Paulo, 17 de setembro de 2015.

Assinatura do autor:

Assinatura do orientador:

\section{Catalogação-na-publicação}

Silva, Ricardo Leandro Piantola da

Uso do conceito de qualidade do conteúdo da memória em algoritmos de gerência de memória paginada/ R. L. P. Silva. - versão corr. - São Paulo, 2015.

$140 \mathrm{p}$.

Tese (Doutorado) - Escola Politécnica da Universidade de São Paulo. Departamento de Engenharia de Computação e Sistemas Digitais.

1. Sistemas operacionais 2. Gerência de memória I. Universidade de São Paulo. Escola Politécnica. Departamento de Engenharia de Computação e Sistemas Digitais II. t. 
À Dayane, minha esposa, meu amor, minha gratidão eterna por participar dos momentos mais felizes de minha vida. 


\section{AGRADECIMENTOS}

Aos meus pais, Edna e Roberto, por tudo que já realizei e vou realizar.

A Deus, por tudo o que me foi concedido.

Ao meu orientador, o professor Edson Toshimi Midorikawa, pela paciência, confiança e apoio nesses últimos nove anos, e por poder dividir seus momentos de inspiração.

À minha orientadora, a professora Líria Matsumoto Sato, pela sua grande ajuda na reta final, dedicando o seu precioso tempo, e pelo aprendizado que vou levar por toda minha vida.

Aos amigos Heloisa Brites Bisca, Ricardo Rocha e Denis Ogura, pela amizade, companheirismo e incentivo constantes.

Ao professor Jorge Kinoshita, pelo apoio à ideia e apontamentos do relatório de qualificação, e pelas várias tardes de conversas que me fizeram refletir sobre minhas convecções.

A todos os colegas do LAHPC pela solidariedade e pelo ótimo ambiente de trabalho.

À Escola Politécnica da Universidade de São Paulo, pela oportunidade da realização da Pós-Graduação.

À Superintendência de Tecnologia da Informação da USP (STI), pela disponibilização de serviços de armazenamento e processamento de dados na InterNuvem Cloud.

Aos meus coordenadores na Universidade Paulista pelo apoio e incentivo.

À minha esposa, Dayane, a quem também dedico esta tese. Pelo apoio infinito em todos os momentos. 


\section{RESUMO}

No contexto da gerência de memória em sistemas operacionais, vários grupos de pesquisa desenvolvem trabalhos na área de algoritmos para gerência de memória virtual e alguns algoritmos para substituição de páginas têm sido propostos na literatura recente. No entanto, essas propostas não chegaram a um algoritmo que resolva satisfatoriamente o problema de desempenho na gerência de memória. Ainda não existe um consenso entre os pesquisadores de como essa questão deve ser tratada de maneira eficiente, e as propostas de algoritmos desenvolvidas possuem grande sobrecarga devido à sua complexidade. O objetivo deste trabalho é propor uma forma eficiente de gerenciar a memória com a composição de técnicas de busca, posicionamento e substituição de páginas. A hipótese aqui adotada é que para tratar o problema da gerência da memória é melhor consumir recursos computacionais determinando quais páginas deveriam estar na memória em um determinado instante de tempo do que gastar recursos determinando qual página será retirada da memória. A tese apresenta uma reanálise dos principais trabalhos que têm como objetivo o desempenho da gerência de memória, tornando possível retirar conclusões e ideias sobre quais fatores influenciam de maneira positiva com relação ao desempenho do sistema. A partir deste estudo, é determinado o conceito de qualidade do conteúdo da memória e criada uma métrica para medi-la. Aplicando tal conceito, formula-se um método sistêmico de construção de algoritmos de gerência de memória. Realiza-se uma aplicação desse método, criando-se então, os algoritmos $R R+n g$ e RRlock+ng. A métrica é aplicada em simulações na fase final do método, mostrando-se adequada para realizar as análises. Os resultados obtidos mostram que a hipótese - tratar o problema da gerência da memória, consumindo recursos computacionais determinando quais páginas devem estar na memória ao invés de quais devem deixá-la - mostrou-se válida e parece promissora.

Palavras-chave: Sistemas operacionais. Gerência de memória. Memória virtual. Paginação sob demanda. Substituição de páginas. 


\section{ABSTRACT}

When it comes to memory management in operating systems, many research groups have been developing works in the memory management algorithms area and some page replacement algorithms have been proposed in the recent literature. Such proposals were not successful in developing algorithms that worked well as far as the performance in memory management is concerned. There is no consensus among the researches about how this problem can be treated efficiently, and the algorithms proposed have high overhead because of their complexity. The objective of this work is to propose an efficient memory management with the composition of page fetch, placement and replacement techniques. This thesis hypothesis is that to treat the memory management problem it is better to consume computational resources determining which pages must be in the memory in a given time than to waste resources defining which pages would be evicted from the memory. This work presents a reanalysis of the main works whose objective is memory management performance, making it possible to draw different conclusions and ideas about what factors may have a positive influence with respect to system performance. This study develops both the concept of quality of memory contents and a metric to measure it. Besides, a systemic method to create memory management algorithms is devised, applying the concept just created. Then, the method is followed, creating the RR+ng and RRlock+ng algorithms. In the final phase of the method, the metric is applied in simulations, proving to be adequate to perform the analysis. The results show that the idea of treating the memory management problem, consuming computational resources to determine which pages must be in the memory instead of which ones must leave it, hold true and seems to be promising.

Keywords: Operating Systems. Memory management. Virtual memory. Demand paging. Page replacement. 


\section{SUMÁRIO}

\section{Lista de llustrações}

Lista de Tabelas

Lista de Abreviaturas e Siglas

\section{Lista de Símbolos}

1 Introdução

1.1 Contexto do trabalho . . . . . . . . . . . . . . . 18

1.2 Motivação . . . . . . . . . . . . . . . . . 20

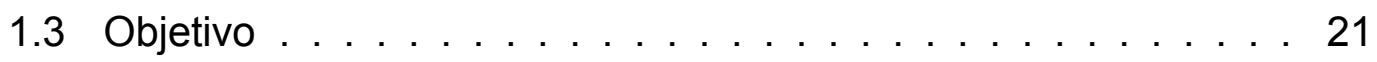

1.4 Contribuições . . . . . . . . . . . . . . . . . . . . . 22

1.5 Metodologia ....................... 23

1.6 Organização do texto . . . . . . . . . . . . 26

2 Revisitação dos principais trabalhos recentes sobre gerência de memória

2.1 Algoritmos de gerência de memória . . . . . . . . . . . . . 27

2.1.1 Algoritmos adaptativos de gerência da memória . . . . . 30

2.2 Influência dos parâmetros de controle no desempenho de algoritmos adaptativos de substituição de páginas . . . . . . . . . . . 33 
2.3 Ajustando o LRU-WAR para uma política de gerência de memória global . . . . . . . . . . . . . . . . . . . . 38

2.3.1 Análise do algoritmo LRU-WARlock . . . . . . . . . . . . 40

2.4 Uso de técnicas e informações para potencializar políticas de substituição em sistemas de memória virtual . . . . . . . . . . . 47

2.4.1 Análise do algoritmo LRU+ng . . . . . . . . . . . . . . 48

2.5 Considerações sobre a revisitação dos trabalhos em gerência de memória . . . . . . . . . . . . . . . . . . 52

3 Técnicas e informações no auxílio da gerência de memória

3.1 As informações que direcionam as técnicas de busca e posicionamento de páginas . . . . . . . . . . . . . . . 53

3.2 Superpages ........................... 54

3.2.1 Arquiteturas e sistemas operacionais com suporte a superpages ..................... 55

3.2.2 Políticas de promoção de páginas . . . . . . . . . . . . 56

3.2.3 Demoção de páginas . . . . . . . . . . . . . . . . 57

3.2.4 O controlador de memória Impulse . . . . . . . . . . . . . 57

3.3 O uso de $n$-gramas . . . . . . . . . . . . . . . 58

3.3.1 Algoritmo de busca de páginas e n-gramas . . . . . . . 60

3.4 Grafo de acessos às páginas . . . . . . . . . . . . . . . 60 
4.1 Definição da métrica de QUALIDADE . . . . . . . . . . . . . . 64

4.2 Exemplo do cálculo da métrica . . . . . . . . . . . . . 65

4.3 Usos da QUALIDADE da memória . . . . . . . . . . . . . . . . 67

4.4 Análise do LRU com a métrica de QUALIDADE . . . . . . . . . . 70

4.5 Análise da política de substituição aleatória usando a métrica de

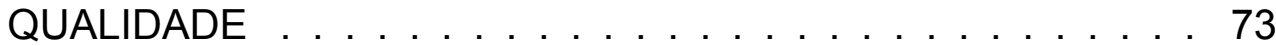

4.6 Análise comparativa de QUALIDADE com outras métricas . . . . 78

5 Método de criação dos algoritmos de gerência de memória basea$\begin{array}{ll}\text { dos em qualidade } & 81\end{array}$

5.1 O método sistêmico de qualidade . . . . . . . . . . . . . . . . 81

5.2 Criação do algoritmo RR+ng . . . . . . . . . . . . . . 86

5.2.1 Definição das técnicas para busca e posicionamento (passo 1) .................... 87

5.2.2 Definição das informações (passo 2) . . . . . . . . . . . . 87

5.2.3 Definição da política de substituição de páginas (passo 3) 87

5.2.4 Criação do algoritmo (passo 4) . . . . . . . . . . . . 88

5.3 Avaliação do algoritmo RR+ng(passo 5) . . . . . . . . . . . . . 90

5.3.1 Avaliação usando a métrica de faltas de páginas . . . . . 91

5.3.2 Avaliação usando a métrica de QUALIDADE . . . . . . . 95

5.3.3 Verificação do desempenho esperado . . . . . . . . . . . 116

5.4 Criação do algoritmo RRlock+ng (segunda iteração) . . . . . . . 117

5.5 Avaliação do algoritmo RRlock+ng . . . . . . . . . . . . . . 120 
5.6 Considerações sobre a aplicação do método e dos algoritmos 123

6 Conclusões 125

6.1 Contribuições . . . . . . . . . . . . . . . . . . 126

6.2 Trabalhos futuros . . . . . . . . . . . . . . . . 127

Referências

Apêndice A - Gráficos adicionais para a análise dos algoritmos 


\section{LISTA DE ILUSTRAÇÕES}

1 Metodologia utilizada para a realização de simulações . . . . . . 25

2 Desempenho do LRU-WAR sobre o programa Gnuplot . . . . . . 35

3 Desempenho do LRU-WAR sobre o programa Grobner . . . . . 36

4 Desempenho do LRU-WAR sobre o programa Sprite . . . . . . . 37

5 Padrão de acessos trace multi1 . . . . . . . . . . . . . . . . . 42

$6 \quad$ Padrão de acessos trace multi2 . . . . . . . . . . . . . . . 42

$7 \quad$ Padrão de acessos trace multi3 . . . . . . . . . . . . . . . 43

8 O algoritmo LRU-WARlock sobre o multi1 . . . . . . . . . . . . . 44

9 O algoritmo LRU-WARlock sobre o multi2 . . . . . . . . . . . . 45

10 O algoritmo LRU-WARlock sobre o multi3 . . . . . . . . . . . . 46

11 Comparação entre LRU, LRU+ng e Ótimo sobre o multi1 . . . . 48

12 Busca sobre total de faltas no multi1 . . . . . . . . . . . . . . 49

13 Comparação entre LRU, LRU+ng e Ótimo sobre o multi2 . . . . 50

14 Comparação entre LRU, LRU+ng e Ótimo sobre o multi3 . . . . 51

15 Grafo estratégico da substituição far . . . . . . . . . . . . . . . . 61

16 Exemplo visual . . . . . . . . . . . . . . . . . 66 66

17 Gráfico de QUALIDADE do LRU no multi1 . . . . . . . . . . . . . 70

18 Gráfico do mapa de acesso trace multi1 . . . . . . . . . . . . . 71

19 Gráfico de QUALIDADE do LRU no multi2 . . . . . . . . . . . . . 72 
20 Gráfico de QUALIDADE do LRU no multi3 . . . . . . . . . . . . . 73

21 QUALIDADE da memória para a política aleatória no Multi1 . . . 75

22 QUALIDADE da memória para a política aleatória no Multi2 . . 76

23 QUALIDADE da memória para a política aleatória no Multi3 . . . 77

24 Método sistêmico para criar algoritmo de gerência de memória . 83

25 Substituição de páginas no algoritmo RR+ng . . . . . . . . . . . 90

26 Gráfico de falta de páginas do trace multi1 . . . . . . . . . . . . 92

27 Gráfico de falta de páginas do trace multi2 . . . . . . . . . . . . 93

28 Gráfico de falta de páginas do trace multi3. . . . . . . . . . . . . 94

29 Gráfico de QUALIDADE do OPT para 300 páginas no trace multi1 96

30 Gráfico de QUALIDADE do LRU para 300 páginas no trace multi1 96

31 Gráfico de QUALIDADE do RND para 300 páginas no trace multi1 98

32 Gráfico de QUALIDADE do RR+ng para 300 páginas no trace multi1 . . . . . . . . . . . . . . . . 98

33 Zoom do gráfico de QUALIDADE do RR+ng e OPT para 300 páginas no trace multi1 f . . . . . . . . . . . . . . . . . . . . . . 99

34 Gráfico de QUALIDADE do OPT para 1400 páginas no trace multi1101

35 Gráfico de QUALIDADE do LRU para 1400 páginas no trace multi1101

36 Gráfico de QUALIDADE do RND para 1400 páginas no trace

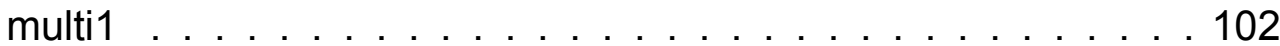

37 Gráfico de QUALIDADE do RR+ng para 1400 páginas no trace multi1 . . . . . . . . . . . . . . . . 102

38 Gráfico de QUALIDADE do OPT para 200 páginas no trace multi2104 
39 Gráfico de QUALIDADE do LRU para 200 páginas no trace multi2104

40 Gráfico de QUALIDADE do RND para 200 páginas no trace multi2105

41 Gráfico de QUALIDADE do RR+ng para 200 páginas no trace

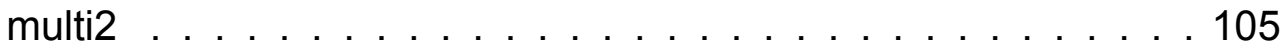

42 Gráfico do mapa de acesso trace multi1 . . . . . . . . . . . . . 107

43 Gráfico do mapa de acesso trace multi2 . . . . . . . . . . . . 108

44 Gráfico de QUALIDADE do OPT para 2000 páginas no trace multi2108

45 Gráfico de QUALIDADE do LRU para 2000 páginas no trace multi2109

46 Gráfico de QUALIDADE do RND para 2000 páginas no trace

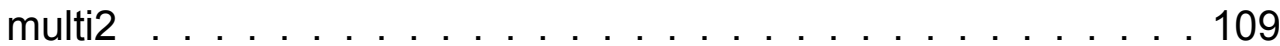

47 Gráfico de QUALIDADE do RR+ng para 2000 páginas no trace

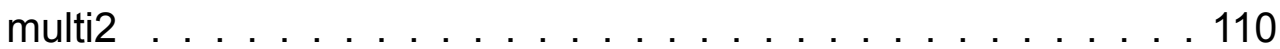

48 Gráfico de QUALIDADE do OPT para 200 páginas no trace multi3111

49 Gráfico de QUALIDADE do LRU para 200 páginas no trace multi3112

50 Gráfico de QUALIDADE do RND para 200 páginas no trace multi3112

51 Gráfico de QUALIDADE do RR+ng para 200 páginas no trace multi3 . . . . . . . . . . . . . . . . . 113

52 Gráfico de QUALIDADE do OPT para 2800 páginas no trace multi3114

53 Gráfico de QUALIDADE do LRU para 2800 páginas no trace multi3114

54 Gráfico de QUALIDADE do RND para 2800 páginas no trace

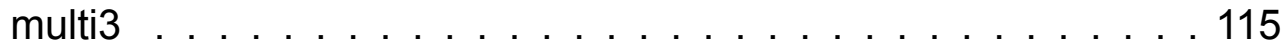

55 Gráfico de QUALIDADE do RR+ng para 2800 páginas no trace

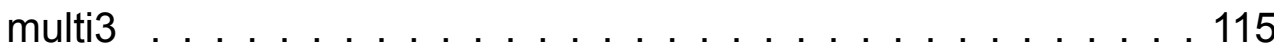


56 Gráfico de falta de páginas do trace multi1. . . . . . . . . . . . 120

57 Gráfico de falta de páginas do trace multi2. . . . . . . . . . . . . 121

58 Gráfico de falta de páginas do trace multi3. . . . . . . . . . . . . 121

59 Gráfico de falta de páginas por tamanhos de memória dos traces do pacote Lirs. Legenda: LRU(rosa), WST(vermelho), OPT(azul), RND(preto), RR+ng(verde) e RRlock+ng(laranja) . . 136

60 Gráfico de QUALIDADE do RRlock+ng para 300 páginas no trace multi1 . . . . . . . . . . . . . . . . . . . 138

61 Gráfico de QUALIDADE do RRlock+ng para 1400 páginas no trace multi1 . . . . . . . . . . . . . . . . . . . . 138

62 Gráfico de QUALIDADE do RRlock+ng para 200 páginas no trace multi2 . . . . . . . . . . . . . . . . . . . . . . . . . 139

63 Gráfico de QUALIDADE do RRlock+ng para 2000 páginas no trace multi2 . . . . . . . . . . . . . . . . . . 139

64 Gráfico de QUALIDADE do RRlock+ng para 200 páginas no trace multi3 . . . . . . . . . . . . . . . . . . . . . . 140

65 Gráfico de QUALIDADE do RRlock+ng para 2800 páginas no trace multi3 . . . . . . . . . . . . . . . . . . . 140 


\section{LISTA DE TABELAS}

1 Descrição dos traces gnuplot, grobner e sprite . . . . . . . . . . 34

2 Descrição dos traces multi1, multi2 e multi3 . . . . . . . . . . . . 41

$3 \quad$ Bigramas mais comuns no New York Times. . . . . . . . . . . . . 59

4 Média de QUALIDADE da política aleatória . . . . . . . . . . . 74

5 Técnicas de busca e posicionamento de páginas . . . . . . . . . 82

6 Informações que auxiliam as técnicas . . . . . . . . . . . . 84

$7 \quad$ QUALIDADE média para cada caso de teste . . . . . . . . . . 97

8 QUALIDADE média para cada caso de teste do RRlock+ng . . . 123

9 Descrição dos traces do pacote Lirs . . . . . . . . . . . . . . . 137 


\title{
LISTA DE ABREVIATURAS E SIGLAS
}

\author{
ARC Adaptive Replacement Cache (algoritmo) \\ EELRU Early Eviction LRU (algoritmo) \\ FIFO First In, First Out (algoritmo) \\ IBM International Business Machines \\ IRR Inter-Reference Recency \\ LAHPC Laboratory of Architecture and High Performance Computing \\ LFU Least Frequently Used (algoritmo) \\ LIRS Low Inter-reference Recency Set (algoritmo) \\ LRFU Least Recently/Frequently Used (algoritmo) \\ LRU Least Recently Used (algoritmo) \\ LRU+ng Least Recently Used with n-grams prefetching (algoritmo) \\ LRU-WAR LRU with Working Area Restriction (algoritmo) \\ MRU Most Recently Used (algoritmo) \\ NRU Not Recently Used (algoritmo) \\ NUMA Non-Uniform Memory Access \\ PGO Profile-Guided Optimization \\ OPT Optimum (algoritmo) \\ PFF Page Fault Frequency (algoritmo) \\ RAM Random Access Memory
}




$\begin{array}{ll}\text { RND } & \text { Random (algoritmo) } \\ \text { RR+ng } & \text { Random Replacement with n-grams (algoritmo) } \\ \text { SEQ } & \text { Algoritmo adaptativo de substituição de páginas } \\ \text { SGBD } & \text { Sistema de Gerenciamento de Banco de Dados } \\ \text { TLB } & \text { Translation Lookaside Buffer } \\ \text { USP } & \text { Universidade de São Paulo } \\ \text { WS } & \text { Working Set (algoritmo) }\end{array}$




\section{LISTA DE SÍMBOLOS}

$q m_{v t} \quad$ Métrica de qualidade no instante $v t$

$\mu\left(S_{P_{x}}\right)$ Função binária integrante da métrica de qualidade

$v t \quad$ Tempo virtual

$P \quad$ Conjunto de páginas do programa

$S_{P} \quad$ Sequência de acessos a memória

$j \quad$ Tamanho da sequência em $S_{P}$ que define a autonomia do programa em algum $v t$

M Conjunto de páginas que definem a memória ótima

$M^{\prime} \quad$ Conjunto de páginas que definem a memória atual

$H_{\infty} \quad$ Série harmônica 


\section{INTRODUÇÃO}

Na década de 1940, Arthur W. Burks, Herman H. Goldstine e John von Neumann já discutiam o uso da hierarquia de memória no documento Preliminary Discussion of the Logical Design of an Electronic Computing Instrument, em que diziam que foram "forçados a reconhecer a possibilidade de construir uma hierarquia de memórias, cada qual com maior capacidade que o seu precedente, mas que fosse acessível com maior latência" (BURKS; GOLDSTINE; NEUMANN, 1989). Desde então, o conceito de hierarquia de memória fez com que gerações de projetistas se deparassem com o problema de buscar a melhor alternativa de gerência da memória. A partir da década de 1980, com os avanços na área de arquitetura de computadores e microarquitetura, criou-se uma grande diferença de desempenho das memórias em relação aos processadores (MAHAPATRA; VENKATRAO, 1999). Para atenuar essa diferença, é imprescindível criar novas estratégias de gerência de memória, que sejam mais robustas em desempenho.

\subsection{Contexto do trabalho}

No contexto da gerência de memória em sistemas operacionais, vários grupos de pesquisa têm desenvolvido trabalhos na área de algoritmos para gerência de memória virtual. Vários algoritmos para substituição de páginas têm sido propostos na literatura recente. Podemos citar, por exemplo, o traba- 
Iho de Cassettari (2004), que em sua dissertação de mestrado avalia políticas de substituição e propõe uma nova estratégia adaptativa de substituição de páginas: o algoritmo LRU-WAR (LRU with Working Area Restriction). Outros exemplos de algoritmos adaptativos de substituição de páginas incluem o algoritmo ARC utilizado em algumas versões do sistema de gerenciamento de banco de dados DB2 (MEGIDDO; MODHA, 2003), assim como o algoritmo adaptativo LIRS que foi implementado no SGBD MySQL (JIANG; ZHANG, 2002). Esses algoritmos impulsionaram novos trabalhos na área, com a busca de uma solução dinâmica e adaptativa para a melhora contínua do uso da memória pelos programas.

A criação e o aperfeiçoamento de políticas de substituição não são o único enfoque que desperta interesse em grupos de pesquisas atuais. Em sistemas de alto desempenho, como por exemplo em arquiteturas NUMA, há pesquisas em posicionamento de páginas (page placement), devido aos tempos de acesso à memória diferenciados (DASHTI et al., 2013). Além disso, a gerência de memória principal é tratada de forma mais direta em sistemas embarcados (embedded systems) (STILKERICH et al., 2014) e em sistemas de tempo real (KIM; RAJKUMAR, 2014).

Os algoritmos de substituição de páginas decidem que página da memória principal será gravada no disco quando uma nova página precisa ser alocada e não há mais espaço em tal memória. Esse é o problema da substituição de páginas que os algoritmos de gerenciamento tentam resolver focalizando seus esforços para descobrir qual página da memória principal não será mais usada ou demorará mais para ser reutilizada. Em um sistema de gerenciamento de memória paginada que não considera as estratégias de busca e posicionamento de páginas, ou seja, busca sob demanda e posicionamento aleatório, todo desempenho depende única e exclusivamente do algoritmo de substitui- 
ção de páginas. No passado, um boa política de substituição poderia tratar o problema de maneira satisfatória, mas agora com o aumento do tamanho da memória, a escolha da página que vai deixar a memória principal deixa de ter grande peso para o desempenho da gerência da memória.

A hipótese adotada por esta tese é que para tratar o problema da gerência da memória é melhor consumir recursos computacionais determinando quais páginas deveriam estar na memória em um determinado instante de tempo do que gastar recursos determinando qual página será retirada da memória.

Este trabalho pretende contribuir para o aprimoramento das técnicas de engenharia dos algoritmos de gerência de memória paginada em sistemas de memórias atuais, através dos estudos dos fatores que afetam diretamente o desempenho das políticas da gerência de memória e alguns meios em potencial de como tratá-los.

\subsection{Motivação}

O aumento da carga computacional e a possibilidade de maior armazenamento de dados têm motivado a evolução dos computadores. No contexto da computação na atualidade, a centralização de recursos tornou-se evidente com o ressurgimento das tecnologias de virtualização, como o sistema Microsoft Hyper-V e o VMware ESX Server (JIA et al., 2015), e com a recente difusão de processadores multi e many-cores (KOBBE; BAUER; HENKEL, 2015). A necessidade de uma gerência eficiente de recursos aumenta consideravelmente, em particular a gerência eficiente da memória principal.

Várias equipes de pesquisadores têm desenvolvido trabalhos no âmbito de algoritmos para gerência de memória em sistemas operacionais, explorando superpaging, que é uma técnica de posicionamento (placement) de páginas na 
memória principal (GORMAN; HEALY, 2012; LI et al., 2012; QIU; REDDY, 2012). Esses trabalhos comprovam que a aplicação do conceito de superpaging pode trazer benefícios bastante satisfatórios. Por consequência, uma superpage bem construída, através de promoções de páginas menores, pode diminuir muito o tempo global de processamento requerido por um sistema de alto desempenho, tornando, assim, o gerenciamento da memória virtual paginada potencialmente muito mais eficiente, pelo fato de expandir o alcance da TLB sem aumentar o número de entradas da TLB e executar implicitamente a prépaginação. Esses assuntos serão detalhados ao longo do trabalho.

Por terem processamento ou estrutura de dados mais complexos, algoritmos adaptativos podem onerar o sistema de memória. Várias propostas apresentadas constituem excelentes alternativas teóricas, mas impraticáveis em um sistema real devido à possível sobrecarga ou falta de suporte de hardware para implementar o algoritmo. Em algumas propostas, a idéia de implementação é muito bem elaborada e, com isso, pode-se obter uma versão online (viável) por meio de alguns ajustes e aproximações, porém perde-se muito da ideia teórica original.

\subsection{Objetivo}

Este trabalho visa estudar, avaliar e propor estratégias para a criação de algoritmos de gerência de memória que integram técnicas e informações utilizadas para diminuir as faltas de páginas. Ele é composto pela revisitação a trabalhos anteriores, uma breve introdução às técnicas e informações utilizadas para aumentar o desempenho da gerência de memória, um método de criação de algoritmos que utilizam como premissa o conceito discutido nesse trabalho, e a criação de uma métrica para analisar e comparar os algoritmos. 
O objetivo é propor uma forma eficiente de gerenciar a memória com a composição de técnicas de busca, posicionamento e substituição de páginas. O uso do conceito de qualidade, apresentado nesta tese, que propõe que é melhor utilizar recursos determinando quais páginas devem estar na memória ao invés de gastar recursos escolhendo qual página será retirada da memória, garante uma gerência eficiente. Assim, a memória principal com qualidade gera melhor desempenho do sistema, menos faltas de páginas, menor tempo de execução ou maior nível de multiprogramação. O objetivo é alcançado através da aplicação do conceito de qualidade da configuração da memória principal, a criação de um método para construir algoritmos de gerência de memória que utilize esse conceito e uma métrica para analisar e comparar o desempenho desses algoritmos. Uma configuração de páginas na memória tem qualidade, quando não somente o working set (WS) do programa em execução está presente na memória principal, como também a maioria das páginas que serão referenciadas em um futuro próximo.

Este trabalho concentra-se essencialmente em projetos de algoritmos de gerência de memória paginada. O foco principal é a qualidade da memória, determinando quais páginas vão para a memória e permanecem lá ao invés de quais páginas deixarão a memória.

\subsection{Contribuições}

Este trabalho apresenta as seguintes contribuições:

- Verificação da importância da configuração da memória, ou seja, é relevante que em um determinado instante de tempo, as páginas que serão acessadas no futuro próximo estejam na memória principal, para que o sistema de gerenciamento de memória fique mais tempo sem faltas de 
páginas. No decorrer deste trabalho, tal conceito é referido como qualidade da memória principal;

- Verificação da correlação entre qualidade da memória principal e desempenho obtido na execução de programas;

- Definição de uma métrica para medir a qualidade da memória principal. Essa métrica é essencial para comparação e análise das técnicas e informações em um sistema de gerenciamento de memória virtual paginada, na busca de maior desempenho nas execuções de programas ;

- A proposta da utilização da técnica de superpaging para substituir ou tornar a pré-paginação e os n-gramas menos custosos para implementação;

- A técnica de pré-paginação é analisada como alternativa de busca para se obter uma configuração de memória com maior qualidade e melhor desempenho na execução de programas;

- Um método para criação de algoritmos que privilegie o conceito definido nessa tese sobre a qualidade do conteúdo da memória principal.

\subsection{Metodologia}

O primeiro passo foi a observação e reanálise dos principais trabalhos que tinham como objetivo aumentar o desempenho da gerência de memória. Isso tornou possível tirar novas conclusões e criar hipóteses sobre quais os fatores que influenciavam o desempenho de maneira positiva e quais os fatores que ficavam em segundo plano.

A partir das ideias concebidas na revisitação dos trabalhos, foi determinado o conceito de qualidade e a métrica para medi-la. Aplicando esse con- 
ceito foi formulado um método sistêmico de criação de algoritmos de gerência de memória e utilizando a métrica proposta foi possível realizar análises de desempenho de algoritmos em experimentos controlados.

A análise dos algoritmos clássicos de gerência de memória paginada, e criados a partir do método é feita por meio de simulação e desenvolvida no LAHPC (Laboratory of Architecture and High Performance Computing), no Departamento de Engenharia de Computação e Sistemas Digitais da Escola Politécnica da USP. O experimentos foram realizados em cinco passos:

- Seleção dos arquivos de traces (traços);

- Desenvolvimentos dos simuladores que calculam a métrica de qualidade;

- Desenvolvimentos dos simuladores dos algoritmos de gerência de memória;

- Execução dos experimentos sob os traces dos programas;

- Análise dos resultados obtidos.

O arquivo de traces é formado pela sequência dos acessos à memória realizados por uma ou várias aplicações. O trace define o comportamento do programa ou programas em relação à utilização da memória. O gerador de traces é o responsável pela coleta dos acessos à memória ao longo do processamento das aplicações alvo (UHLIG; MUDGE, 1997).

Após a obtenção dos arquivos de traces, várias simulações podem ser executadas com configurações de tamanho de memória diferentes, no intuito de avaliar o desempenho dos algoritmos de gerência de memória. A figura 1 apresenta o processo para realizar os experimentos.

Os dados de desempenho obtidos são então analisados sob o ponto de 
Figura 1: Metodologia utilizada para a realização de simulações

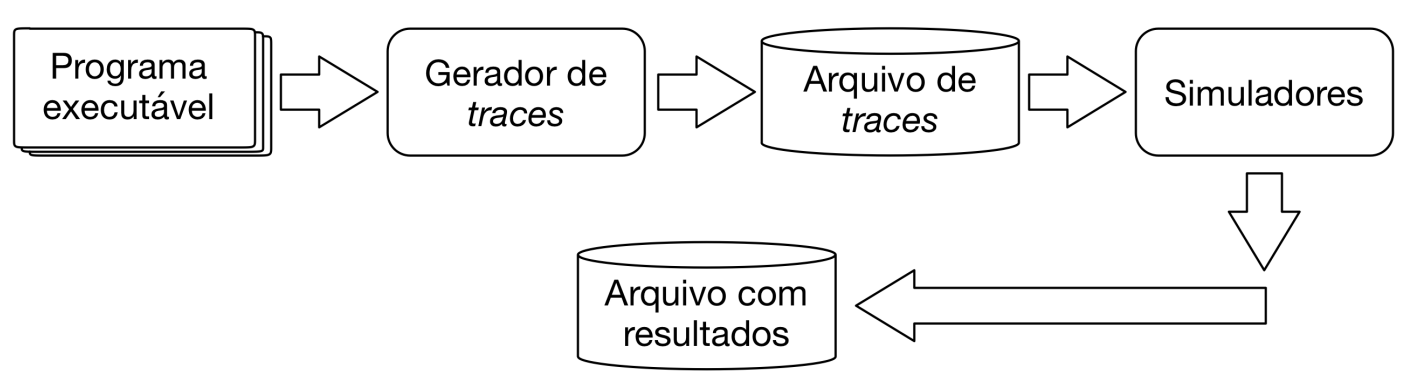

Fonte: Adaptado de Piantola (2010)

vista das características de localidade de referências presentes em cada aplicação. Ou seja, a eficiência ou não das técnicas e informação utilizadas no algoritmo de gerência de memória procura ser explicada de acordo com os padrões de acesso observados nos programas. As simulações são executadas em equipamentos disponíveis no laboratório, independentemente de detalhes de hardware. As máquinas possuem arquitetuta x86 e o sistema operacional é MAC OS X, Linux ou Windows.

Os algoritmos são avaliados através de simuladores confeccionados em linguagem $C$ e PERL. O simulador do algoritmo adaptativo LRU-WAR, que complementa nossos estudos, foi cedido por seus autores (CASSETTARI; MIDORIKAWA, 2004), assim como o simulador do algoritmo do EELRU (SMARAGDAKIS; KAPLAN; WILSON, 1999).

Procura-se determinar um método de construção de algoritmos de gerência de memória no contexto geral independente de aplicação. Os resultados para as análises foram obtidos através de simulações. Tais análises permitem a comparação de desempenho entre vários algoritmos. 


\subsection{Organização do texto}

O trabalho está organizado da seguinte forma: o Capítulo 2 compila uma revisitação aos principais trabalhos apresentados em congressos mostrando uma nova visão a qual deu início a este trabalho. Ainda neste capítulo, apresentam-se as novas possibilidades de aprimoramento dos algoritmos e aborda-se a importância do tratamento da frequência de acessos e as vantagens dos algoritmos que utilizam pré-paginação. Discute-se o uso de informações no auxílio das políticas de substituição, descrevendo a sua importância e a adequação em sistemas de gerência de memória.

O Capítulo 3 revisa aspectos básicos sobre gerência de memória com paginação e as estratégias que podem ser utilizadas para conseguir um melhor desempenho. Neste capítulo também são abordadas algumas técnicas e informações que podem ser usadas em busca e posicionamento de páginas para algoritmos de gerência de memórias.

O Capítulo 4 apresenta o conceito de qualidade na configuração da memória principal. Também descreve a métrica utilizada para medir a qualidade da memória numa execução completa de um programa.

No Capítulo 5 é apresentado um método sistemático para criação de algoritmos de gerência de memória que tem como diretriz o conceito de qualidade. Os algoritmos RR+ng e RRlock+ng são concebidos como exemplo do uso do método. Por fim são apresentados no capítulo 6 a conclusão e os trabalhos futuros. 


\section{REVISITAÇÃO DOS PRINCIPAIS TRABALHOS RECENTES SOBRE GERÊNCIA DE MEMÓRIA}

As ideias e a hipótese desta tese foram concebidas durante os anos de pesquisa sobre algoritmos adaptativos de substituição de páginas e a partir das numerosas tentativas de encontrar um algoritmo teórico perfeito ou uma técnica que possibilitasse a criação de algoritmos robustos que atingissem um desempenho próximo do algoritmo Ótimo, em um sistema de gerenciamento por demanda, independentemente do software e seu padrão de acesso à memória.

Por esse motivo, é importante uma revisitação aos trabalhos apresentados. As ideias e hipóteses que sustentam esta tese foram construídas a partir da evolução dos trabalhos e principalmente das experiências, "erros" e acertos.

A seção 2.1 apresenta os principais algoritmos de gerência de memória tradicionais e adaptativos.

\subsection{Algoritmos de gerência de memória}

A gerência de memória paginada é composta por três estratégias: busca (fetch), posicionamento (placement) e substituição (replacement) de páginas. A busca de páginas determina quando uma página que está no disco será trazida para a memória; o posicionamento determina em qual lugar da memó- 
ria a página será colocada e a substituição controla qual página vai deixar a memória principal e vai para o disco.

O aspecto mais importante tratado na literatura até o momento foi o algoritmo de substituição de páginas (SILBERSCHATZ; GALVIN; GAGNE, 2008; PIANTOLA, 2010). As principais propostas de algoritmos encontradas na literatura são descritos a seguir:

- LRU (Least Recently Used): uma das políticas mais estudadas na literatura, ela substitui a página que não foi acessada há mais tempo. Por causa da sua correlação entre o passado recente e o futuro próximo, a política LRU tenta imitar a política ótima. Alguns sistemas operacionais implementam uma aproximação do algoritmo LRU. Essa política apresenta um desempenho relativamente eficiente para a maioria das aplicações, comparada com outras políticas tradicionais.

- MRU (Most Recently Used): é o oposto da política LRU. Ela substitui a página que foi referenciada mais recentemente. Geralmente, a política MRU atinge um desempenho ruim, mas é uma alternativa para as desvantagens do algoritmo LRU e é usada em algumas políticas adaptativas como o LRU-WAR (CASSETTARI; MIDORIKAWA, 2004).

- LFU (Least Frequently Used): guarda o número de vezes que uma página é referenciada na memória. Quando a memória está cheia e uma página é requerida pelo sistema, a política LFU substitui a página com a menor frequência de acessos. O LRFU é uma algoritmo que combina o LFU e o LRU (LEE et al., 2001).

- OPT ou MIN: é o algoritmo com melhor desempenho possível entre todas as políticas de substituição de páginas sob demanda (BELADY, 1966). 
Não é possível implementá-lo em um sistema operacional real, mas é muito útil para comparar o desempenho de outras políticas.

- WORST: é a política péssima. Seu comportamento é o oposto da política OPT. Nenhum algoritmo pode obter desempenho pior que o da WORST (AGRAWAL; BENDER; FINEMAN, 2007). Tanto o algoritmo OPT quando o WORST são importantes para analisar os algoritmos de substituição de páginas. Eles são os limites superiores e inferiores, e assim, podemos calcular a média e fazer uma melhor comparação entre os outros algoritmos.

- RND: é a política de substituição de páginas aleatória. Ela seleciona aleatoriamente uma página candidata da memória principal e a descarta quando uma falta de página ocorre em um sistema de paginação sob demanda. Essa política não requer armazenamento de qualquer informação sobre o histórico de acessos à memória. Ela foi usada no gerenciamento da memória cache dos processadores ARM e SPARC pela sua simplicidade (ARM HOLDINGS, 2006; AEROFLEX GAISLER, 2011).

- FIFO (First In, First Out): O critério de substituição da política FIFO é escolher a página da memória principal carregada há mais tempo, independentemente das referências a ela enquanto esteve residente na memória. Esse algoritmo apresenta uma deficiência chamada de "anomalia de Belady" (BELADY; KUEHNER, 1969): o número de falta de páginas pode aumentar quando o tamanho da memória principal disponível aumenta. Entretanto, sua principal vantagem á a simplicidade e facilidade de implementação.

- CLOCK: No algoritmo Clock, ou algoritmo do relógio, uma fila circular é utilizada. As páginas estão nessa fila em ordem que foram carregadas na 
memória. A página a ser substituída é geralmente aquela carregada há mais tempo; porém, é verificado o bit de uso ao mecanismo de escolha: a página há mais tempo na memória só é substituída se o seu bit de uso estiver com zero; caso contrário, a próxima página com bit com valor zero na sequência é escolhida para a deixar a memória. Dessa forma, o algoritmo do relógio se comporta como LRU, não correndo o risco de remover uma página residente há muito tempo na memória, mas que continua sendo referenciada.

\subsubsection{Algoritmos adaptativos de gerência da memória}

Os algoritmos adaptativos de substituição de páginas atuam dinamicamente, adaptando seu comportamento conforme o padrão de acesso à memória em tempo de execução. Para isso, podem ser usadas inúmeras técnicas adaptativas, como, por exemplo, alterar o critério de substituição das páginas, o tamanho da memória a ser utilizada ou os parâmetros de controle do próprio algoritmo.

A ideia da adaptação é descobrir um comportamento padrão a partir de informações coletadas sobre as páginas referenciadas recentemente e então alterar aspectos do algoritmo adequando ao comportamento desses acessos à memória. O princípio dos algoritmos adaptativos de substituição de páginas não é novo: o Atlas loop detector (BAYLIS; FLETCHER; HOWARTH, 1968), é o predecessor dos mais recentes detectores de looping usados, por exemplo, nos algoritmos SEQ (GLASS; CAO, 1997) e EELRU (SMARAGDAKIS; KAPLAN; WILSON, 1999); ele já poderia ser considerado uma política que se adapta ao comportamento do sistema.

Existem alguns padrões bem explorados por esses algoritmos, tais como a frequência de acesso às páginas na memória (localidade temporal), a recên- 
cia (localidade espacial), a probabilidade de referência individual, a previsão de futuro de acesso à página baseado no reuso, as referências sequenciais e os loopings. As estratégias usadas pelos algoritmos de substituição de páginas variam bastante. Nos últimos quatorze anos, porém, surgiram algumas propostas baseadas somente na mistura de frequência e recência, exemplos são: LIRS (JIANG; ZHANG, 2002), LRFU (LEE et al., 2001) e ARC (MEGIDDO; MODHA, 2003).

Outras pesquisas um pouco mais recentes nesta área utilizam como ferramentas a inteligência artificial para auxiliar a adaptação dos algoritmos de substituição de páginas. Exemplos são os sistemas baseados em regras e lógica fuzzy. Quando um algoritmo de substituição de páginas utiliza mais de um parâmetro para a decisão, encontrar a relação entre esses parâmetros e combiná-los torna-se um problema. Dessa forma, um modo de combinar os parâmetros é modelá-los para a utilização de lógica fuzzy (SABEGHIL; YAGHMAEE, 2006).

O algoritmo LIRS — Low Inter-reference Recency Set - tem como principal objetivo minimizar as deficiências apresentadas pela política LRU usando uma informação adicional interessante: a chamada IRR (Inter-Reference Recency), que representa o número de páginas referenciadas entre as duas últimas referências consecutivas a uma mesma página. O algoritmo deduz uma inércia comportamental e, de acordo com as IRRs já conhecidas, substitui a página da memória que provavelmente levará mais tempo para ser novamente referenciada. Em outras palavras, o algoritmo LIRS usa uma fonte de informação extra: além do grau de recência atual das páginas, isto é, que páginas foram referenciadas mais recentemente que outras, ele leva em conta também a recência observada entre as duas últimas referencias realizadas em cada página. Isso significa que o LIRS não substitui necessariamente a página 
referenciada há mais tempo, mas sim que ele usa o histórico recente desta informação para prever quais páginas têm maiores probabilidades de referência em um futuro próximo.

O algoritmo adaptativo de substituição de páginas ARC (MEGIDDO; MODHA, 2003) - Adaptive Replacement Cache - divide a memória em duas partes para o gerenciamento, uma contendo as páginas recém-carregadas e outra guardando aquelas que receberam mais de um referência. Entretanto, a substituição é realizada sempre usando o mesmo critério da política LRU em uma das duas partes. A seleção da parte da memória acontece de forma balanceada, de acordo com o estado em que cada uma das partes se encontram nos momentos de substituição de páginas.

O algoritmo LRU-WAR (LRU with Working Area Restriction, ou LRU com Confinamento da Área de Trabalho) é uma proposta adaptativa direcionada a solucionar o mau desempenho do algoritmo LRU na presença de referencias à memória em grandes loops ou acessos sequenciais. O LRU utiliza um mecanismo para detectar esses padrões de acesso, e então, muda sua política de LRU para MRU (CASSETTARI; MIDORIKAWA, 2004).

Na próxima seção apresenta-se o trabalho intitulado Influência dos Parâmetros de Controle no Desempenho de Algoritmos Adaptativos de Substituição de Páginas (MIDORIKAWA; PIANTOLA; CASSETTARI, 2007) que mostra a primeira análise que tem por objetivo descobrir a importância dos parâmetros no desempenho dos algoritmos de substituição de páginas. 


\subsection{Influência dos parâmetros de controle no desempenho de algoritmos adaptativos de substituição de páginas}

O objetivo principal deste trabalho foi apresentar um estudo da variação do comportamento e do respectivo desempenho de algoritmos adaptativos de substituição de páginas com relação a seus parâmetros de controle. O algoritmo avaliado foi o LRU-WAR.

A estratégia utilizada pelo algoritmo LRU-WAR é baseada na localidade espacial, ou seja, o quão recentemente uma página foi acessada. Com essa informação e o número de faltas de páginas, o LRU-WAR, utilizando seus parâmetros, toma a decisão de trocar de política de substituição de páginas para MRU ou LRU. Essa decisão é tomada entre faltas de página consecutivas. Uma descrição mais detalhada do funcionamento do LRU-WAR e o detalhamento de seus parâmetros são encontrados em Midorikawa, Piantola e Cassettari (2007).

\subsubsection{Análise}

A avaliação dos algoritmos foi executada usando-se três diferentes traces de programas, a saber, gnuplot, grobner e sprite (Tabela 1). Esses foram escolhidos com base no seu padrão de acessos e desempenho dos diversos algoritmos de substituição de páginas estudados.

O programa gnuplot caracteriza-se por apresentar dois padrões de acessos bem definidos: um conjunto de páginas com forte localidade temporal ao longo da execução (com endereços virtuais baixos) e um padrão de acessos sequenciais devido à execução de laços que percorrem três vezes quase todo o espaço de endereçamento virtual. Essa característica faz com que o algo- 
Tabela 1: Descrição dos traces gnuplot, grobner e sprite

\begin{tabular}{llll}
\hline Trace & Descrição & Origem & Total de páginas \\
\hline \hline gnuplot & Trace relativo à geração de um & VMTrace & 7718 \\
& gráfico em postscript. & & \\
\hline grobner & Programa para reorganização & VMTrace & 67 \\
& de fórmulas baseado em fun- & \\
& ções base de Grobner. & \\
\hline sprite & Proveniente do sistema de ar- & LIRS & 7075 \\
& quivos de rede Sprite. Contém & \\
& requisições a um servidor de & \\
& arquivos a partir de várias es- & \\
& tações de trabalho cliente em & \\
& um período de dois dias. &
\end{tabular}

ritmo LRU apresente um desempenho "em forma de degrau", devido ao fato deste não ser adequado a este padrão de acessos sequenciais, o algoritmo sempre faz uma escolha ruim, até que o espaço de memória disponível seja igual ou maior ao tamanho total do programa, conforme observado na Figura 2. O gnuplot tem o padrão de acessos mais adequado ao LRU-WAR, que apresenta um desempenho muito próximo do algoritmo Ótimo (OPT).

O programa grobner também apresenta um padrão de acessos sequencial bem definido. Contudo, ao contrário do gnuplot, esse padrão sequencial está intercalado com outros padrões de acesso à memória. Essa característica faz com que o LRU-WAR apresente um ganho modesto de desempenho em relação ao LRU. Esse programa foi escolhido, pois se trata de um caso em que o LRU-WAR poderia explorar melhor o padrão sequencial presente, conforme 
Figura 2: Desempenho do LRU-WAR sobre o programa Gnuplot

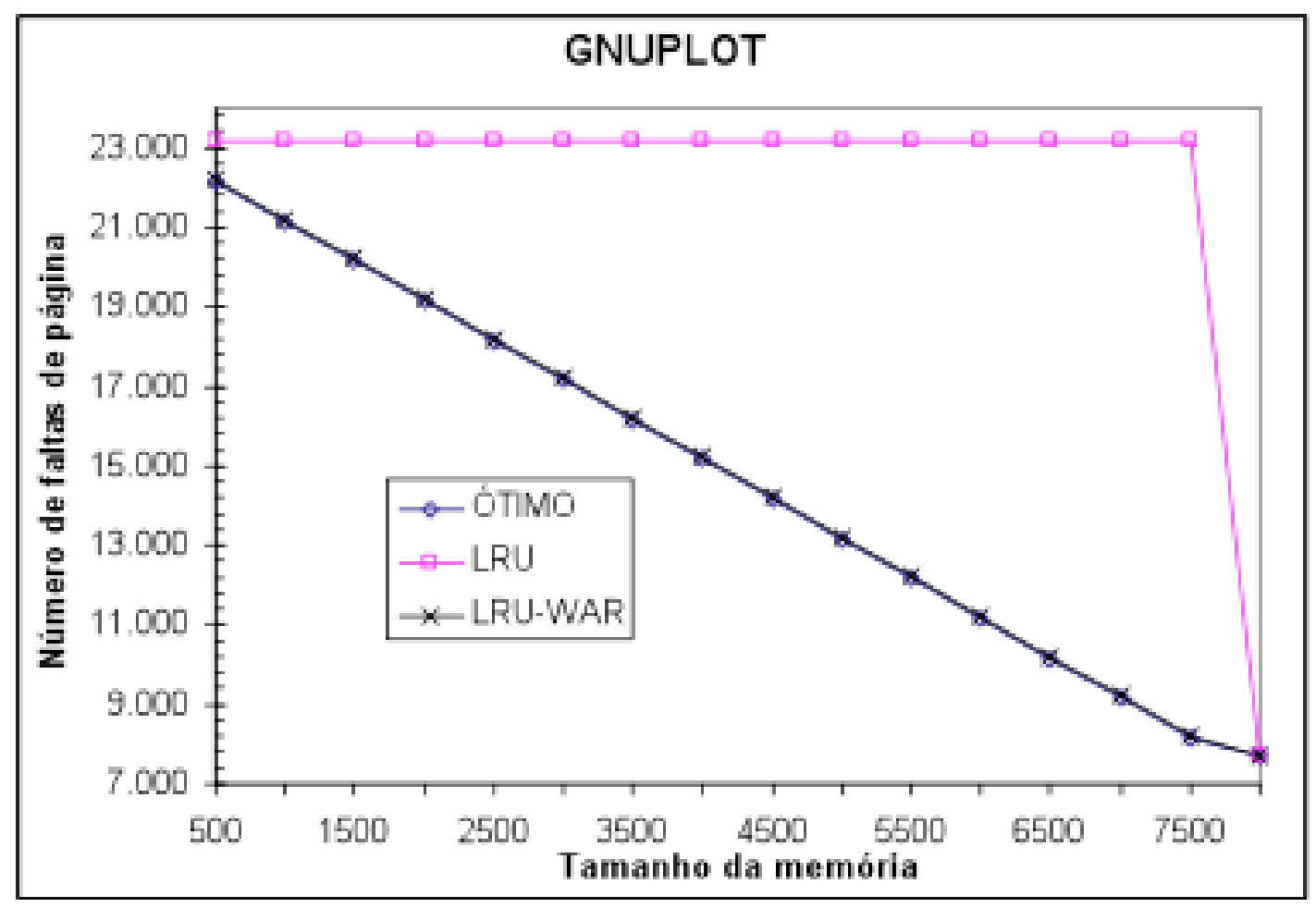

Fonte: Midorikawa, Piantola e Cassettari (2007)

a Figura 3.

O terceiro programa escolhido foi o sprite. O padrão de acessos observado para tal programa mostra um grande conjunto de páginas que são acessadas com frequência, mas sem apresentar um padrão destacado e com intervalos irregulares. O LRU-WAR comete decisões equivocadas, cujas consequências são amenizadas pelo mecanismo de detecção de erros. Contudo, o desempenho final do algoritmo é pior que o LRU, chegando a cerca de $7 \%$ para tamanho de memória igual a 2200 páginas, que se pode ver na Figura 4.

Os parâmetros C e L do algoritmo LRU-WAR foram modificados neste trabalho de forma exaustiva para todos os valores possíveis. O parâmetro C é o tamanho da região protegida, que não vai ser substituída, e é formada pelas C últimas páginas acessadas mais recentemente. Já o L é o tamanho do working 
Figura 3: Desempenho do LRU-WAR sobre o programa Grobner

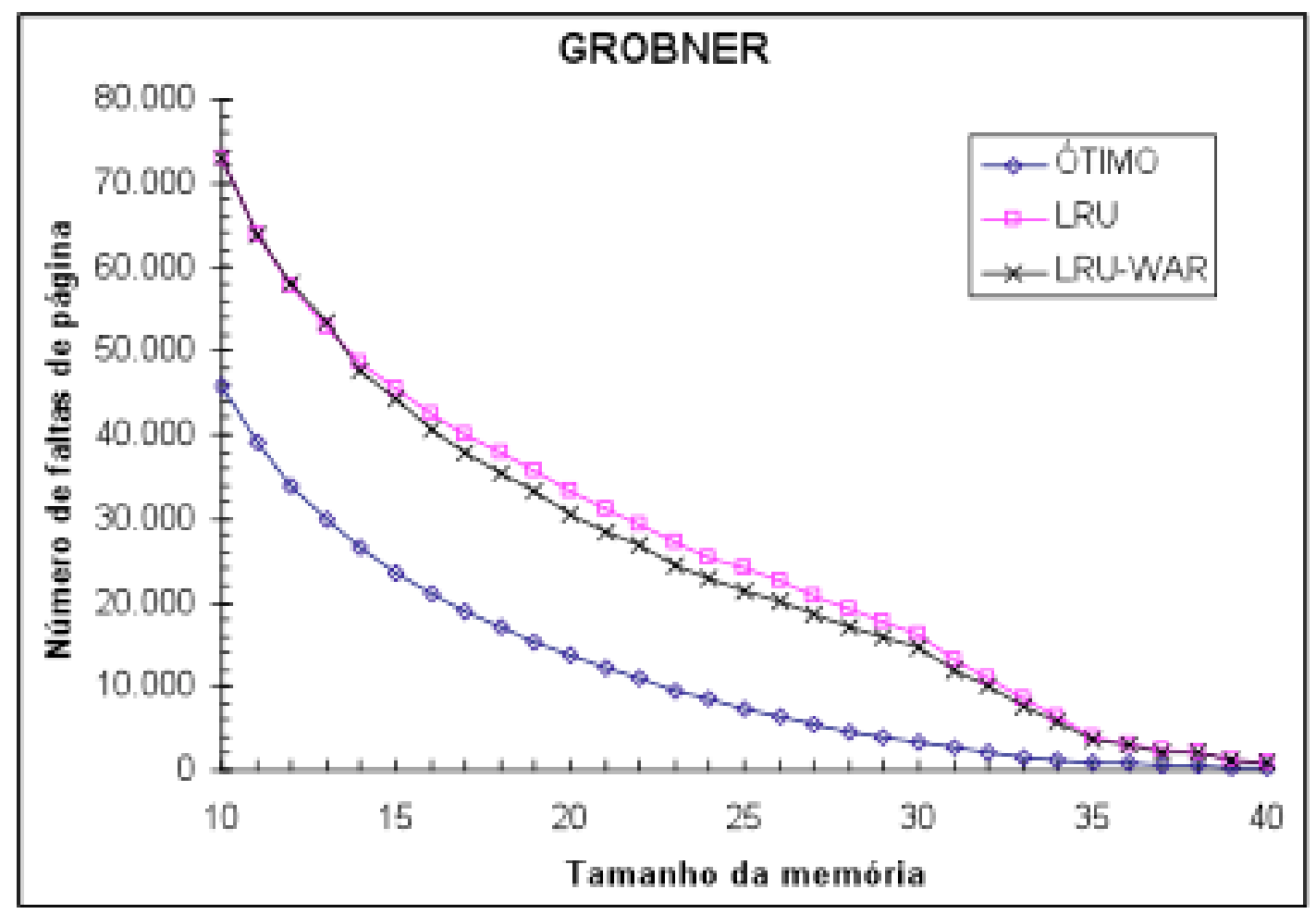

Fonte: Midorikawa, Piantola e Cassettari (2007)

set atual, chamado de região sequencial pelo LRU-WAR. Os resultados obtidos não foram muito elevados, sendo que a maioria dos valores para $C$ e $L$ no Gnuplot deixaram o LRU-WAR com desempenho pior. Para o programa Sprite, o melhor que a busca exaustiva conseguiu foi igualar os resultados do LRU. Nesse caso, o algoritmo LRU-WAR funcionava como o LRU não importando seus parâmetros. O único bom desempenho foi na execução do Grobner que obteve uma melhoria de $15 \%$ em relação a seus valores padrão de C e L.

A conclusão foi que era possível melhorar o algoritmo LRU-WAR ajustando seus parâmetros em tempo de execução. O problema era como fazer isso e a questão que surgiu foi: "Quanto de recurso computacional será gasto para achar esses valores?"

Estudos posteriores sobre o LRU-WAR utilizando o conceito do algoritmo 
Figura 4: Desempenho do LRU-WAR sobre o programa Sprite

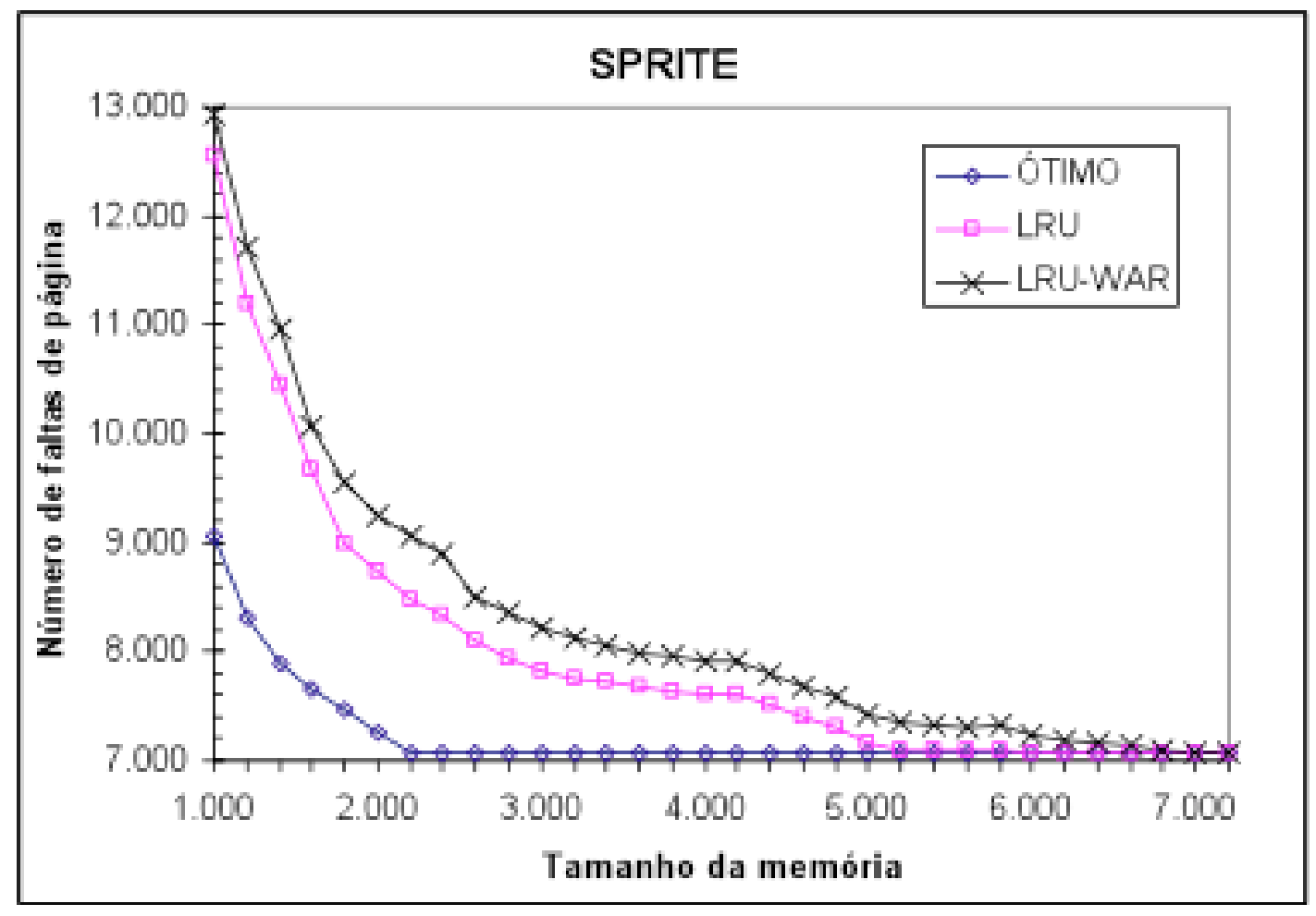

Fonte: Midorikawa, Piantola e Cassettari (2007)

ótimo mostraram que não era possível melhorá-lo usando distância de reuso, e pelo contrário, poderia piorá-lo e bastante. A experiência consistiu em escoIher a página que seria retirada da memória, mas somente entre os 2 pontos possíveis de escolha do LRU-WAR, que seria o ponto MRU-n ou LRU, com a informação dos futuros acessos para otimizar as escolhas.

Se conhecendo futuro não era possível melhorar o desempenho do LRUWAR, deveríamos mudar o foco da pesquisa, mesmo porque, matematicamente, o LRU-WAR tem baixíssima autonomia de escolha: somente duas páginas participam da decisão, MRU-n e LRU. Em uma memória com 100 páginas a autonomia de escolha é de $2 \%$, já em um sistema de memória global com 4GB de memória RAM, seria menor que 0,00001\%.

A solução nesse caso seria criar um novo algoritmo com diferentes premis- 
sas ou talvez aumentar a autonomia de escolha e inserir novos parâmetros ao LRU-WAR. Com a esperança de obter melhores resultados, continuamos a insistir no mesmo algoritmo, mas tentando melhorar seu principal ponto fraco: o padrão de acesso de frequência.

\subsection{Ajustando o LRU-WAR para uma política de gerência de memória global}

O objetivo principal deste trabalho (PIANTOLA; MIDORIKAWA, 2008) foi apresentar uma forma de ajustar o algoritmo adaptativo de substituição de páginas LRU-WAR para uma política de sistema de gerência de memória global, utilizando a técnica profiling e a adição de um parâmetro de controle, que levou à criação de um novo algoritmo chamado LRU-WARlock.

Toda política de substituição de páginas em um sistema de paginação por demanda deve escolher uma vítima para dar lugar a uma nova página referenciada, quando não há mais espaço disponível na memória. Caso a página escolhida seja sempre uma página do próprio processo que sofreu a falta de página, a política utilizada pelo sistema de memória é dita local. Porém, é possível que o sistema de gerência de memória trabalhe de uma forma global. Um algoritmo de substituição global atua com todas as páginas da memória e escolhe a vítima independentemente do processo que sofreu a falta de página.

Existem algumas vantagens em utilizar políticas globais em sistemas de gerência de memória. Alguns processos podem precisar de mais memória que outros e, neste caso, a política global pode dimensionar corretamente a quantidade de memória para cada processo. Os processos que estão bloqueados, esperando algum serviço, mantêm páginas na memória consumindo espaço que poderia ser utilizado por páginas de outros processos. Em um sistema 
com política global isso é minimizado.

A maioria dos algoritmos adaptativos "tradicionais" é inadequada para um sistema de memória com política global. Os projetos desses algoritmos visam analisar um padrão de acesso de uma única aplicação. Quando os acessos são contabilizados de forma global, ou seja, as referências à memória são coletadas de múltiplas aplicações, tais algoritmos comportam-se de maneira ineficiente. Muitos deles, incluindo o LRU-WAR, investem maior foco de suas análises na recência dos acessos e não na frequência. A análise da frequência de acessos é um fator importante para uma política global.

O principal objetivo da adaptação do algoritmo LRU-WAR é fazer com que ele obtenha bom desempenho em ambientes com política de gerência de memória global, onde se torna mais difícil a detecção de padrões de acessos. Para conquistar esse objetivo, foi criado o algoritmo LRU-WARlock, que complementa o LRU-WAR, sem modificar sua ideia original da exploração dos acessos sequenciais.

O princípio do funcionamento de LRU-WARlock surgiu da ideia de separar os acessos diferentes do padrão de acesso sequencial e tratá-los de outra maneira. A questão crucial foi descobrir o que mais atrapalhava a detecção de referências sequenciais. A resposta estava no bom funcionamento geral do LRU. Em um ambiente multiprogramado com sistema de gerência de memória global paginado, a memória é composta pelas páginas de diferentes programas. Neste cenário, com vários working sets (DENNING; SCHWARTZ, 1972) de diferentes programas presentes na memória, é possível encontrar vários padrões de acesso diferentes: por exemplo, muitas páginas com poucos acessos e algumas páginas com alta quantidade de referências. A solução neste cenário seria remover as páginas dos working sets da detecção do padrão sequencial do LRU-WAR, ou seja, separar as páginas acessadas mais frequentemente. 
O mecanismo utilizado pelo LRU-WARlock é a reserva de parte da memória para as páginas com a maior frequência de acessos. A outra parte da memória mantém o funcionamento original do LRU-WAR desconsiderando a parte reservada. Foi criado um parâmetro de controle do algoritmo chamado $K$. O parâmetro $K$ está relacionado com a porcentagem de memória que é reservada para as páginas com alta frequência de acesso, e pode ser controlado diretamente pelo sistema operacional.

Com relação à determinação das páginas de maior frequência, foi escoIhida a técnica de profiling, que possibilita capturar informações em tempo de execução da aplicação e utilizar esse conhecimento em futuras execuções. Alguns compiladores já utilizam essa técnica para prover otimização na geração do código executável. O compilador Intel C++ utiliza a técnica Profile-Guided Optimization (PGO) (INTEL, 2008), que localiza quais partes da aplicação são mais frequentemente executadas, direcionando assim o foco da otimização. Uma descrição mais detalhada do funcionamento do LRU-WARlock é encontrada em Piantola e Midorikawa (2008).

\subsubsection{Análise do algoritmo LRU-WARlock}

Apresenta-se a composição dos traces utilizados nos testes, além de uma breve descrição dos padrões de acesso e seu comportamento com alguns algoritmos de substituição apresentados na literatura como o LRU e o LRUWAR, entre outros.

O trace multi1 é composto pelas aplicações cscope e cpp. O cscope é uma ferramenta interativa de verificação de programa fonte escrita em linguagem C. Seu padrão de acesso à memória faz referências a looping com forte localidade temporal e outras referências de padrão diverso. O cpp é o préprocessador do GNU C, durante cuja execução podem ser observados blocos 
Tabela 2: Descrição dos traces multi1, multi2 e multi3

\begin{tabular}{llll}
\hline Trace & Descrição & Origem & Total de páginas \\
\hline \hline multi1 & Execução simultânea das apli- & LIRS & 2606 \\
& cações cscope e cpp. & \\
\hline multi2 & Execução simultânea das apli- & LIRS & 5684 \\
& cações cscope, cpp e post- & \\
& gres. & \\
\hline multi3 & Execução simultânea das apli- & LIRS & 7454 \\
& cações cpp, gnuplot, glimpse e & \\
& postgres.
\end{tabular}

de referências sequenciais à memória em conjunto com outras referências. $\mathrm{O}$ trace multi1 intercala acessos dessas duas aplicações, uma com referências a looping e a outra com acesso sequencial. Esse padrão de acesso prejudica muito o desempenho do algoritmo LRU e isso acontece até que o espaço de memória disponível seja maior ou igual ao tamanho total das duas aplicações. O mapa de acessos do multi1 é apresentado na Figura 5. Os programas individuais apresentam um padrão de acessos adequado ao LRU-WAR, porém, como estão intercalados pela multiprogramação, diminuem consideravelmente o desempenho do algoritmo.

O trace multi2 tem a mesma composição do trace multi1 com a adição do programa postgres. O postgres é um sistema de banco de dados relacional da Universidade da Califórnia, que apresenta um padrão de acessos sequencial e looping com períodos não constantes. A Figura 6 mostra o padrão de acessos do trace multi2, de modo geral, a maioria dos algoritmos apresenta um desempenho muito próximo ao LRU.

O terceiro trace escolhido, o multi3, tem a configuração um pouco diferente 
Figura 5: Padrão de acessos trace multi1

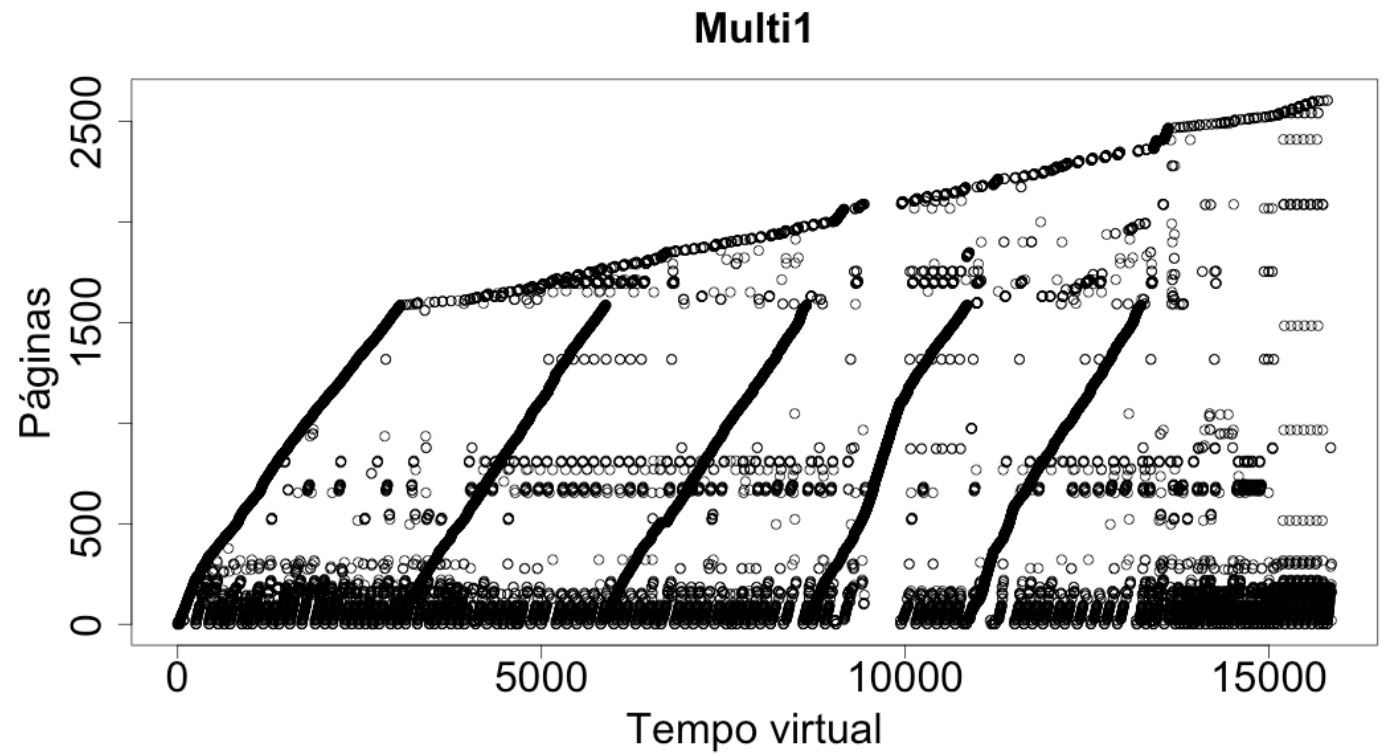

Fonte: Piantola e Midorikawa (2008)

Figura 6: Padrão de acessos trace multi2

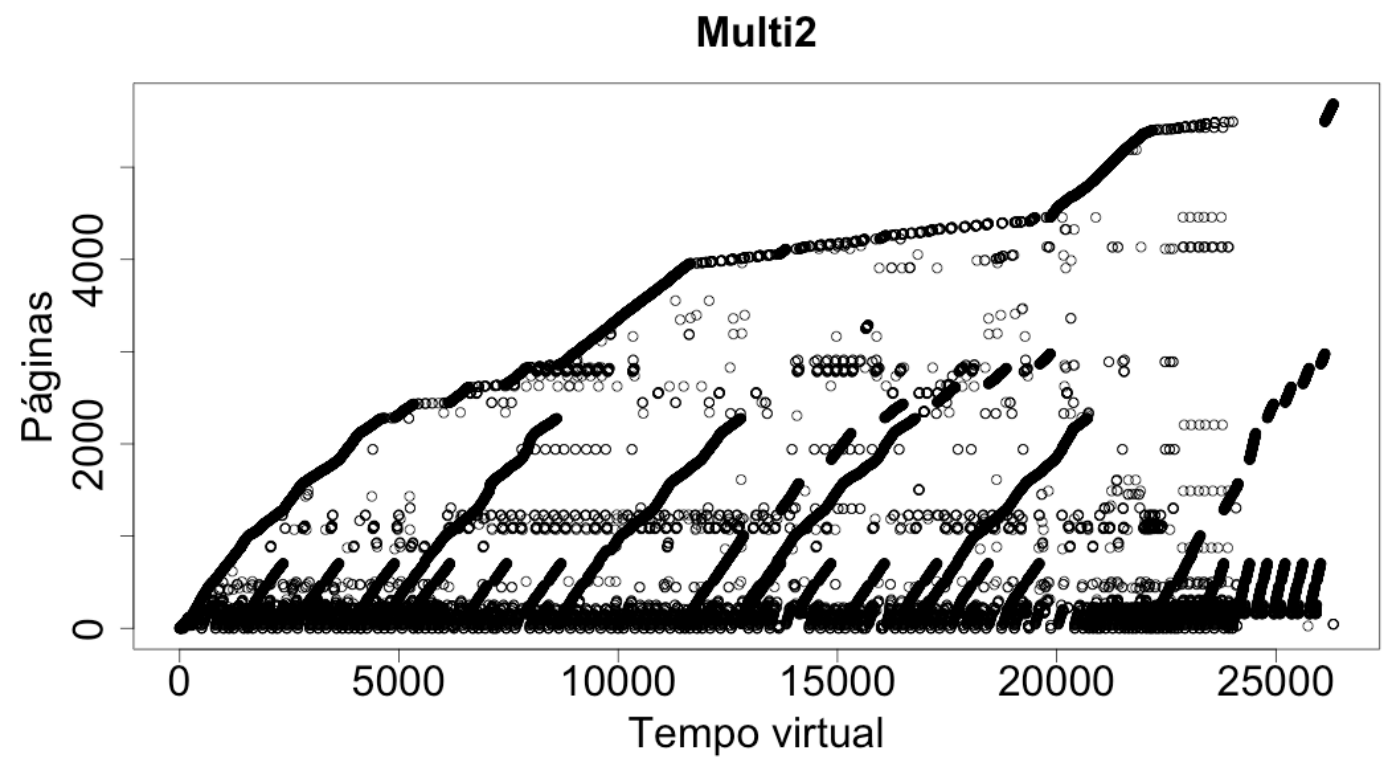

Fonte: Piantola e Midorikawa (2008)

dos dois primeiros. É formado pelo cpp, prostgres, glimpse e gnuplot. O cpp está contido nos dois primeiros traces e o prostgres no multi2. O glimpse é um 
utilitário usado na busca de informações em textos e seu padrão de referência à memória é bem diverso. Já o gnuplot tem um padrão de acessos sequenciais bem definido. O gnuplot é um programa interativo de plotagem gráfica. É possível observar na Figura 7 que com o aumento da quantidade de programas contidos no multi3, a diferença de desempenho entre o algoritmo LRU e LRUWAR diminui.

Figura 7: Padrão de acessos trace multi3

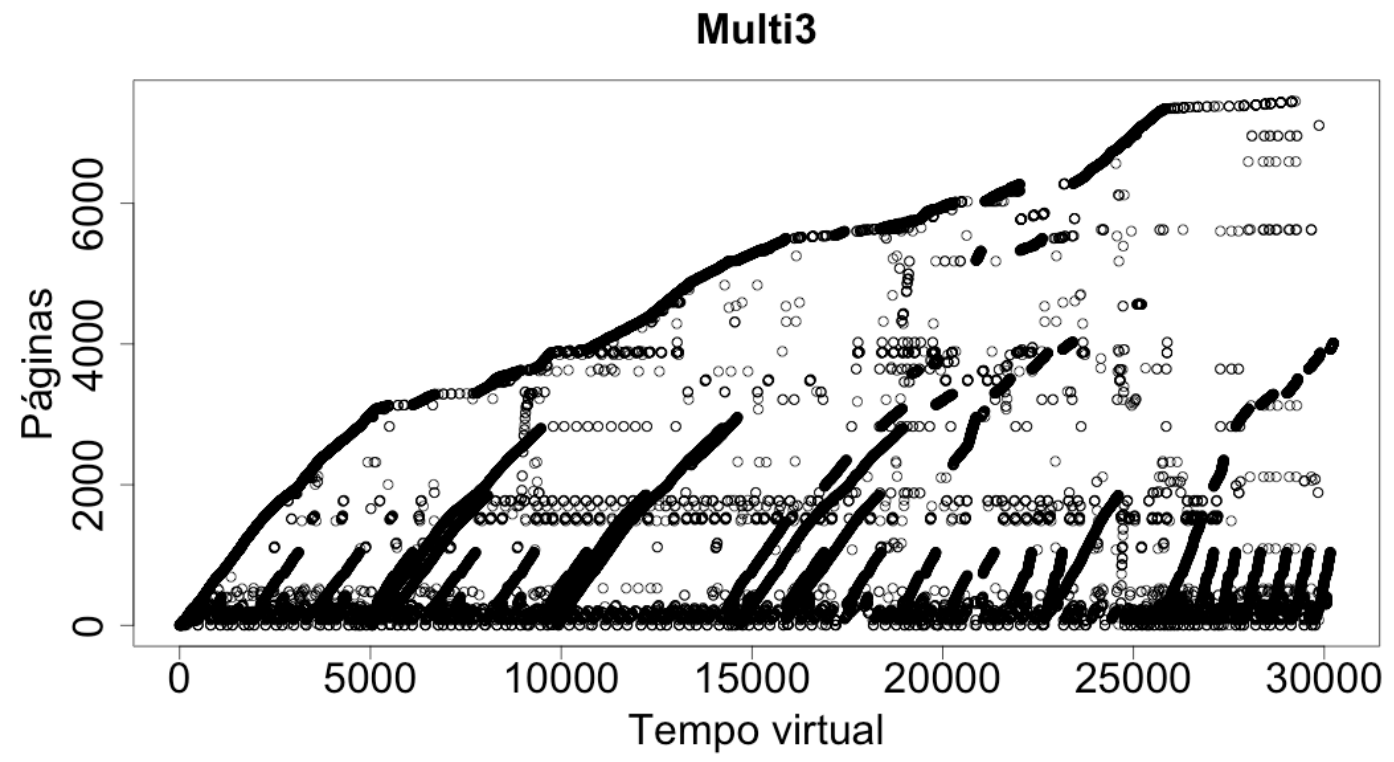

Fonte: Piantola e Midorikawa (2008)

Após a breve descrição dos programas que fazem parte do trace e amostra de desempenho com relação a políticas amplamente discutidas em textos científicos, vamos agora realizar a análise do sobre o algoritmo LRU-WARlock.

\section{- Multi1}

Em um programa com padrões de acessos sequenciais, o algoritmo LRUWAR atinge um excelente desempenho. Como o trace multi1 apresenta acessos de duas aplicações intercaladas em um sistema de gerência de memória global, o LRU-WAR apresentou desempenho não muito bom, mesmo com os dois programas que compõem o multi1 tendo acessos sequenciais. 
Figura 8: O algoritmo LRU-WARlock sobre o multi1

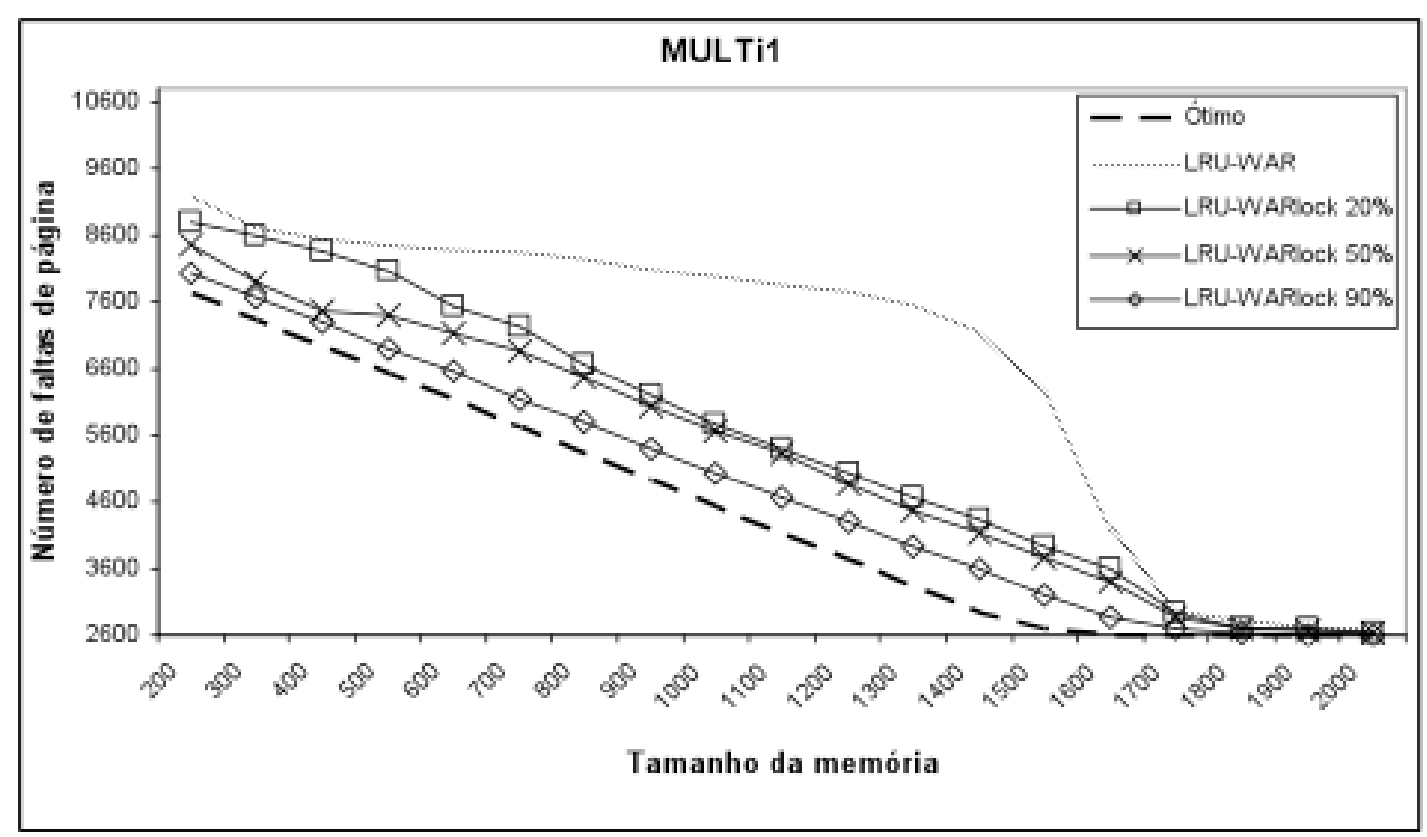

Fonte: Piantola e Midorikawa (2008)

No multi1, a análise do perfil de frequência de acessos às páginas mostra que somente $7,5 \%$ das páginas são responsáveis por $50 \%$ dos acessos à memória. Quando a Região Reservada tem tamanho $90 \%$ do total da memória, o maior desempenho continua sendo para o tamanho de memória igual a 1400, que é de quase $50 \%$ melhor que a desempenho do algoritmo LRU-WAR. O ganho em desempenho médio também é alto e quase chega a $26 \%$ como podemos observar na Figura 8.

\section{- Multi2:}

A maior característica do trace multi2 para a análise surge do fato de ser semelhante ao multi1. A diferença entre eles é a adição do programa postgres, desta forma aumentando o nível de multiprogramação. O desempenho do LRU-WAR diminui, pois se torna mais difícil ainda distinguir padrões de acessos com a inserção de novas referências intercaladas. A estratégia do LRU-WARlock também garante bom desempenho para este trace, conforme 
mostra a Figura 9. Desse modo, algoritmos que utilizam técnicas para separar padrões podem obter bons resultados.

Figura 9: O algoritmo LRU-WARlock sobre o multi2

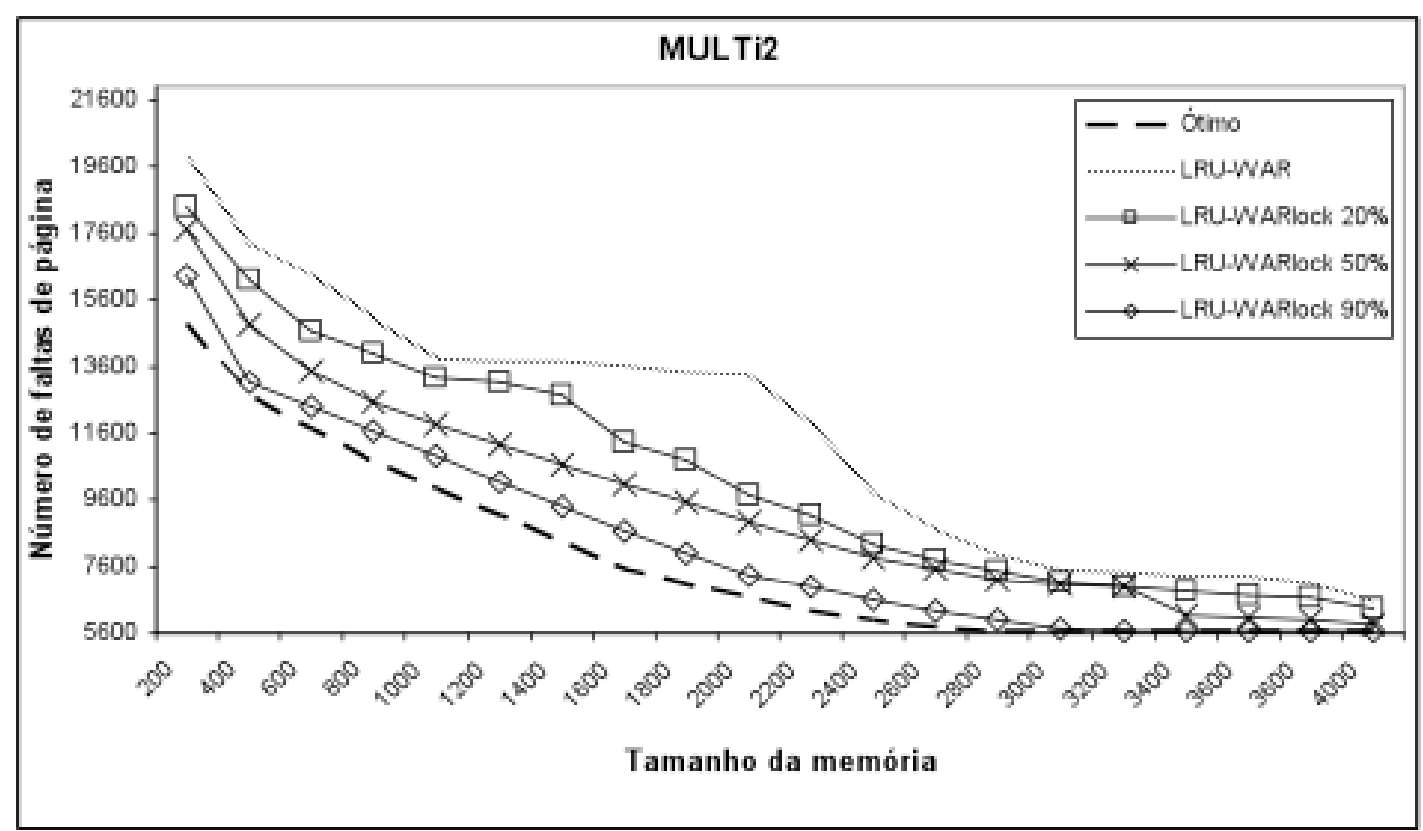

Fonte: Piantola e Midorikawa (2008)

A análise do perfil de frequência de acessos às páginas mostra que metade das 26311 referências é feita por apenas 348 páginas de um total de 5684 páginas, ou seja, somente $6 \%$ das páginas são responsáveis por $50 \%$ dos acessos a memória.

Um fato que deve ser bem observado, relativo à aproximação do algoritmo testado ao Ótimo, é quando a memória tem tamanho de 400 páginas. Por muito pouco, o LRU-WARlock não se iguala ao desempenho teórico do algoritmo Ótimo, com uma diferença de apenas $3,35 \%$ do total de faltas.

\section{- Multi3:}

Dos traces usados, aquele que tem o maior nível de multiprogramação é o multi3: são quatro programas com diversos padrões de acessos intercalados entre eles. Nesse caso o algoritmo LRU-WAR toma decisões equivocadas 
entrando muitas vezes em operação sequencial, e assim apresenta, para alguns tamanhos de memória, desempenho pior que o LRU. Como não existe uma uniformidade da localidade temporal, páginas que serão acessadas em um futuro próximo são descartadas prematuramente. Para essa sequência de referências, o LRU-WARlock também supera o LRU-WAR, revelado na Figura 10.

Figura 10: O algoritmo LRU-WARlock sobre o multi3

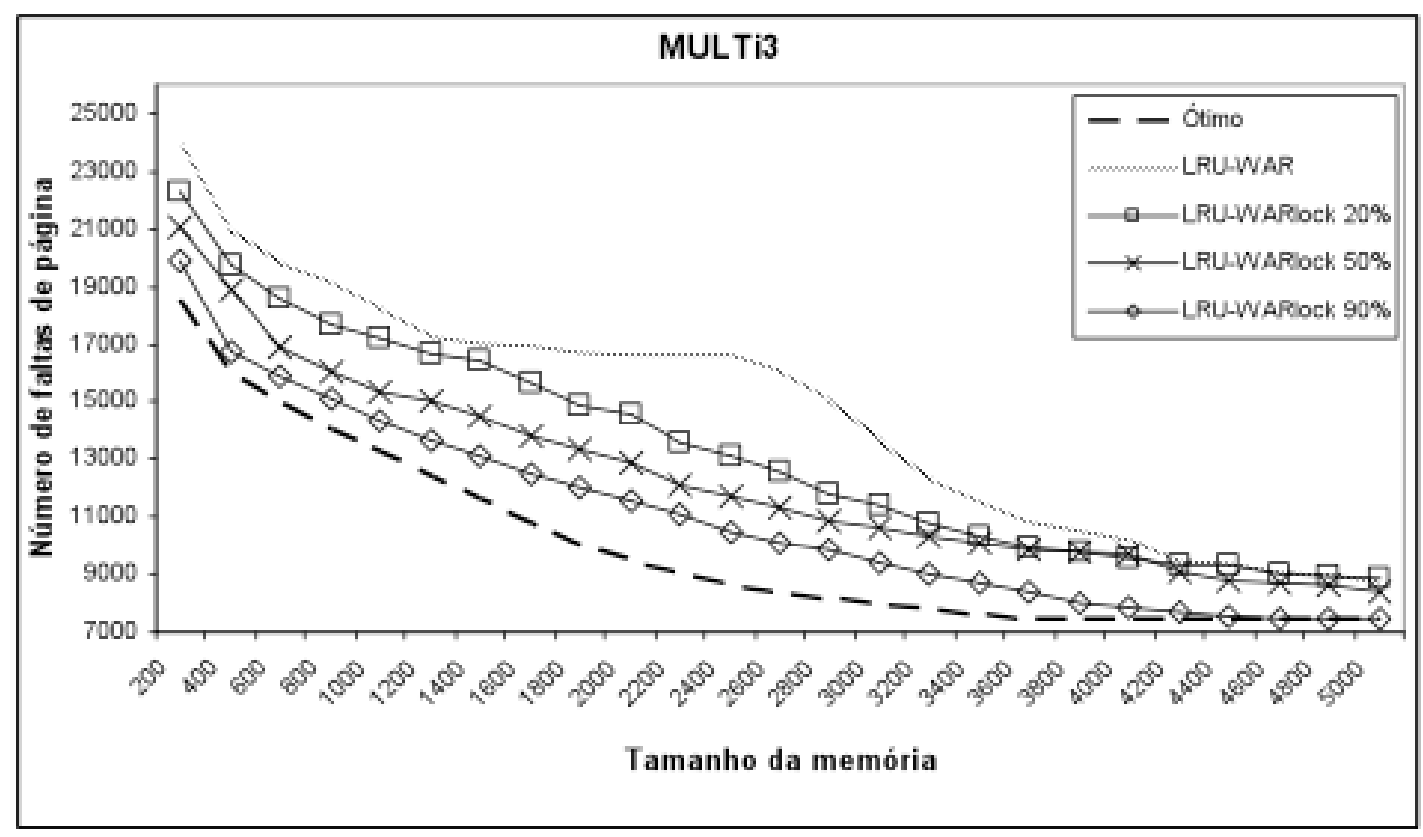

Fonte: Piantola e Midorikawa (2008)

A contribuição mais importante apontada neste trabalho havia sido que apesar dos algoritmos adaptativos terem sido projetados para sistemas que utilizem políticas de gerência de memória locais, é possível ajustá-los para apresentarem também bom desempenho em sistemas de gerência de memorial global. Hoje, porém, fica claro que essa não foi a contribuição mais importante. O algoritmo LRU-WAR não foi ajustado: ele continuou funcionando com os mesmo valores de seus antigos parâmetros. Adicionaram-se a informação de frequência e a técnica de profiling. Neste momento, o foco de toda pes- 
quisa deixa de ser a política de substituição de páginas em si e passa a ser a qualidade em que a memória é alimentada com páginas. O ponto importante é o conjunto de páginas que está ocupando a memória em um determinado tempo e não qual página vai ser substituída.

Outra contribuição importante foi descobrir que a frequência é imprescindível, já que menos de $9 \%$ do número total de páginas é responsável por $50 \%$ das referencias a memória.

\subsection{Uso de técnicas e informações para potencia- lizar políticas de substituição em sistemas de memória virtual}

O intuito deste trabalho (PIANTOLA; MIDORIKAWA, 2009) foi apresentar uma forma de obter maior desempenho para uma política de gerência de memória, através da adoção de técnicas complementares e da inclusão de informações, sem precisar modificar a política e seu comportamento original. Isso levou à criação de um novo algoritmo chamado LRU+ng. O artigo utilizou o modelo de bigrama (n-gramas), descrito no Capítulo 3, para trazer à memória principal, além da página responsável pela falta, a possível próxima página a ser referenciada.

No sistema operacional Windows Vista, da Microsoft, foi criada uma tecnologia denominada SuperFetch. O SuperFetch utiliza, ao mesmo tempo, prefetching e profiling; ele reconhece o programa de uma execução anterior e, por meio da técnica de profiling: grava o padrão de referências às páginas. Nesse momento, o sistema operacional tenta pré-paginar a maior parte das páginas necessárias (PIANTOLA; MIDORIKAWA, 2010). 


\subsubsection{Análise do algoritmo LRU+ng}

A avaliação do LRU+ng foi efetuada usando três diferentes traces de aplicações, são eles: multi1, multi2 e multi3. Os três traces foram selecionados pelo fato de conterem acessos simultâneos de aplicações, simulando um ambiente multiprogramado. Os traces utilizados foram os mesmos da seção 2.3.1 para a análise do algoritmo LRU-WARlock.

\section{- Multi1:}

No multi1, a análise do perfil de frequência de acessos às páginas mostra que somente $7,5 \%$ das páginas são responsáveis por $50 \%$ dos acessos à memória. Podemos, então, prever que a informação de frequência de acessos, obtida pelo modelo dos n-gramas, irá proporcionar menos faltas de páginas. $\mathrm{O}$ LRU+ng supera o LRU em todos os tamanhos de memória, com ganho médio de quase $36 \%$, a Figura 11 confirma a previsão.

Figura 11: Comparação entre LRU, LRU+ng e Ótimo sobre o multi1

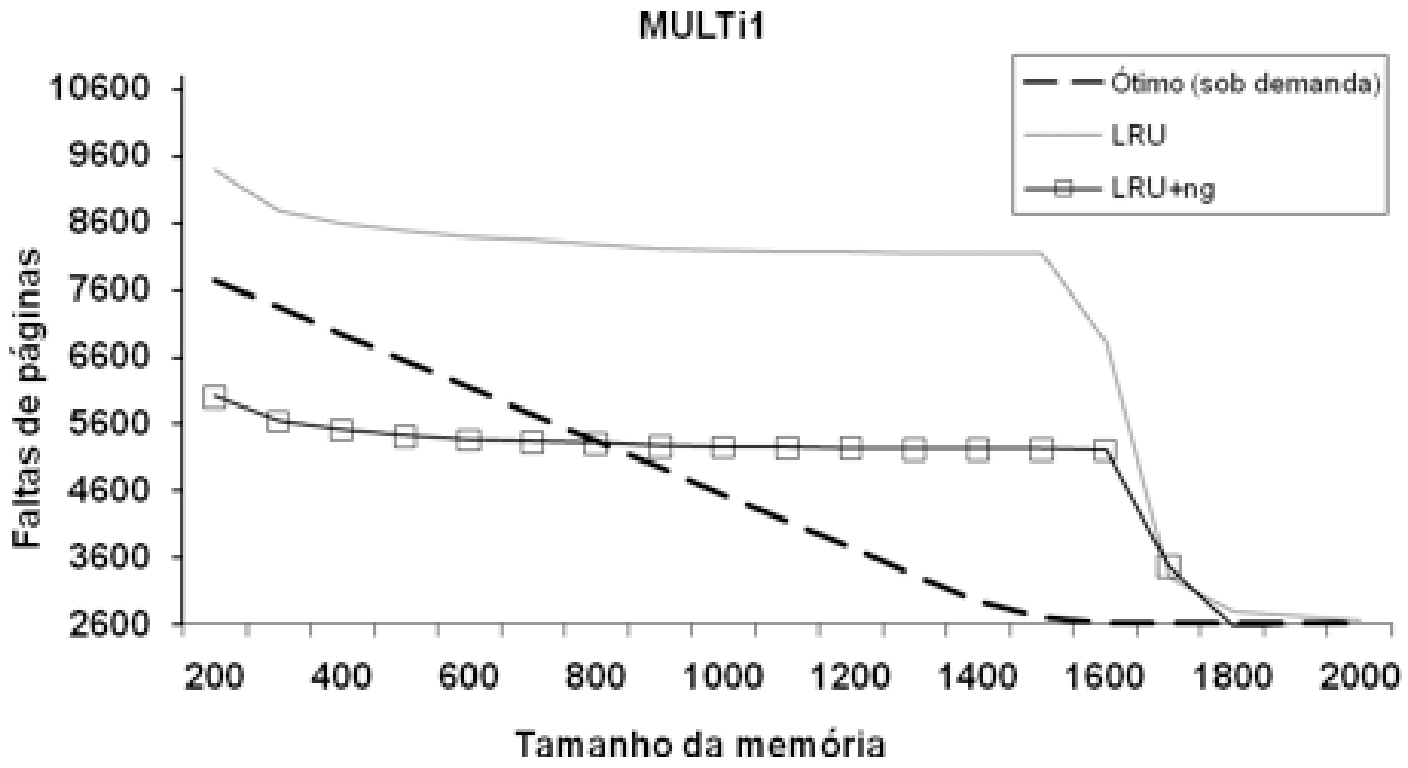

Fonte: Piantola e Midorikawa (2009) 
O gráfico da Figura 12 representa duas grandezas de eficiência sobre a busca antecipada no algoritmo testado. A primeira, com o tracejado em "x", representa em porcentagem de quantas vezes LRU+ng fez a busca antecipada sobre todos as faltas de páginas ocorridas em um tamanho de memória especificado pela abscissa. A segunda, com o tracejado em forma de quadrado, representa o total de acertos sobre a página buscada. Um acerto só é mensurado nas páginas que foram buscadas e imediatamente acessadas, ou seja, acessadas na próxima referência.

Figura 12: Busca sobre total de faltas no multi1

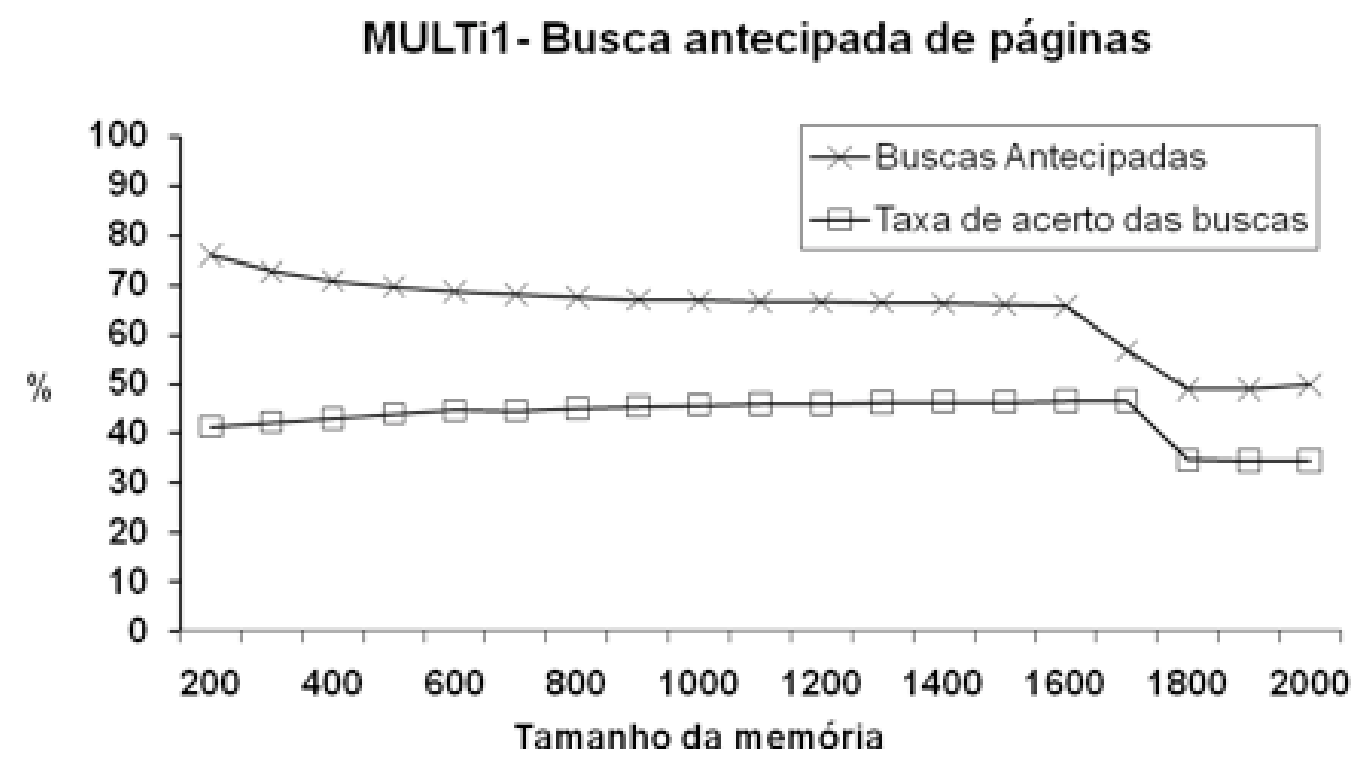

Fonte: Piantola e Midorikawa (2009)

Um fato de importante sobre o algoritmo LRU+ng é que ele supera o algoritmo Ótimo em todos os tamanhos de memória menores que 800 páginas. No caso do LRU+ng, a razão para seu melhor desempenho em relação ao algoritmo Ótimo é o fato de que ele não é um algoritmo de paginação sob demanda, pois usa uma técnica de busca antecipada de páginas. Portanto, concluímos que, como nenhum algoritmo de paginação sob demanda pode ser melhor 
que o Ótimo, nenhum pode alcançar o desempenho obtido pelo LRU+ng para memórias de tamanho pequeno com o trace Multi1. Toda referência ao algoritmo Ótimo neste trabalho se trata da substituição ótima sob demanda e não a busca antecipada ótima.

\section{- Multi2:}

O LRU é superado pelo LRU+ng em todos os tamanhos de memória. O mesmo acontece com o algoritmo Ótimo, que é superado pelo LRU+ng em tamanhos de memórias pequenas. A eficiência do LRU+ng em memórias de pequeno tamanho no trace multi2, é determinado pelo fato do algoritmo não encontrar a página da busca antecipada na memória e trazê-la para a memória em quase $75 \%$ das vezes, contra $22 \%$ das vezes em memórias de tamanho grande. A Figura 13 mostra a comparação do LRU+ng com o LRU e Ótimo.

Figura 13: Comparação entre LRU, LRU+ng e Ótimo sobre o multi2

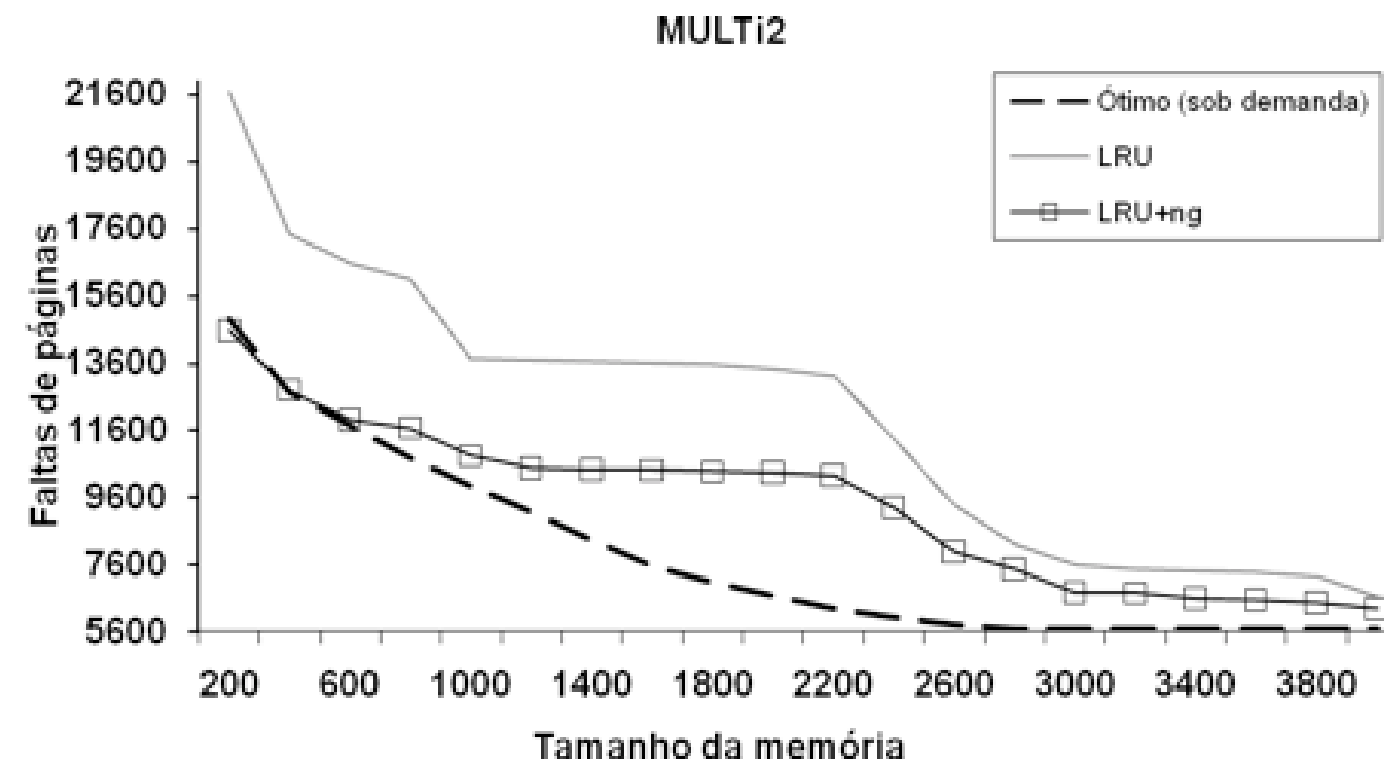

Fonte: Piantola e Midorikawa (2009)

\section{- Multi3:}

Dos traces utilizados na análise, o que contém o maior nível de multiprogra- 
mação é o trace multi3. São muitos padrões de acessos intercalados entre os quatro programas. Como não existe uma uniformidade da localidade temporal, páginas que serão acessadas em um futuro próximo são descartadas prematuramente. Para essa sequência de referências, o LRU não é bom, porém o $L R U+n g$ recupera essas páginas que foram descartadas prematuramente e supera o desempenho do LRU. Como nos outros dois traces estudados, o multi3 também atinge excelente desempenho quando se tem disponíveis quantidades mínimas de memória. Como mostra a Figura 14.

Figura 14: Comparação entre LRU, LRU+ng e Ótimo sobre o multi3

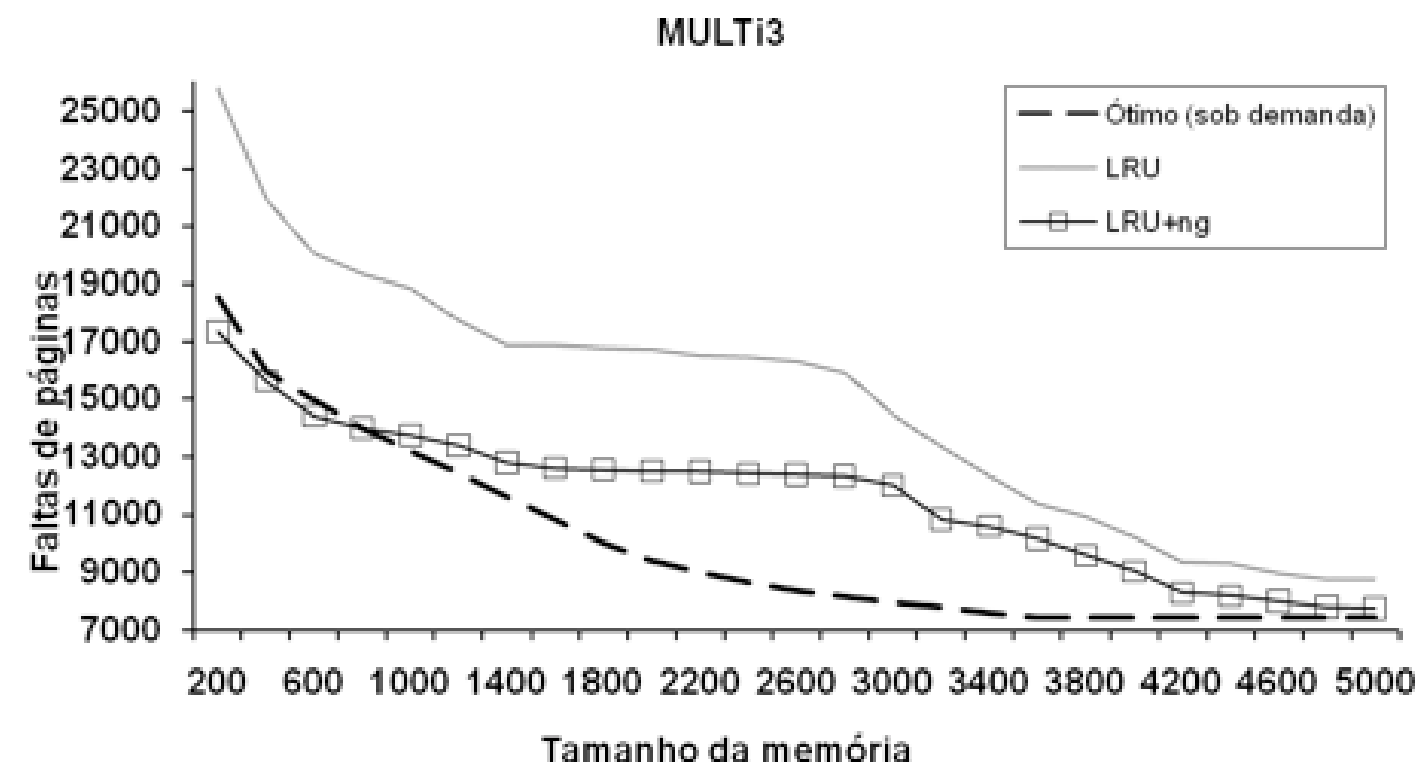

Fonte: Piantola e Midorikawa (2009)

Esse trabalho foi o ponto de partida da pesquisa apresentada nesta Tese, e mostra que a política de substituição deixa de ser o único objeto de esforços para a solução e novas técnicas complementares ganham valor. Outra ideia importante é que todo algoritmo sob demanda é limitado ao Ótimo e, quando usamos pré-paginação, esse limite pode ser ultrapassado. Assim surge a ideia, descrita nesta tese, sobre a qualidade do conteúdo das páginas na me- 
mória.

\subsection{Considerações sobre a revisitação dos traba- Ihos em gerência de memória}

As pesquisas na área de algoritmos de substituição de páginas não chegaram a um algoritmo que resolva satisfatoriamente o problema de desempenho na gerência de memória. Ainda não existe um consenso entre os pesquisadores de como a questão deve ser tratada de maneira eficiente, e os algoritmos desenvolvidos recentemente possuem grande sobrecarga devido à sua complexidade (GEROFI et al., 2014; KANRAR; MANDAL, 2014; SHAIK; PASHA, 2015).

As reanálises dos trabalhos mostraram que é necessário uma nova abordagem para chegar a uma gerência eficiente de memória. Esta tese propõe analisar o conteúdo da memória, e tirar o foco da substituição de páginas, enfatizando os outros aspectos da gerência de memória, e maximizar a qualidade.

O próximo capítulo introduz alguns aspectos sobre gerência de memória com paginação e as estratégias que podem ser exploradas para atingir um bom desempenho. Também são mostradas algumas técnicas e informações promissoras, que podem ser aproveitadas em algoritmos de busca e posicionamento de páginas. 


\section{TÉCNICAS E INFORMAÇÕES NO AUXÍLIO DA GERÊNCIA DE MEMÓRIA}

Neste capítulo são definidas as técnicas e informações que permitem obter um melhor desempenho na gerência de memória. Além disso, são tratadas detalhadamente algumas das principais técnicas e informações, tais como: a técnica de posicionamento de Superpáginas (Superpages), na seção 3.2, com uma proposta para sua implementação em conjunto com informações, que atualmente necessita de um hardware específico; a informação obtida pelo grafo de acessos ou referências à memória, na seção 3.4, com uma proposta de modificação do algoritmo Far que parece promissora; e por fim a informação obtida através dos n-gramas, utilizadas nos algoritmos LRU+ng, LRUWARlock+ng (PIANTOLA; MIDORIKAWA, 2010), RR+ng e RRlock+ng.

\subsection{As informações que direcionam as técnicas de busca e posicionamento de páginas}

As técnicas às quais este trabalho se refere são os mecanismos de busca e posicionamento de páginas, incorporados nos algoritmos de gerência de memória. Como exemplo de técnicas de busca, podem-se citar a paginação sob demanda e a pré-paginação (TRIVEDI, 1976; SMITH, 1978; DAHLGREN et al., 1995). A diferença entre a paginação sob demanda e a pré-paginação é que a segunda não espera faltar a página na memória para trazê-la do disco para 
a RAM. O algoritmo LRU+ng, discutido no capítulo 2, usa as duas técnicas. Dentre as técnicas de posicionamento de páginas, podem ser listadas: a técnica de superpages, o Buddy Systems (PETERSON; NORMAN, 1977) e trava de páginas (lock). O algoritmo LRU-WARlock utiliza a trava de páginas em $20 \%$ da memória alocada. O lock é uma técnica de posicionamento temporal, independentemente da posição da página na memória, ela ficará naquela posição escolhida por determinado tempo controlado pelo algoritmo.

Como o título indica, as informações direcionam as técnicas de busca e posicionamento de páginas. O ganho de desempenho só acontece quando as técnicas são utilizadas pelo sistema com inteligência, ou seja, guiadas por informações. Basicamente, as informações resumem-se a recência e frequência de acessos e relações entre páginas. O algoritmo LRU+ng usa os bigramas que contêm as informações de frequência e relações entre páginas. Assim como o LRU-WARlock, aproveita a informação de frequência de acesso das páginas.

Novas técnicas e informações podem ser criadas para serem utilizadas. Da mesma forma que a técnica de n-gramas foi importada da área de processamento estatístico de linguagem natural, outra informação ou técnica pode ser trazida para a área de gerência de memória. O importante é a combinação da técnica com a informação. Assim, mesmo uma técnica existente e considerada ruim pode se tornar uma boa opção.

\subsection{Superpages}

A maioria dos processadores atuais suporta páginas de memória com tamanhos diferentes. Duas décadas atrás, páginas de tamanho relativamente grande, chamadas superpages, começaram a ser utilizadas por reduzir seu 
tempo gasto nas faltas na TLB (Translation Lookaside Buffer) pelo aumento do alcance na TLB. A TLB é um dispositivo de hardware usado para mapear páginas virtuais em endereços físicos rapidamente, não precisando assim passar pela tabela de páginas. O número de entradas na TBL é pequeno, então quanto maiores são as páginas, mais informação é mapeada. O uso transparente das superpages permanece limitado pela arquitetura e o custo para implementar algoritmos de promoção e demoção de páginas é alto.

A técnica de superpaging parece promissora pelos seguintes motivos: é sabido e bem experimentado que a técnica aumenta o alcance do TLB; o tamanho padrão das páginas em um sistema operacional que utiliza sistema de gerência de memória com paginação é $4 \mathrm{~KB}$, e para o tamanho da memória principal que temos hoje, 4KB é um valor muito pequeno e produz uma quantidade grande de páginas dificultando o gerenciamento. Assim a superpage diminui a quantidade de páginas gerenciadas (WEISBERG; WISEMAN, 2009); por fim, a ideia de utilização das superpages para substituir ou tornar o prefetching e n-gramas menos custoso.

\subsubsection{Arquiteturas e sistemas operacionais com suporte a superpages}

Várias arquiteturas modernas suportam superpages, permitindo que os sistemas operacionais utilizem tamanhos diferentes de páginas em execução. Esse é o caso, por exemplo, do sistema operacional Solaris MPSS (MCDOUGALL, 2004). Já no sistema operacional IRIX, o tamanho das páginas são escolhidas pela aplicação através de chamadas de sistemas (GANAPATHY; SCHIMMEL, 1998). Outro sistema operacional que suporta superpages é o HP-UX, em que o tamanho das páginas pode ser escolhido pela aplicação ou de forma transparente pelo sistema operacional (SUBRAMANIAN et al., 1998). O sistema 
operacional Linux também suporta páginas de diferentes tamanhos chamada Hugepages (NAVARRO et al., 2002). Outras arquiteturas também suportam superpages, tais como Power, Itanium, MIPS R4x00 e Alpha.

Alguns problemas surgem com esse modo de gerenciamento de memória. Quando o sistema operacional deve transformar uma página base em uma superpage? Essa questão se torna mais complexa quando o sistema suporta mais de um tamanho de superpage como é o caso do Itanium que tem vários tamanhos diferentes de superpages que variam em potência de 2 de $4 \mathrm{~KB}$ até 4GB (caso do Itanium com o sistema HP-UX). Duas políticas de promoção de páginas em superpages são descritas na próxima seção.

\subsubsection{Políticas de promoção de páginas}

A política de promoção de páginas em superpages é o principal fator de desempenho em um sistema operacional. Ela transforma páginas base em superpages em tempo de execução, de forma transparente à aplicação. Duas das principais políticas de promoção online são approx-online e asap (ROMER, 1998).

A política asap promove um grupo de páginas em superpages assim que elas são referenciadas. Essa política elimina a sobrecarga do sistema em relação à coleta e processamento de informações para tomada de decisão, pelo fato de não ser necessário guardar nenhuma informação para realizar a promoção. A informação de frequência de acesso, vista como muito importante, é ignorada. O preço pago pela simplicidade pode onerar o sistema, já que algumas páginas promovidas podem nunca mais ser referenciadas novamente.

A política approx-online usa uma estratégia competitiva para determinar quando as páginas devem ser agrupadas. Se uma página $p$ acumula mui- 
tas faltas, possivelmente será referenciada no futuro novamente e, promovendo essa página, pode-se prevenir falta na TLB. Essa política é baseada na frequência de faltas das páginas e, pelo fato de guardar um histórico de faltas de páginas, ela apresenta um custo 3 vezes maior que a política asap, porém o custo pode compensar em comparação com asap, pois approx-online erra menos suas promoções.

\subsubsection{Demoção de páginas}

Outro fator tão importante quanto a promoção de páginas é a demoção. A demoção é o ato de reduzir uma superpage em uma superpage de tamanho menor ou em uma página de tamanho base. A demoção pode ocorrer quando todas ou algumas páginas base da superpage foram eleitas como vítimas para substituição.

Uma forma de determinar se a superpage inteira ou se apenas algumas de suas partes estão sendo utilizadas é fazer uma demoção especulativa. Esse tipo de demoção pode ser necessário quando o sistema operacional está precisando de mais espaço disponível na memória principal.

\subsubsection{O controlador de memória Impulse}

Duas páginas somente podem ser promovidas para uma superpage quando são fisicamente contíguas. Quando as páginas não são fisicamente vizinhas é necessário copiá-las para que se tornem contíguas. O processo desse tipo de promoção causa sobrecarga no sistema operacional, produzindo custos diretos e indiretos. Os custos diretos são de copiar as páginas para ficarem uma ao lado da outra e o processo de modificar o seu mapeamento. Já os custos indiretos vêm do aumento do número de instruções executadas em cada falta na TLB e o aumento de contenção na hierarquia do cache (atra- 
vés do código e informações usadas no processo de promoção das páginas). Quando se criam superpages, todos os custos devem ser balanceados com relação ao ganho de desempenho.

O controlador de memória Impulse mantém suas próprias tabelas de páginas para mapeamentos de memória, permitindo a construção de superpages de páginas que não estão fisicamente contíguas sem a necessidade de copiálas ou remapeá-las (ZHANG et al., 2001).

O Impulse é uma peça essencial para a utilização de n-gramas, de modo que nem sempre páginas que são acessados uma após a outra estão fisicamente contíguas. E a forma menos custosa de se usar os n-gramas é através das superpages.

\subsection{O uso de n-gramas}

Os n-gramas são tipos de modelos probabilísticos para prever o próximo elemento em uma sequência. Eles são usados em várias aplicações de processamento estatístico de linguagem natural e em Biologia, especificamente, em Genética (MANNING; SCHÜTZE, 1999). Dada uma sequência, um n-grama é uma sub-sequência de n elementos. Os elementos podem ser letras, palavras, fonemas, nucleotídeos ou, como ocorre neste trabalho, páginas do sistema de memória virtual. Um n-grama de tamanho 1 é chamado de unigrama, de tamanho 2 é conhecido como bigrama, tamanho 3 é trigrama e tamanho 4 ou mais é nomeado n-grama.

A base matemática dos n-gramas foi proposta por Markov em 1913. O problema de como prever o próximo elemento foi muito estudado e é conhecido como Shannon Game (SHANNON, 1955). O jogo é: dada uma sequência de letras, qual seria provavelmente a próxima letra? Exemplo: "prova de geo...". De 
uma coleção de dados para treinamento de um programa que dará a resposta, o próprio programa pode retirar a distribuição probabilística para a próxima letra onde as probabilidades de todas as letras somadas seja 1,0. (exemplo: $a=0,0001, b=0,0002, \ldots, g=0,8, \ldots)$.

A Tabela 3 mostra os bigramas mais comuns encontrados no jornal The New York Times de agosto a novembro de 1990 (MANNING; SCHÜTZE, 1999). É possível, por meio deste corpus obtido com o jornal, aplicar os bigramas a um programa de reconhecimento de escrita para melhorar sua precisão. Um modelo de trigrama foi usado no sistema de reconhecimento de voz chamado IBM TANGORA já na década de 70 (JURAFSKY; MARTIN, 2008).

Este trabalho pretende utilizar o modelo de bigrama para trazer à memória principal, além da página responsável pela falta, a possível próxima página a ser referenciada.

Tabela 3: Bigramas mais comuns no New York Times.

\begin{tabular}{ccc}
\hline Frequência & Palavra 1 & Palavra 2 \\
\hline \hline 80871 & of & the \\
\hline 58841 & in & the \\
\hline 26430 & to & the \\
\hline 21842 & on & the \\
\hline 21839 & for & the \\
\hline 18568 & and & the \\
\hline 16121 & that & the \\
\hline 15630 & at & the \\
\hline
\end{tabular}




\subsubsection{Algoritmo de busca de páginas e n-gramas}

O algoritmo LRU+ng, analisado no capítulo 2, utiliza a técnica de n-grama para decidir qual página trazer para memória no momento da ocorrência de uma falta de página. A informação capturada do n-grama possibilita prever, com uma certa probabilidade, a próxima página em uma sequência de referências à memória. A informação do n-grama foi usada para auxiliar a técnica de pré-paginação. Os n-gramas carregam a informação de recência e frequência.

\subsection{Grafo de acessos às páginas}

Nessa subseção é apresentada uma proposta de modificação da política de substituição de páginas far que pode ser utilizada para aumentar a qualidade na configuração da memória, o conceito que será detalhado no capítulo 4.

A estratégia da política de substituição far é construir um grafo dos acessos às páginas da memória e usá-lo para tomar decisões quando uma página precisa ser substituída. O desempenho da estratégia far, (da palavra "longe" em inglês), é bem próximo da substituição ótima, mas sua implementação é de complexa execução (FIAT; ROSEN, 1997).

O grafo de acesso criado (Fig. 15) mostra o padrão de referência do programa em execução (DEITEL; DEITEL; CHOFFNES, 2005). Assim, cada vértice representa uma página do programa. Uma aresta do vértice $p$ para o $q$ significa que após a página $p$ a página $q$ foi referenciada. O grafo pode ficar complexo dependendo de como as páginas do programa são referenciadas no decorrer de sua execução. 
Figura 15: Grafo estratégico da substituição far

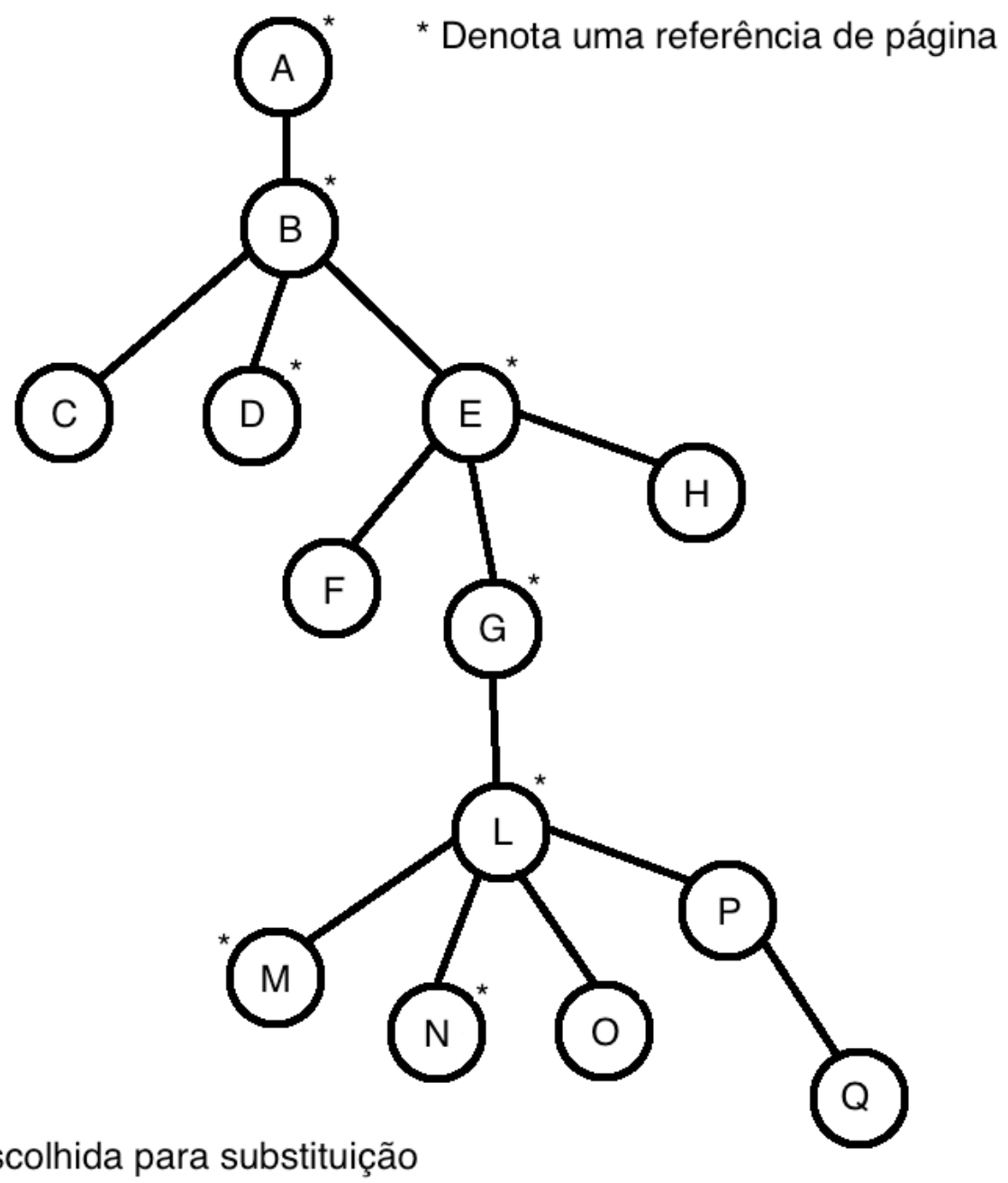

Q é escolhida para substituição

Fonte: Adaptado de Deitel, Deitel e Choffnes (2005), tradução nossa.

Uma outra possibilidade é criar o grafo de acessos analisando o programa compilado. A maior parte dos estudos sobre o Far foram feitos com grafos construídos antes da execução do programa. $\mathrm{N}$-gramas podem ser retirados facilmente dos grafos de acesso.

No exemplo da Figura 15 , depois da referência da página $B$ do programa, a próxima página a ser referenciada será a página $A, C, D$ ou $E$, mas não se referenciará a página $G$ antes da $E$. $O$ algoritmo de substituição Far escolhe a página que está, no grafo, mais longe da página $B$ e que não está marcada 
como referenciada há pouco tempo, que neste caso é a $Q$.

Pode-se notar, pelo exemplo, que os algoritmos para construir e procurar as páginas que compõem a estratégia do Far são complexos e produzem sobrecarga na execução. Por esse motivo, o Far nunca foi implementado em um sistema operacional real.

Com a meta de privilegiar os algoritmos de busca e posicionamento de páginas, a proposta é utilizar o grafo de acesso para a busca de páginas e não para a substituição. Desta forma podemos eliminar o processo custoso da busca da página no grafo do algoritmo de substituição Far e manter o foco nas páginas que possivelmente serão acessadas no futuro próximo. Retornando ao exemplo, depois da página $B$ ser acessada, pode-se trazer a $A, C, D$ ou $E$ para a memória. A informação mais valiosa está perto e não longe da página $B$. São dois os benefícios diretos dessa nova proposta: primeiro, elimina-se a busca da página Far; e segundo, podem-se evitar faltas de páginas futuras.

O capítulo seguinte apresenta o conceito de qualidade, conforme definido nesta tese, e o cálculo da métrica criada para quantificar a qualidade do conteúdo da memória. 


\section{QUALIDADE NA CONFIGURAÇÃO DA MEMÓRIA PRINCIPAL}

A qualidade do conteúdo de memória pode auxiliar o desenvolvimento de algoritmos de gerência de memória mais eficientes. Uma gerência eficiente é a que mantém a memória com boa qualidade, garantindo melhor desempenho do sistema, menos faltas de páginas, menor tempo de execução ou maior nível de multiprogramação.

Define-se aqui como qualidade do conteúdo da memória o quanto esta abriga páginas que serão referenciadas no futuro próximo. O conceito de qualidade leva a estabelecer que é melhor consumir recursos computacionais determinando quais páginas deveriam estar na memória em um determinado tempo virtual do que gastar recursos determinando qual página será retirada da memória. Uma medida quantitativa é necessária para saber quanto um algoritmo se aproxima da máxima qualidade possível, ou seja, a configuração perfeita de páginas na memória. Este capítulo propõe uma métrica de qualidade, que será referida em letras maiúsculas, QUALIDADE, para que não haja confusão com o conceito de qualidade.

A proposta da métrica de QUALIDADE consiste em criar um índice para quantificar o conteúdo atual da memória de acordo com seu uso futuro. O índice compara as páginas que estão na memória em um determinado tempo virtual $v t$ com a melhor configuração possível de páginas na memória e pontuála através de dois critérios na respectiva ordem: recência e frequência com que 
a página é acessada. Com relação à recência, quanto mais próxima a página está para ser acessada, maior é seu peso na configuração da memória. O peso também é maior quanto mais frequentemente a página for acessada. Quanto mais próxima a QUALIDADE é de 1 , mais qualidade tem a configuração da memória.

\subsection{Definição da métrica de QUALIDADE}

Definição 1. Chama-se de qm a qualidade do conteúdo da memória principalou qualidade da memória - um número real, tal que $0 \leq q m \leq 1$. Expressando desempenho futuro do algoritmo de gerência de memória após um determinado tempo virtual $v t$.

A equação 4.1 calcula a QUALIDADE da memória:

$$
q m_{v t}=\frac{\sum_{i=v t}^{v t+j-1} \frac{\mu\left(S_{P_{i}}\right)}{i-v t+1}}{\sum_{i=v t}^{v t+j-1} \frac{1}{i-v t+1}}
$$

onde:

$$
\mu\left(S_{P_{x}}\right)= \begin{cases}1 & \text { se } S_{P_{x}} \in M^{\prime} \\ 0 & \text { caso contrário }\end{cases}
$$

$v \boldsymbol{t}$ Tempo virtual, número inteiro tal que $1 \leq v t \leq\left|S_{P}\right|$;

$j$ Tamanho da sequência em $S_{P}$ que começa em $v t$ e termina antes do primeiro elemento $x \notin M$, ou seja, $j=k-v t \mid S_{P_{k}} \notin M$ e $\forall r, v t \leq r<k, S_{P_{r}} \in M$;

$S_{P}$ Sequência finita ordenada de acessos à memória; 
$\boldsymbol{P}$ Conjunto finito representando as páginas do programa.

$M$ Conjunto finito contendo os primeiros elementos distintos de $S_{P}, \forall x \in M$, tal que, $x \in P$ e representa a melhor configuração possível de memória;

$M^{\prime}$ Conjunto finito, $\forall x \in M^{\prime}$, tal que, $x \in P$ e representa a memória atual do programa;

Quanto mais próximo qm é de 1, melhor é a qualidade da memória. Por outro lado, quanto mais perto ela é de 0 , pior é a qualidade. A memória perfeita - ou ótima - é a que tem $q m=1$, ou seja, a configuração da memória principal atinge $100 \%$ de qualidade.

Na próxima seção, exemplificam-se o passo a passo de como calcular a QUALIDADE em um determinado tempo virtual.

\subsection{Exemplo do cálculo da métrica}

Se ja $P=\{a, b, c, d, e, f, g, h, i, j\}$ páginas do programa, $S_{P}=(\ldots, a, a, e, j$, $a, c, c, a, e, b, f)$ sequência ordenada de acessos à memória e $\left|M^{\prime}\right|=4$ como tamanho da memória principal. Foram omitidos os primeiros 22 elementos de $S_{P}$ para melhor visualização.

Suponha que $v t=23$ quando a primeira página $a$ de $S_{P}$ é acessada, assim, a última página da sequência é a $f, v t=33$. No $v t=23, M^{\prime}=\{a, g, j, b\}$.

Quer-se saber a QUALIDADE no tempo vitual $v t=23$, ou seja, $q m$ no tempo virtual 23. Primeiro é necessário calcular o conjunto $M$. $M$ é composto dos primeiros elementos distintos de $S_{P}$ que preenchem a memória de tamanho 4. Então, tem-se $M=\{a, e, j, c\} . M$ é em $v t=23$, a melhor configuração da memória. Agora, pode-se comparar com $M^{\prime}$ encontrando o valor de qm. 
Figura 16: Exemplo visual

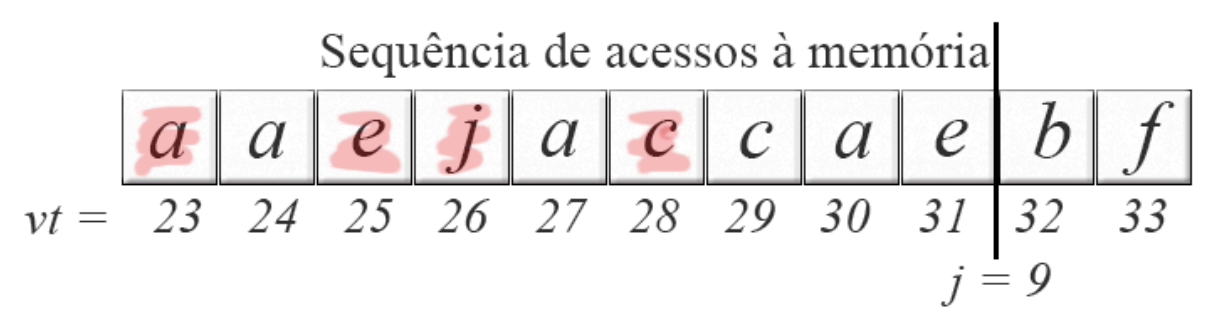

Melhor configuração de memória Memória atual do programa

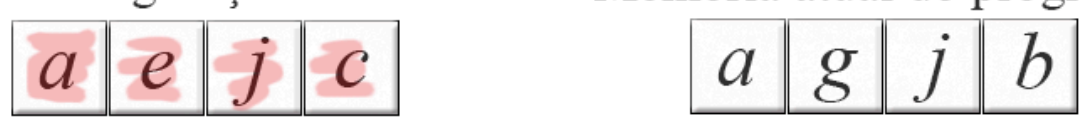

Fonte: Próprio Autor (2015)

A última variável a encontrar é $j$. Para fazer isso, deve-se calcular o tamanho da subsequência em $S_{P}$ que começa em $v t=23$ e termina antes do primeiro elemento $x \notin M$. Criamos a subsequência $S_{j}=(a, a, e, j, a, c, c, a, e)$, para calcular seu tamanho. O tamanho de $S_{j}$ é 9, como podemos ver representado na barra vertical na Figura 16.

Os passos 4.3, 4.4, 4.5 e 4.6 são o desenvolvimento do cálculo da QUALIDADE:

$$
\begin{gathered}
q m_{23}=\frac{\sum_{i=23}^{23+9-1} \frac{\mu\left(S_{P_{i}}\right)}{i-23+1}}{\sum_{i=23}^{23+9-1} \frac{1}{i-23+1}} \\
q m_{23}=\frac{\frac{\mu(a)}{1}+\frac{\mu(a)}{2}+\ldots+\frac{\mu(e)}{9}}{\frac{1}{1}+\frac{1}{2}+\ldots+\frac{1}{9}} \\
q m_{23}=\frac{\frac{1}{1}+\frac{1}{2}+\frac{0}{3}+\frac{1}{4}+\frac{1}{5}+\frac{0}{6}+\frac{0}{7}+\frac{1}{8}+\frac{0}{9}}{\frac{1}{1}+\frac{1}{2}+\ldots+\frac{1}{9}}
\end{gathered}
$$




$$
q m_{23}=\frac{2,075}{2,829}=0,7334
$$

No $v t=23, M^{\prime}$ tem QUALIDADE de $73,34 \%$. Isso significa que para futuros acessos à memória, até $v t=31$ (nove tempos virtuais a contar de $v t=23$ ), o programa terá bom desempenho causando poucas faltas de páginas. Este exemplo mostra como calcular a QUALIDADE em um determinado tempo virtual.

É importante notar que o denominador da equação qm é uma sequência denominada série harmônica $\left(H_{\infty}=\sum_{k=1}^{\infty} \frac{1}{k}\right)$. Na concepção da métrica, a série harmônica contribui com duas propriedades, a primeira delas fundamental para a métrica de QUALIDADE: a série é divergente e pode ser resolvida através da fórmula Euler-MacLaurin (KNOPP, 1921). Pelo fato da série ser divergente, ou seja, não importa o tamanho do somatório, ela nunca converge para um número. Isso atesta a validade da métrica de QUALIDADE para qualquer quantidade de páginas em memória próximo ao infinito. A fórmula de Euler-MacLaurin facilita o cálculo quando se tem um número considerável de páginas em memória.

A próxima seção apresenta os usos da métrica QUALIDADE em diferentes contextos na gerência de memória.

\subsection{Usos da QUALIDADE da memória}

A priori, a métrica da QUALIDADE foi criada para quantificar o conceito de qualidade na configuração da memória, ou seja, o quanto as páginas que 
fazem parte da memória principal em um dado momento serão usadas em referências futuras. Quanto maior o número de páginas carregadas na memória a serem acessadas nas próximas referências do programa, maior é o índice de qualidade. Por outro lado, quanto mais tempo levar para as páginas contidas na memória principal serem acessadas, pior é o índice de QUALIDADE. A QUALIDADE pode então ser entendida como índice de usabilidade do conteúdo atual da memória.

Como o cálculo da QUALIDADE pode ser feito em cada referência de memória, é possível criar um gráfico contendo a QUALIDADE da memória em toda a execução de um programa, ou um gráfico referente à memória durante a execução de todos os programas do sistema multiprogramado. A análise visual da execução de um programa, ou do sistema completo, torna-se possível. Com a análise visual, pode-se detalhar as partes da execução do programa que têm boa qualidade e quais deixam a desejar. Essa informação apoia a criação de novas estratégias para aumentar o desempenho em sistemas de gerência de memória. Um exemplo de gráfico como este mencionado é encontrado na seção 4.4 .

Outra utilidade do índice de QUALIDADE é na comparação entre políticas e algoritmos de gerência de memória. Além dos números de QUALIDADE resultantes de cada instante de tempo em toda a execução de um programa, é possível fazer a média e compará-los entre vários algoritmos executados com a mesma quantidade de memória. Essa informação, além de ser resumida como o número total de faltas de páginas, é normalizada. Em uma comparação usando a métrica de faltas de páginas, não se pode dizer se 1500 faltas de páginas é um bom número se não compararmos com as faltas de páginas dos algoritmos ótimo e péssimo, mas pode-se afirmar que uma QUALIDADE acima de $80 \%$ é bastante satisfatória. 
Além da métrica de QUALIDADE ser usada como informação na análise e engenharia de novos algoritmos de gerência de memória, ela poderia ser aproveitada em uma estratégia para gerenciar melhor a memória. Já que a QUALIDADE é um índice de usabilidade do conteúdo atual da memória, é também uma informação muito valiosa que pode ser utilizada para auxiliar as técnicas de busca e posicionamento de páginas. Como o índice precisa de informação futura para descobrir a QUALIDADE atual, em uma implementação o índice somente pode ser achado no passado. De acordo com a QUALIDADE passada, o algoritmo toma decisões para melhorar o desempenho atual da gerência de memória.

A métrica de QUALIDADE pode ser utilizada em outros contextos de gerência de memória como, por exemplo, para alocação de memória para máquinas virtuais. Calculando o índice de QUALIDADE para todas as máquinas virtuais em um ambiente, é possível determinar a máquina com pior qualidade e a com melhor qualidade. Dessa forma, é possível implementar uma estratégia em que se tire memória de uma máquina virtual com bom índice de QUALIDADE e se passe para uma com índice ruim, equilibrando assim o sistema como um todo.

Esses são alguns exemplos do uso da QUALIDADE da memória, no contexto de criação dos algoritmos de gerência de memória e no contexto do próprio algoritmo como informação de auxílio às técnicas de gerência. Nas próximas seções são apresentados exemplos de utilização da métrica de qualidade na análise de algoritmos de gerência de memória. 


\subsection{Análise do LRU com a métrica de QUALIDADE}

Apresentamos a análise da qualidade da política de substituição de páginas LRU utilizando os traces já descritos anteriormente: multi1, multi2 e multi3. O simulador da política LRU e o simulador do cálculo da QUALIDADE foram escritos em linguagem PERL. O algoritmo LRU foi escolhido por ser amplamente utilizado como política de substituição de páginas. Em aplicações com padrões de acessos sequenciais e que contêm grandes loops, a política LRU não atinge um bom desempenho, os traces multis, apresentados na seção 2.3.1, têm esses padrões de acesso, motivo também dessa escolha (PIANTOLA; MIDORIKAWA, 2014).

Figura 17: Gráfico de QUALIDADE do LRU no multi1

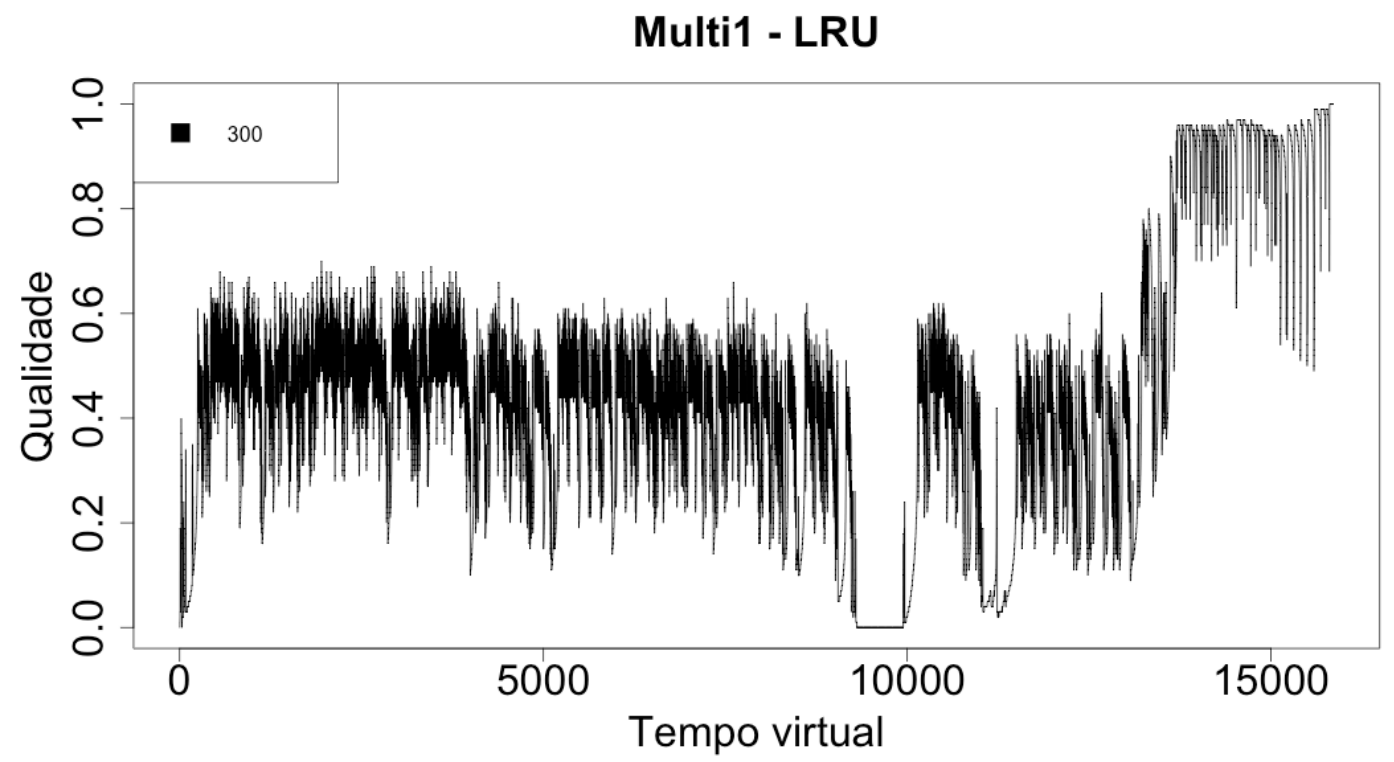

Fonte: Próprio Autor (2015)

No multi1, os valores da qualidade para memória de tamanho 300, no gráfico da Figura 17, são bem inferiores no decorrer dos acessos a memória, mas não tão inferiores se compararmos o início do programa e seu término. É possível verificar que o tamanho da memória influencia na métrica da qualidade, 
ou seja, quanto maior a memória melhor sua qualidade.

O gráfico da Figura 18 representa as páginas no eixo Y, e o tempo virtual em que a página é acessada no eixo X. Existe uma correspondência entre o padrão de acesso da aplicação, a política LRU e a métrica de QUALIDADE. Toda vez que temos acessos sequenciais e loopings maiores que a memória, o valor da qualidade da memória nesses pontos cai. O motivo é o desempenho ruim da política LRU nesses padrões de acesso. Uma das vantagens da métrica de qualidade é que podemos visualizar os pontos de fraqueza da política de substituição vigente. O gráfico da Figura 18 mostra o mapa de acessos com o tempo virtual para efeito de comparação.

Figura 18: Gráfico do mapa de acesso trace multi1

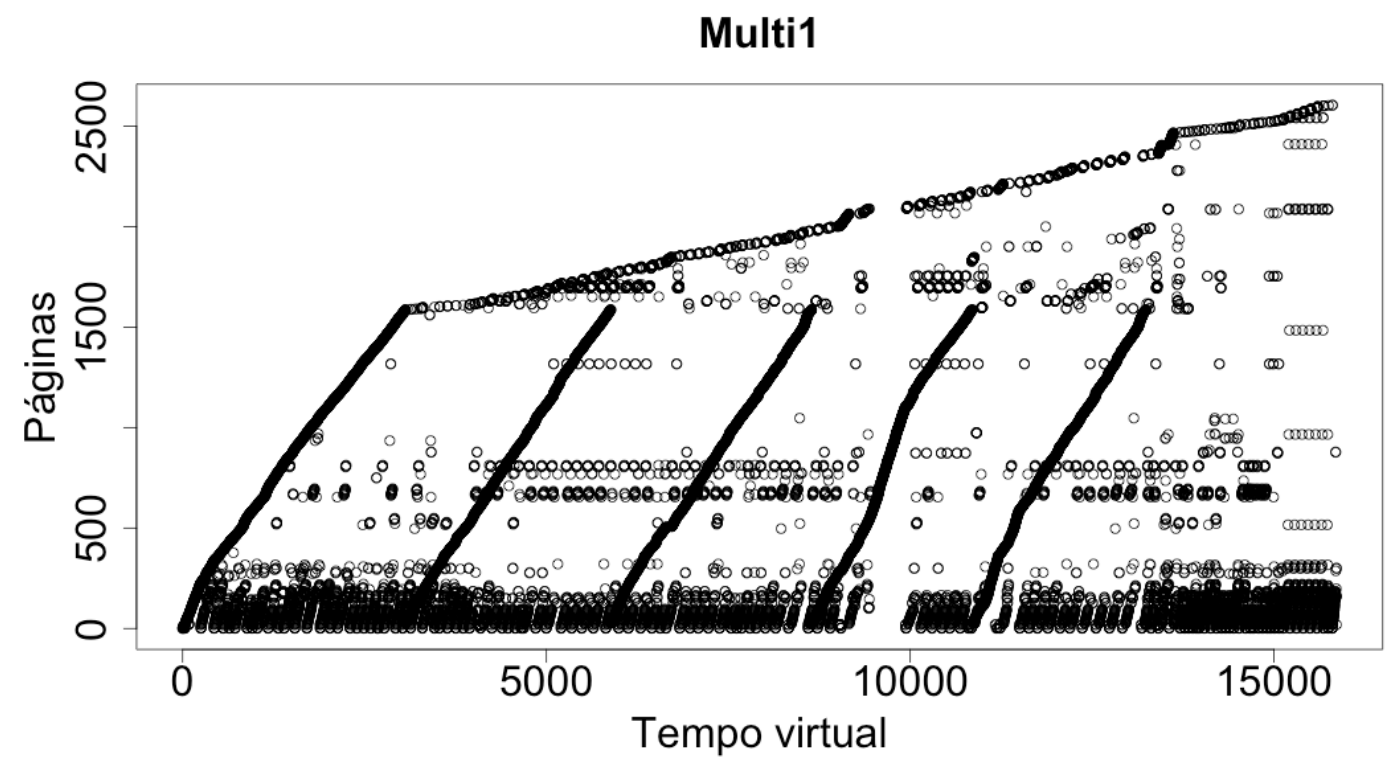

Fonte: Próprio Autor (2015)

No multi2, acontece o mesmo: os valores da qualidade para memória de tamanho 200, no gráfico da Figura 19, são inferiores no decorrer dos acessos a memória. É possível verificar que o tamanho da memória influencia na métrica da qualidade. A média de qualidade é 19,65\% para memórias pequenas de tamanho $200,51,57 \%$ para tamanho 2000 e $80,54 \%$ para tamanhos de me- 
mória de 4000. É possível perceber que a qualidade aumenta com relação ao tamanho de memória e é inversamente proporcional às faltas de páginas que diminuem com o aumento da memória.

Figura 19: Gráfico de QUALIDADE do LRU no multi2

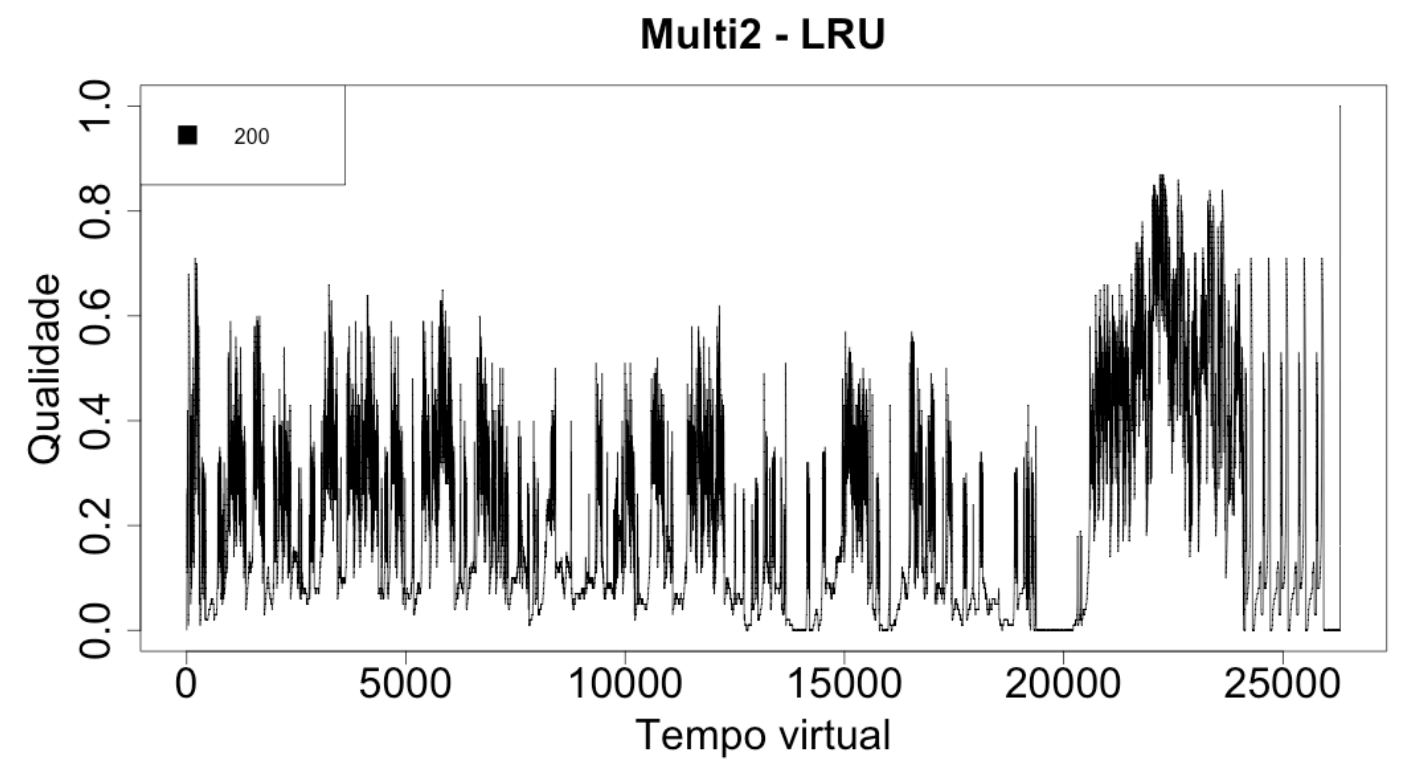

Fonte: Próprio Autor (2015)

No multi3, os valores da qualidade para memória de tamanho 200, no gráfico da Figura 20, também são inferiores no decorrer dos acessos à memória. É possível verificar mais uma vez que o tamanho da memória influencia na métrica da qualidade. A média de qualidade é 15,37\% para memórias pequenas de tamanho $200,50,37 \%$ para tamanho 2800 e $75,66 \%$ para tamanhos de memória de 5000. É possível perceber que quando aumenta o nível de multiprogramação a qualidade também diminui proporcionalmente.

O estudo da qualidade da memória foi realizado sobre os traces multiprogramados multi1, multi2 e multi3. Este método pode prover informações importantes para construção de novos algoritmos de substituição de páginas e novas estratégias de captura de informações. Além disso, pode ser uma técnica viável para a utilização em algoritmos online. Contudo, estudos mais profundos 
Figura 20: Gráfico de QUALIDADE do LRU no multi3

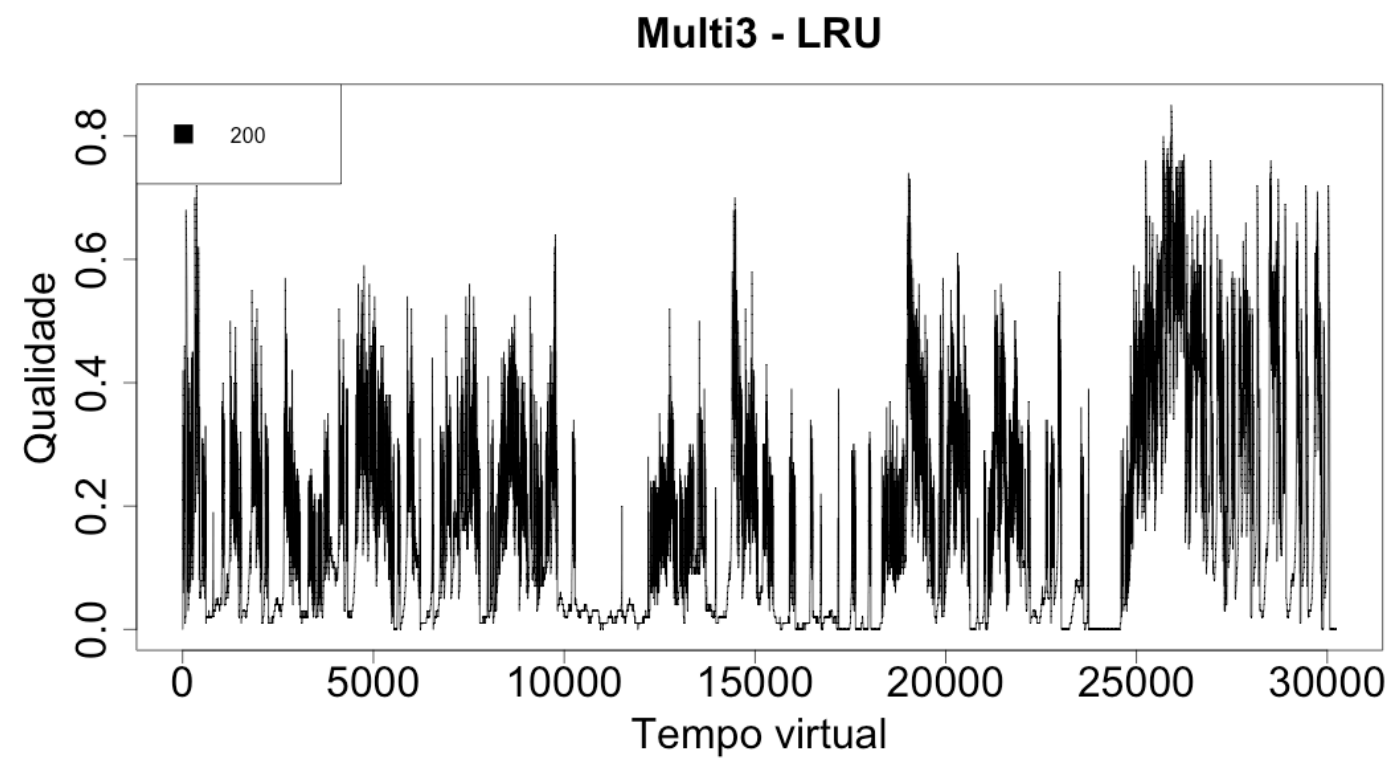

Fonte: Próprio Autor (2015)

são necessários para corroborar essa afirmação.

\subsection{Análise da política de substituição aleatória usando a métrica de QUALIDADE}

Nesta seção apresentamos a análise da qualidade da política de substituição aleatória, usando os traces multi1, multi2 e multi3 que contêm as referências de páginas da execução de um conjunto de programas simulando um sistema multiprogramado. Ambos os simuladores, o da política aleatória e o do calculo da qualidade, foram escritos em linguagem C e PERL (PIANTOLA; MIDORIKAWA, 2015).

Foram feitas três simulações para cada trace usando a política de substituição de páginas aleatória, cada uma com um tamanho diferente de memória. O tamanho da memória é medido em páginas, assim uma memória de tamanho 200 pode guardar 200 páginas. 
No trace multi1, o valor da QUALIDADE para memórias de tamanho 200 - em vermelho no gráfico (Figura 21) - são muito menores no decorrer das referências de memória, mas não tão menores quando comparadas com o início e fim do programa. É possível ver que a métrica de qualidade é afetada de acordo com o tamanho da memória, ou seja, quanto maior é a memória, melhor é a sua qualidade, pois a maior parte do working set das aplicações está na memória principal (DENNING, 1980). Memórias de maiores (tamanho de 1000 páginas, em verde; e 2000, em azul), mostram melhores valores de QUALIDADE, confirmando o resultado de desempenho da política de substituição de páginas aleatória, para esses tamanhos de memória. A Tabela 4 apresenta a média de QUALIDADE para a execução do trace multi1.

Tabela 4: Média de QUALIDADE da política aleatória

\begin{tabular}{cccc}
\hline Trace & Tamanho da memória & Média $\mathbf{q m}$ & Faltas de páginas \\
\hline \hline \multirow{2}{*}{ Multi1 } & 200 & $32,04 \%$ & 11.064 \\
& 1000 & $56,82 \%$ & 7.083 \\
& 2000 & $81,73 \%$ & 2.989 \\
\hline \multirow{2}{*}{ Multi2 } & 200 & $18,82 \%$ & 21.915 \\
& 2000 & $56,89 \%$ & 11.568 \\
& 4000 & $75,15 \%$ & 6.512 \\
\hline \multirow{2}{*}{ Multi3 } & 200 & $15,47 \%$ & 26.051 \\
& 2600 & $54,03 \%$ & 14.167 \\
& 5000 & $70,71 \%$ & 8.899 \\
\hline
\end{tabular}

Voltando ao gráfico da Figura 18, que representa páginas no eixo $Y$ e o tempo virtual em que a página é referenciada no eixo $X$, existe uma correspondência entre o padrão de acesso das aplicações, o desempenho da polí- 
tica aleatória e a métrica de QUALIDADE. Um ponto que se destaca no gráfico é que existe uma correspondência na Figura 21 um pouco antes do tempo virtual 10.000. Podemos identificar que o comportamento dos acessos a memória se modifica neste ponto, resultado de uma mudança no working set, e depois causando um aumento nas faltas de páginas. Tudo isso acaba em uma diminuição do valor da QUALIDADE.

Uma das vantagens da métrica de QUALIDADE é que podemos encontrar os pontos fracos da política de substituição e, principalmente, quais são as mudanças de localidade referencial.

Figura 21: QUALIDADE da memória para a política aleatória no Multi1

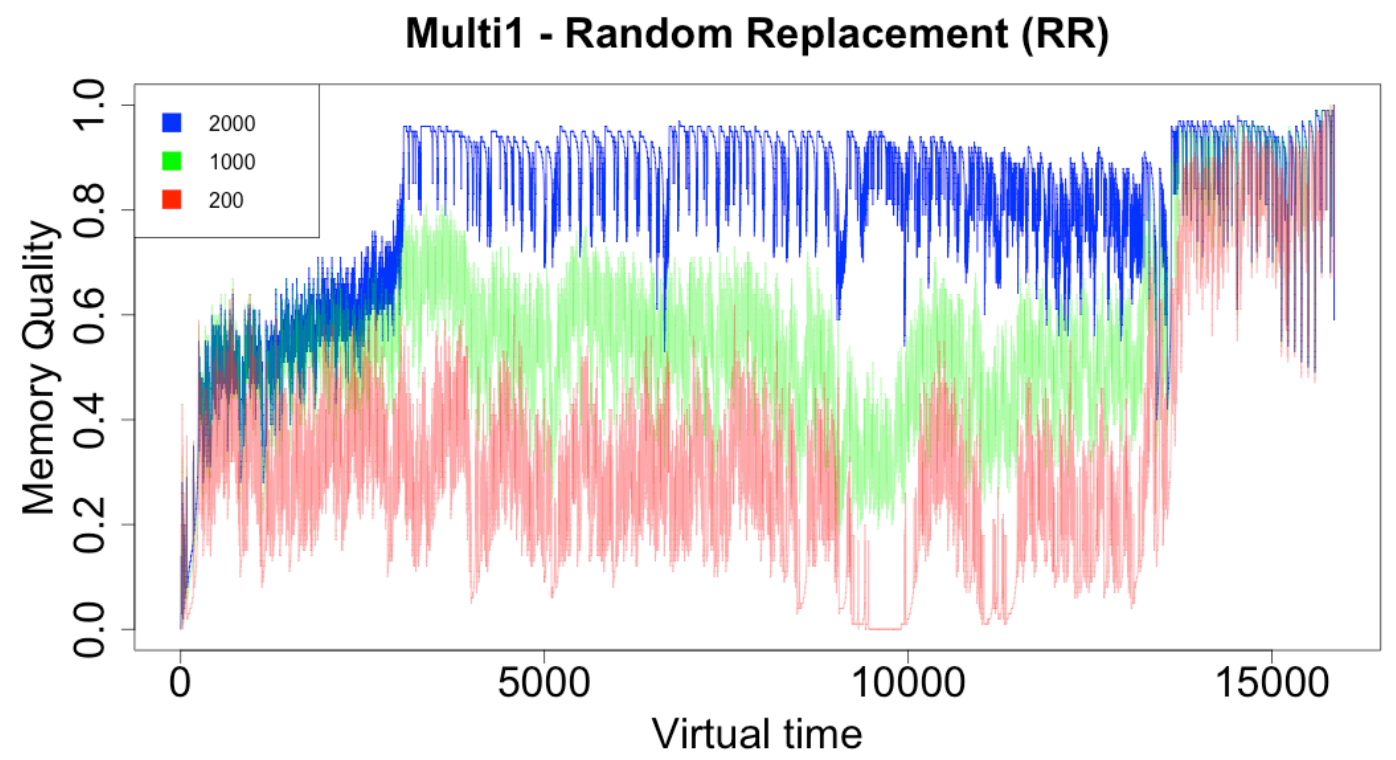

Fonte: Piantola e Midorikawa (2015)

O mesmo evento acontece quando executamos a simulação do trace multi2 com valores de tamanho de memórias pequenos, ou seja, com 200 páginas (cor vermelha no gráfico, Figura 22). A qualidade da memória é baixa em todas as referências à memória como no multi1. É possível verificar que o tamanho da memória afeta a métrica de QUALIDADE. A média da QUALIDADE é de $56.89 \%$ para memórias de tamanho médio. Assim, podemos observar 
que existe um equilíbrio para esse tamanho em todos os três traces (Tabela 4). Também podemos verificar que a QUALIDADE aumenta quando o tamanho da memória aumenta. De forma contrária, as faltas de páginas diminuem quando o tamanho da memória aumenta. A Tabela 4 mostra que as faltas de páginas e a média de qm são inversamente correlacionados. Quanto maior a QUALIDADE da memória menos faltas de páginas ocorrem.

Figura 22: QUALIDADE da memória para a política aleatória no Multi2

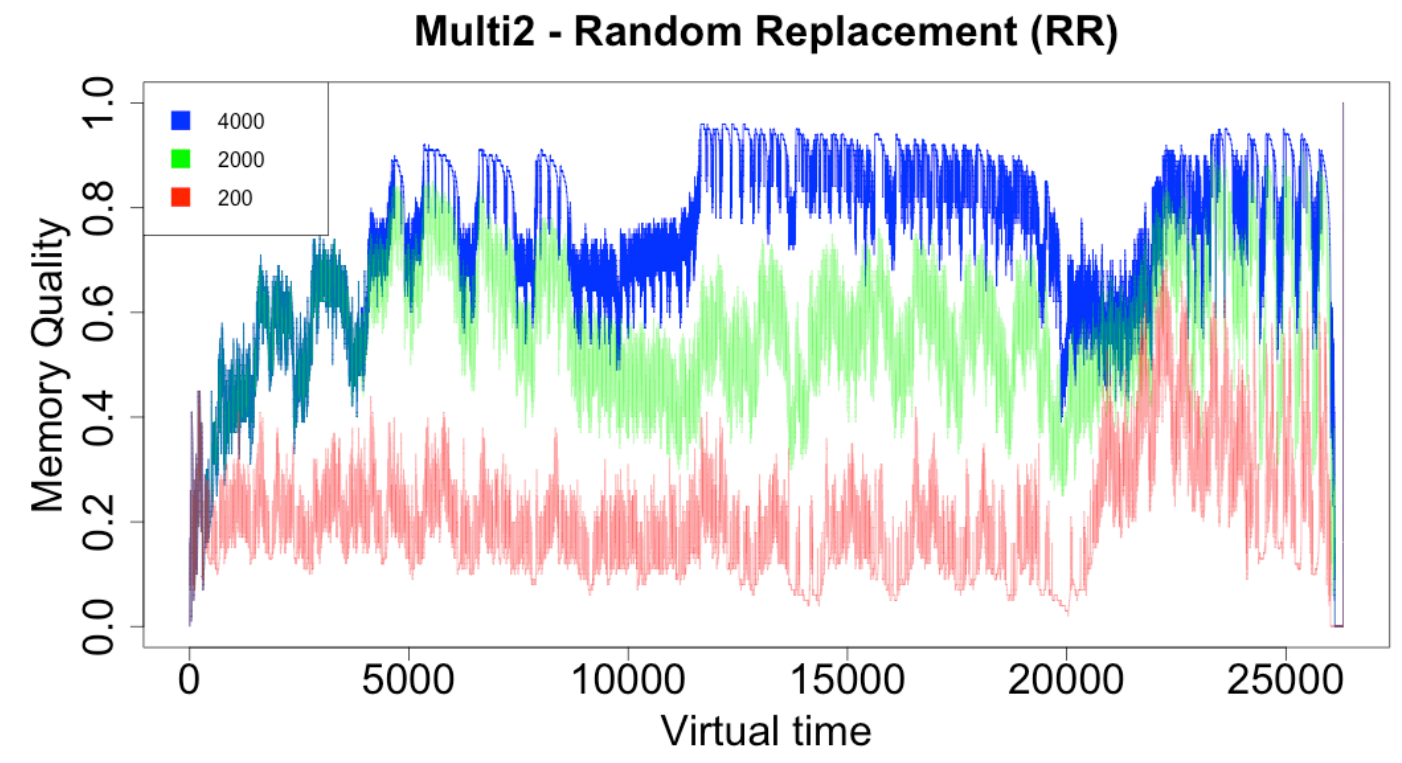

Fonte: Piantola e Midorikawa (2015)

No multi3, os valores da QUALIDADE da memória apresentados em vermelho (Figura 23) são muito baixos em todas as referências dos programas, como nas simulações anteriores. Mais uma vez, é possível verificar que o tamanho da memória influencia a métrica de qualidade. A média da QUALIDADE da memória é respectivamente 15\%, 54\% e 71\% para memórias de tamanho 200, 2600 e 5000 (Tabela 4). Como podemos ver, a média da QUALIDADE no decorrer da execução dos traces com tamanho de memória média, flui melhor quando comparado com a média de todos os traces multi. Quando o nível de multiprogramação aumenta, a qualidade diminui proporcionalmente. 
Figura 23: QUALIDADE da memória para a política aleatória no Multi3

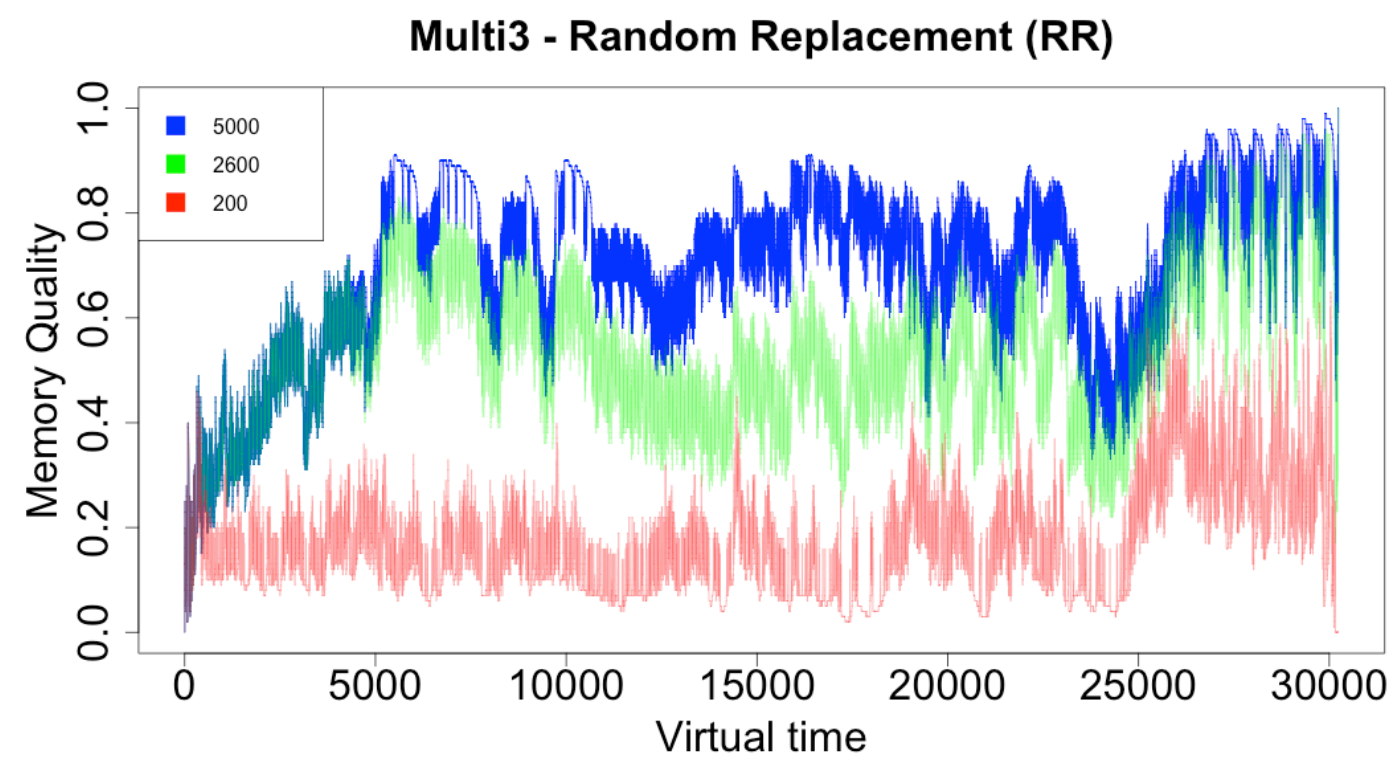

Fonte: Piantola e Midorikawa (2015)

O estudo sobre a métrica de QUALIDADE foi baseado nos traces multiprogramados multi1, multi2 e multi3. Tal métrica pode prover informações importantes para a construção de novos algoritmos de gerência de memória e novas estratégias para coleta de informações que ajudam no desempenho do sistema. Além disso, pode ser uma técnica viável usada em algoritmos online. Usando algoritmos de substituição local e olhando em um vt passado, podemos calcular a QUALIDADE da memória no passado. Se qm for baixo, o algoritmo pode aumentar o tamanho da memória para a aplicação, caso contrário, pode diminuí-la para a aplicação. Como o estudo demonstra, mais memória aumenta o valor de qm e diminui as faltas de páginas, causando melhor desempenho do sistema de gerência de memória.

Na próxima seção, a métrica de QUALIDADE é comparada coma as métricas tradicionais utilizadas na área de gerência de memória. 


\subsection{Análise comparativa de QUALIDADE com ou- tras métricas}

A comunidade científica propôs diferentes métodos e métricas para analisar algoritmos de substituição de páginas. A maioria deles usam uma das seguintes métricas tradicionais: razão de acerto/erro ou taxa de falta de páginas. Outros importantes métodos ou métricas podem ser encontrados na literatura científica, por exempo: Localidade referencial (DENNING; SCHWARTZ, 1972), Mapa de acesso à memória (CASSETTARI; MIDORIKAWA, 2004), Recência

de Inter-Referência (JIANG; ZHANG, 2002), Frequência de acesso a memória (LEE et al., 2001) e Análise competitiva (SLEATOR; TARJAN, 1985).

A taxa de falta de páginas resume todas as faltas de páginas que ocorreram durante a execução inteira ou parcial de um programa. Assim, o número de faltas de páginas não é uma medida normalizada tornando difícil a comparação entre diferentes programas. A razão de acerto é uma métrica que mostra a porcentagem de todos os acessos que são satisfeitos pelas páginas na memória principal. A razão de erro é o oposto da razão de acerto e ambos são métricas resumidas.

Outra métrica é a localidade referencial, também conhecida com "localidade espacial". Ela determina que uma aplicação pode ser executada eficientemente mesmo com apenas um pequeno subconjunto de suas páginas na memória em um instante de tempo qualquer. A teoria sobre o comportamento do working set do programa aponta o caminho para determinar qual é esse conjunto privilegiado de páginas e que mantendo esse conjunto na memória principal atinge-se um desempenho melhor na gerência de memória.

Uma métrica de quão bem um programa está sendo executado no sistema é a taxa de faltas de páginas. Um programa que tem muitas faltas de páginas 
pode entrar em hiperpaginação (thrashing) porque ele tem poucas páginas na memória e não pode manter seu working set nela. Um programa que nunca tem faltas de páginas pode ter muitas páginas na memória e assim pode evitar que o sistema operacional aumente o nível de multiprogramação. $O$ algoritmo page-fault-frequency (PFF) ajusta quantas páginas um programa tem na memória, baseado na frequência com que cada programa tem faltas de páginas. O PFF é um método retroativo e não é possível visualizar o motivo dele ser baixo ou alto por si só.

Um mapa de acesso à memória (ou gráfico) é uma representação visual de uma matriz de pontos que informam quais páginas da memória são referenciadas por um processo no decorrer de sua execução. Neste gráfico, o eixo horizontal representa o tempo virtual do programa, calculado pelo número de acessos, enquanto os endereços das páginas são distribuídos no eixo vertical. Hatfield e Gerald (HATFIELD; GERALD, 1971) usaram mapas de acesso à memória há mais de 44 anos para analisar otimizações no programa para melhorar o desempenho dos sistemas de memória virtual. Muitos trabalhos também utilizaram os mapas de acesso à memória a fim de exemplificar técnicas para reconhecimento de padrões (CHOI et al., 1999; CHOI et al., 2000; KIM et al., 2000) ou para investigar o comportamento de cargas de trabalho (workloads) (GLASS; CAO, 1997; MARKATOS, 1997; PHALKE, 1995). O mapa de acesso à memória é usado na seção 4.4, na Figura 18, mas não é possível comparar ou testar o desempenho das políticas e algoritmos de substituição de páginas usando esse gráficos.

Recência é o fator mais importante que afeta o desempenho dos algoritmos de substituição de páginas. Um algoritmo fundamental que usa recência é o LIRS - Low Inter-reference Recency Set (JIANG; ZHANG, 2002). Seu principal objetivo, como explicado no capítulo 2, é diminuir as deficiências da política 
LRU, substituindo a página que demoraria mais tempo para ser referenciada novamente de acordo com o IRR coletado. Isso significa que não apenas o LIRS não substitui a página que não terá sido referenciada há mais tempo, mas também usa a informação de acesso recente para tentar prever qual página tem maior probabilidade de ser acessada em um futuro próximo. Uma desvantagem do LIRS é que ele não funciona bem se o sistema utilizar política de memória global ou se o programa apresentar uma sequência muito grande de acessos à memória como um processamento de vídeo.

Algoritmos online de substituição de páginas são analisados usando a análise competitiva, em que o algoritmo é comparado com um algoritmo ótimo offline. Um algoritmo é $c$-competitivo se o número de falta de páginas obtido é até um fator de $c$ distante do resultado do ótimo offline. Toda política de substituição determinística tem uma razão competitiva de pelo menos $k$, e alguns algoritmos $k$-competitivos conhecidos. Uma desvantagem é que pode ser muito difícil ou quase impossível analisar algoritmos adaptativos ou sofisticados que modifiquem seu comportamento dependendo do padrão de acesso às páginas.

Diferentemente da análise competitiva, a métrica de QUALIDADE pode facilmente analisar qualquer algoritmo de memória adaptativo ou sofisticado. Diferente da métrica de recência inter-referência, a equação da QUALIDADE usa, além da recência, a frequência. Entretanto, ela não depende somente da recência das páginas. Em fim, a QUALIDADE é apropriada para comparar algoritmos com informações resumidas ou detalhadas sobre a execução e pode mostrar a mudança da localidade de referência. 


\section{MÉTODO DE CRIAÇÃO DOS ALGORITMOS DE GERÊNCIA DE MEMÓRIA BASEADOS EM QUALIDADE}

O objetivo deste capítulo é apresentar uma forma de obter maior desempenho na gerência de memória por meio da adoção de um método sistêmico na criação do algoritmo de gerência. O conceito de qualidade é a diretriz para os passos deste método, com a finalidade de buscar e manter páginas que adicionem boa qualidade ao conteúdo da memória atual dos programas. $\mathrm{O}$ RR+ng e o RRlock+ng são os algoritmos de gerência de memória especialmente criados neste capítulo para demonstrar o método.

\subsection{O método sistêmico de qualidade}

Conforme discutido no capítulo 2, "a gerência de memória paginada é composta por três estratégias: busca (fetch), posicionamento (placement) e substituição (replacement) de páginas. A busca de páginas determina quando uma página que está no disco será trazida para a memória, o posicionamento determina em qual lugar da memória a página será colocada e a substituição controla qual página vai deixar a memória principal e vai para o disco." O conceito de qualidade privilegia a busca e o posicionamento, já que os esforços computacionais devem ser focados em trazer e manter páginas que deveriam estar na memória em um determinado intervalo de tempo. 
A figura 24 mostra os passos do método proposto para criar algoritmos de gerência de memória com foco na qualidade. O método é estruturado em duas fases: a construção e a avaliação. A fase de construção visa conceber e implementar o algoritmo tendo como diretriz o conceito de qualidade do conteúdo de memória. Essa fase inclui os passos: 1, 2, 3 e 4. Na fase de avaliação são analisados o comportamento e o desempenho do algoritmo. Esta fase contém o passo 5.

O primeiro passo define as técnicas que serão utilizadas para a busca e posicionamento de páginas. A tabela 5 descreve as técnicas que podem ser usadas. O uso de uma técnica não exclui o uso de outra, pois elas podem ser complementares. Esta é uma fase muito importante para o desenvolvimento do algoritmo de gerência de memória, pois ela define as informações necessárias para o próximo passo e como serão utilizadas. Um exemplo de escolhas ruins é o uso de políticas aleatórias tanto para busca como para posicionamento de páginas, porque as informações adicionais não serão utilizadas pelas políticas.

Tabela 5: Técnicas de busca e posicionamento de páginas

\begin{tabular}{cc}
\hline Tipo & Técnica \\
\hline \hline Busca & pré-paginação \\
& sob demanda \\
\hline Posicionamento & Superpaging \\
& Trava de páginas (lock) \\
& Aleatório \\
\hline
\end{tabular}

O segundo passo escolhe uma ou mais informações que vão guiar as técnicas que foram definidas no passo anterior. Tabela 6 apresenta as principais 
Figura 24: Método sistêmico para criar algoritmo de gerência de memória

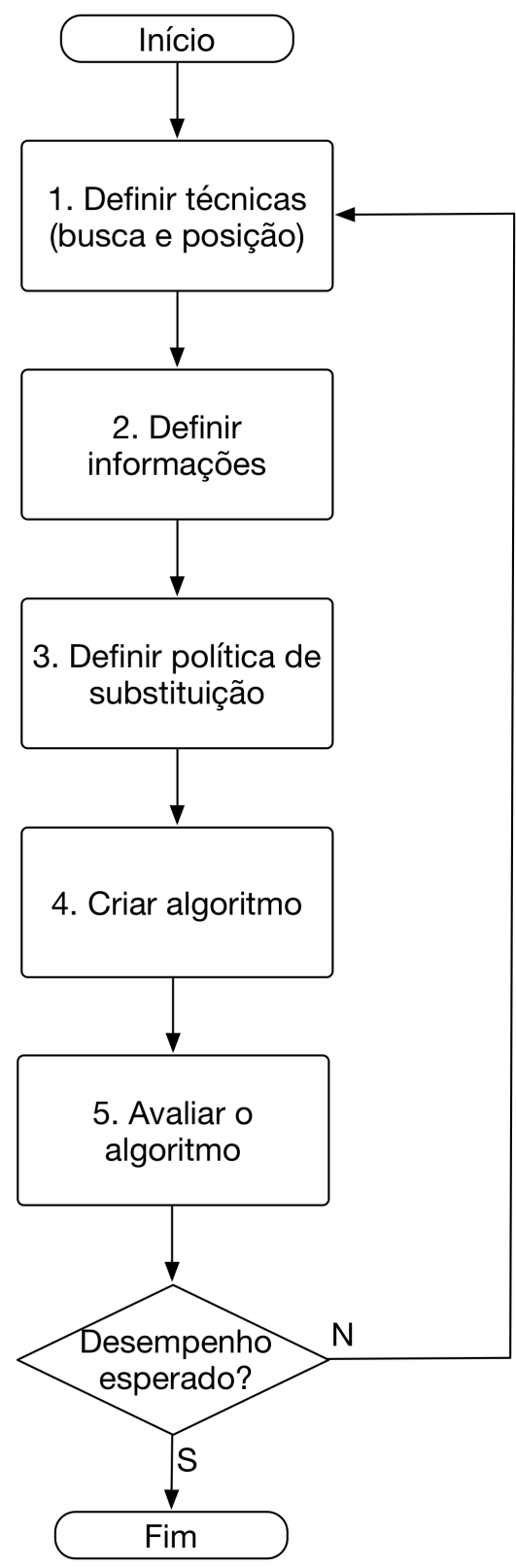

Fonte: Próprio Autor (2015)

informações. As informações são essenciais para o auxiliar as técnicas de busca e posicionamento, promovendo um melhor desempenho em comparação aos algoritmos que as ignora. A essência das informações é baseada em algum tipo de recência ou frequência de acesso de páginas, ou seja, nos mesmos alicerces em que foi construída a métrica de QUALIDADE. Na escolha de 
uma ou mais informações que vão auxiliar as técnicas, é importante sempre ter em mente em primeiro lugar a recência e, em segundo, a frequência.

Tabela 6: Informações que auxiliam as técnicas

\begin{tabular}{c}
\hline Informações \\
\hline recência \\
frequência \\
inter-referência \\
profiling \\
n-grama \\
grafo de referências \\
\hline
\end{tabular}

O terceiro passo define a política de substituição, que pode ser qualquer uma clássica, ou inclusive um algoritmo adaptativo de substituição de páginas. Apesar de ser permitido escolher qualquer algoritmo de substituição de páginas, uma escolha inteligente, segundo o conceito de qualidade, é um algoritmo que produza o menos possível de sobrecarga no sistema. O algoritmo de substituição que apresenta menos sobrecarga, ou seja processamento, é o algoritmo aleatório. A política aleatória é uma escolha aceitável para o método, contudo isso não quer dizer que a escolha de outro algoritmo não produzirá uma gerência de memória melhor. Por outro lado, teremos certeza de que a escolha de outro algoritmo apresentará uma sobrecarga maior.

Com as técnicas, informações e políticas definidas, o quarto passo integra as escolhas para criar um único algoritmo de gerência de memória. A confecção do algoritmo torna-se mais fácil quando todas as partes foram definidas e colocá-lo em funcionamento passa a ser uma tarefa mais mecânica. Nessa fase é necessária a definição das estruturas de dados que serão utilizadas para a manipulação das informações e funcionamento das técnicas. A busca 
de um algoritmo otimizado é uma tarefa importante nesse passo. Assim, construir um algoritmo com a quantidade mínima de instruções e que obedeça as definições é um dos objetivos do método.

O último passo avalia o novo algoritmo criado. Isso é feito com o uso de métricas que permitem comparar o novo algoritmo com outros algoritmos conceituais da literatura ou em uso nos atuais sistemas operacionais. A métrica de faltas de páginas é uma candidata para a primeira parte de avaliação. Um dos motivos para utilizá-la é que ela é amplamente empregada na comunidade científica, e assim podemos encontrar outras avaliações já feitas na literatura. É importante pelo menos comparar o novo algoritmo com a política ótima (OPT) e a política péssima (WORST) de substituição de páginas. Isso porque esses algoritmos determinam os limites impostos pelos algoritmos sob demanda. $\mathrm{O}$ novo algoritmo deve ficar mais próximo possível do ótimo e longe da política péssima. Não adianta ficar bem próximo ao ótimo e muito mais próximo à política péssima.

Nesta etapa, também são definidos quais traces serão utilizados na avaliação dos algoritmos por simulação. Após a análise de faltas de páginas é feita a análise detalhada com a métrica de QUALIDADE, que fornece uma visualização da variação da QUALIDADE ao longo da execução do programa. Os traces multi1, multi2 e multi3 (KIM et al., 2000) foram selecionados pelo fato de conterem acessos simultâneos de aplicações, simulando um ambiente multiprogramado. Os traces são representativos, todos contendo acessos à memória de aplicações CPU e I/O bound. Estas aplicações com diversos tipos de padrões de referências à memória são descritas no capítulo 2 .

Neste passo, é importante definir um objetivo, ou seja, um desempenho esperado. Um exemplo para esse objetivo pode ser atingir uma QUALIDADE média de $50 \%$ ou mais, com tamanho de memória de 10.000 páginas para 
os traces analisados. Com essa última análise é possível determinar em que momento da execução o algoritmo é bom e em qual ele é ruim.

Na próxima seção, são detalhados os passos da criação do algoritmo $\mathrm{RR}+\mathrm{ng}$ utilizando o método aqui proposto.

\subsection{Criação do algoritmo RR+ng}

O RR+ng foi idealizado utilizando o método sistêmico proposto com base no conceito de qualidade. O objetivo principal da criação do algoritmo $R R+n g$, além de servir como exemplo do uso do método, mostra que:

1. Uma gerência de memória eficiente deve levar em consideração também a busca e posicionamento de páginas;

2. É possível obter bom desempenho mesmo usando um algoritmo de substituição de páginas que sozinho não obtém bom desempenho (como analisada a política aleatória no capítulo 4);

3. A validade da hipótese de que não é necessário gastar muitos recursos para o algoritmo de substituição e deve-se investir mais nos outros aspectos;

4. As informações que auxiliam as técnicas de busca e posicionamento devem privilegiar principalmente a recência e a frequência.

Esses são os aspectos que devemos priorizar no momento das escolhas na criação do algoritmo. Nesta seção mostra-se a concepção do RR+ng passo a passo. 


\subsubsection{Definição das técnicas para busca e posicionamento (passo 1)}

O algoritmo RR+ng usa as técnicas de paginação sob demanda e prépaginação para a política de busca. A escolha da técnica de pré-paginação se deu com o intuito de ganhar uma vantagem competitiva sobre os algoritmos puramente sob demanda, trazendo páginas que serão acessadas em um futuro próximo e não estão na memória.

Não foi escolhida uma técnica de posicionamento, portanto o RR+ng adota a política aleatória. É importante ressaltar que poderia escolher-se outra técnica de posicionamento, como superpaging. A escolha da política aleatória foi feita para seguir os princípios do método para favorecer algoritmos com menos sobrecarga.

\subsubsection{Definição das informações (passo 2)}

No algoritmo que serve de exemplo, utiliza-se a informação dos n-gramas apresentada no capítulo 3, para auxiliar a pré-paginação. Os n-gramas resumem as duas informações mais importantes para obter uma QUALIDADE boa: a recência e a frequência. É uma escolha que está diretamente ligada com o objetivo da qualidade. O RR+ng utiliza um tipo de n-grama chamado bigrama, para auxiliar a pré-paginação.

\subsubsection{Definição da política de substituição de páginas (passo 3)}

Seguindo a diretriz especificada no método sistêmico proposto, foi escoIhida a política aleatória para substituição de páginas. O principal motivo dessa escolha é mostrar que para decidir qual a página a ser retirada da memória, 
pode ser adotado um algoritmo simples com baixa sobrecarga e ainda assim conseguir bom desempenho. Isso é possível devido ao uso do conceito de qualidade.

\subsubsection{Criação do algoritmo (passo 4)}

O algoritmo RR+ng é composto de duas técnicas de busca, uma informação e a política de substituição aleatória. As técnicas são a pré-paginação e a paginação sob demanda, e a informação escolhida é a de frequência de acesso, que é capturada com os bigramas. Todas elas foram definidas nos passos anteriores. A política de substituição de páginas do RR+ng é o algoritmo aleatório, em que ao ocorrer uma falta de página, a página referenciada é movida para a memória e uma página escolhida aleatoriamente é descartada da memória. É importante notar que o algoritmo é híbrido, ou seja, usa paginação sob demanda e pré-paginação. A pré-paginação só é usada quando a página que está no n-grama não está na memória.

O Algoritmo 1, a seguir, apresenta o pseudocódigo do RR+ng. As condições referentes ao processamento da pré-paginação são referenciadas nas linhas 5 até 9 . A linha 5 verifica se a página para a busca antecipada encontrase na memória. Em caso negativo, as linhas seguintes tratam de trazê-la para a memória e remover uma outra página de forma aleatória (caso não tenha mais memória disponível); no pseudocódigo, a linha 9 cria, exclui e atualiza a estrutura a cada referência para a busca antecipada. 


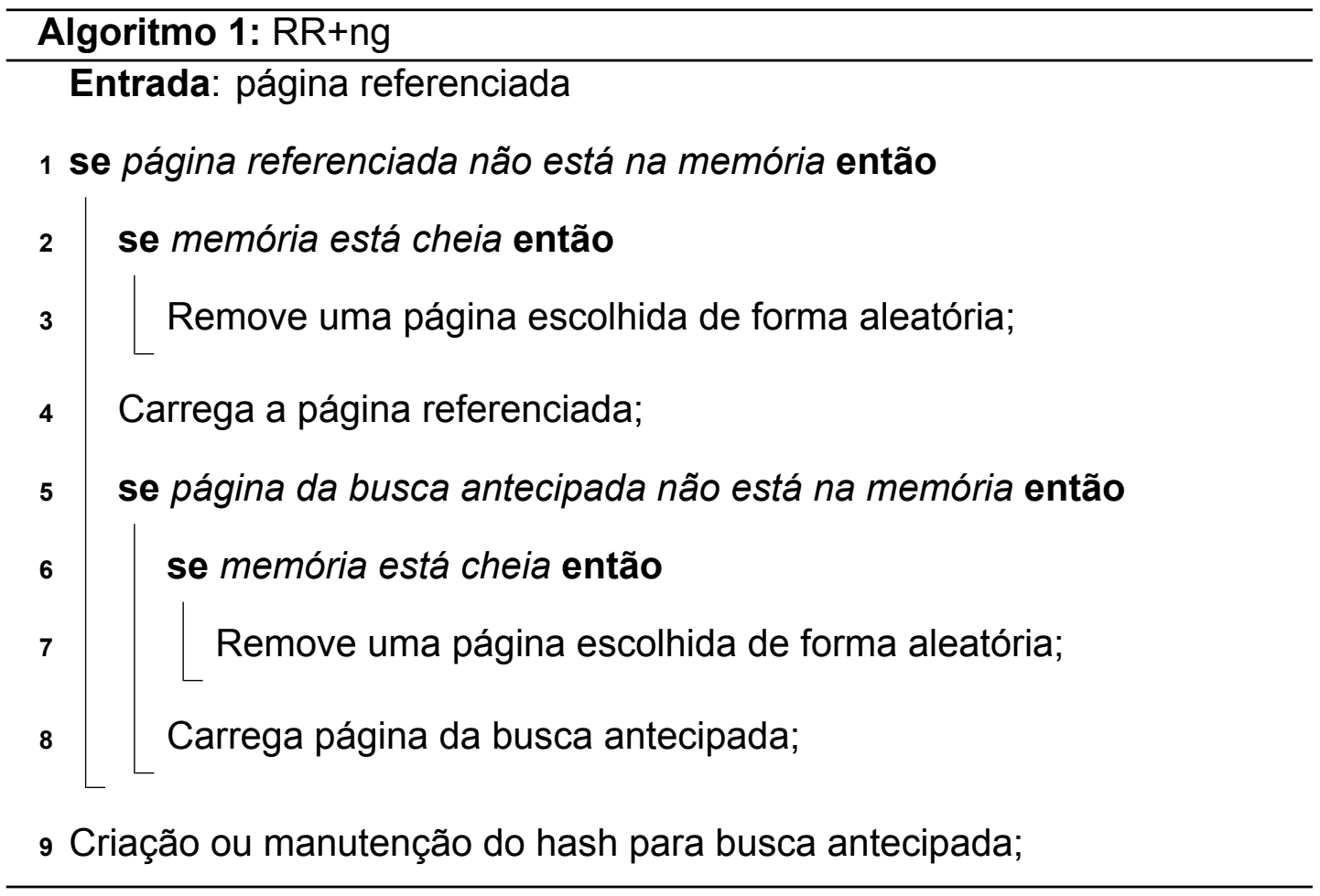

A busca antecipada de páginas pode ou não acontecer quando ocorre uma falta de página, isso depende da configuração atual do sistema de memória. Se a página escolhida para a busca antecipada já estiver na memória, não haverá busca antecipada e o algoritmo funcionará como o aleatório sob demanda. A escolha da página da busca antecipada é feita através do método de bigramas. Para cada duas referências consecutivas é guardada a frequência com que essas duas páginas são referenciadas novamente em sequência. A página que aparece com maior frequência após a referenciada é a escolhida para a busca antecipada.

Um exemplo: se a sequência de acesso para a página $p$ é a $m$ e isto já ocorreu 22 vezes até o momento, e nenhuma outra página a supera, então a página $m$ é a candidata da busca antecipada quando ocorre uma falta para a página $p$. A estrutura escolhida para guardar esta relação foi um hash, pela velocidade da busca nesta estrutura, em que a chave é a página responsável pela falta e o valor é a página da busca antecipada. 
No exemplo apresentado na Figura 25, considere que o acesso à página $p$ gera uma falta de página. Durante a execução do $\mathrm{RR}+\mathrm{ng}$, se o algoritmo detecta que a página seguinte do bigrama $p-m$ também não está na memória, então a página $m$ será trazida para a memória como busca antecipada. Dessa forma, o algoritmo deve retirar 2 páginas da memória, selecionando de forma aleatória as páginas nas posições 1 e 6 , ou seja, as páginas $a$ e $c$.

Figura 25: Substituição de páginas no algoritmo RR+ng

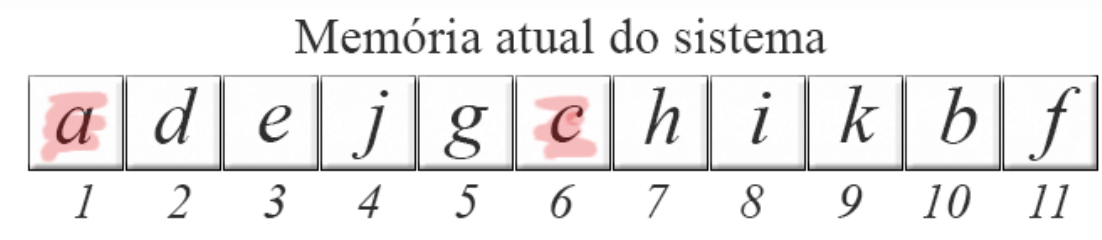

Fonte: Próprio Autor (2015)

Apesar do algoritmo ser apresentado em Algoritmo 1 na forma sequencial, a busca antecipada pode ser realizada em paralelo com o processamento da página referenciada, ou seja, enquanto o SO volta da interrupção da falta de página e o programa continua sua execução, o disco busca a página da busca antecipada. Assim, o processamento da falta de página fica mais eficiente.

\subsection{Avaliação do algoritmo RR+ng(passo 5)}

Nesta seção, é apresentada uma avaliação do algoritmo $R R+n g$ criado pelo método proposto, mostrando uma análise comparativa com outras políticas, usando gráficos de falta de páginas, e uma análise com a métrica de QUALIDADE. 


\subsubsection{Avaliação usando a métrica de faltas de páginas}

A última fase do método de criação do algoritmo de gerência de memória é a avaliação. A comparação com políticas clássicas é muito importante nessa fase e a métrica utilizada aqui é o número de faltas de página, conforme descrito no método.

Foram escolhidas as seguintes políticas clássicas para a realização da análise comparativa: OPT, WORST, LRU e RND. Essas políticas criam o limite inferior e o superior para a comparação. Políticas baseadas no LRU são amplamente utilizadas nos sistemas operacionais atuais. Já o RND é a política aleatória, que é o algoritmo de substituição do RR+ng.

Os traces multi1, multi2 e multi3 foram selecionados pelo fato de conterem acessos de várias aplicações, simulando um ambiente multiprogramado. Neste cenário é muito mais difícil encontrar padrões de acesso já que o acesso a memória é intercalado entre várias aplicações diferentes. Tanto as políticas tradicionais como as adaptativas têm o desempenho prejudicado por esse motivo. A descrição de cada um dos traces é apresentada no capítulo 2.

O algoritmo LRU tornou-se o mais amplamente utilizado como política de substituição de páginas, porque ele consegue prever razoavelmente o comportamento geral dos programas, atingindo, assim, bom desempenho na maioria dos padrões de acesso a memória. Em programas com padrões de acessos sequenciais e aqueles que contêm grandes loopings, o algoritmo LRU não atinge um desempenho bom.

No multi1, a análise do perfil de frequência de acessos às páginas mostra que somente $7,5 \%$ das páginas são responsáveis por $50 \%$ dos acessos à memória (PIANTOLA; MIDORIKAWA, 2008). Pode-se, então, prever que a informação de frequência de acessos, obtida pelo modelo dos n-gramas, irá proporcionar 
menos faltas de páginas. O RR+ng supera todas as políticas, com exceção do OPT, em todos os tamanhos de memória, o que confirma a previsão.

Figura 26: Gráfico de falta de páginas do trace multi1

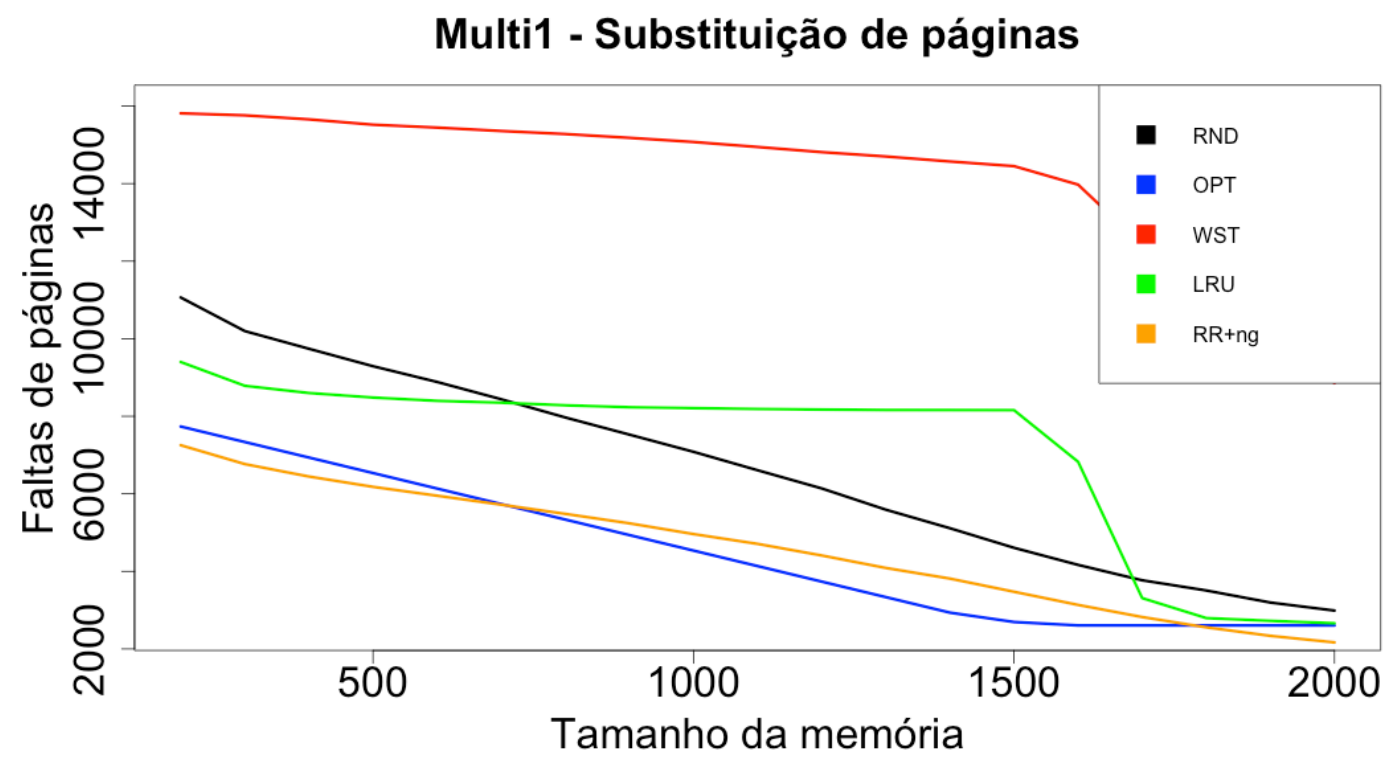

Fonte: Próprio Autor (2015)

Uma marca de extrema importância sobre o algoritmo RR+ng é que ele supera o algoritmo OPT em todos os tamanhos de memória menores que 700 páginas conforme a Figura 26. O algoritmo OPT se refere ao algoritmo teórico que apresenta o melhor desempenho possível entre os algoritmos de paginação sob demanda. A razão para seu melhor desempenho em relação ao algoritmo OPT é o fato do RR+ng não ser um algoritmo de paginação sob demanda puro, pois ele usa uma técnica de busca antecipada de páginas. Portanto, conclui-se que, como nenhum algoritmo de paginação sob demanda puro pode ser melhor que o OPT, nenhum pode alcançar o desempenho obtido pelo RR+ng para memórias de tamanho pequeno com o trace Multi1.

Pode-se observar também que, como o RR+ng usa política aleatória de substituição, a curva no gráfico do novo algoritmo permanece similar à curva do RND (aleatório). No gráfico da Figura 26, as linhas representadas pelos 
algoritmos permanecem quase paralelas.

O que marca a grande eficiência do RR+ng em memórias de pequeno tamanho é que quando temos pouca memória e muitas páginas compondo o programa, a probabilidade das páginas acessadas estarem fora da memória principal é alta.

Uma característica importante do trace multi2 para a análise surge do fato de ser semelhante ao multi1. O que difere os dois traces é a adição do programa postgres. O desempenho do RR+ng, assim como no multi1, também é bom.

Figura 27: Gráfico de falta de páginas do trace multi2.

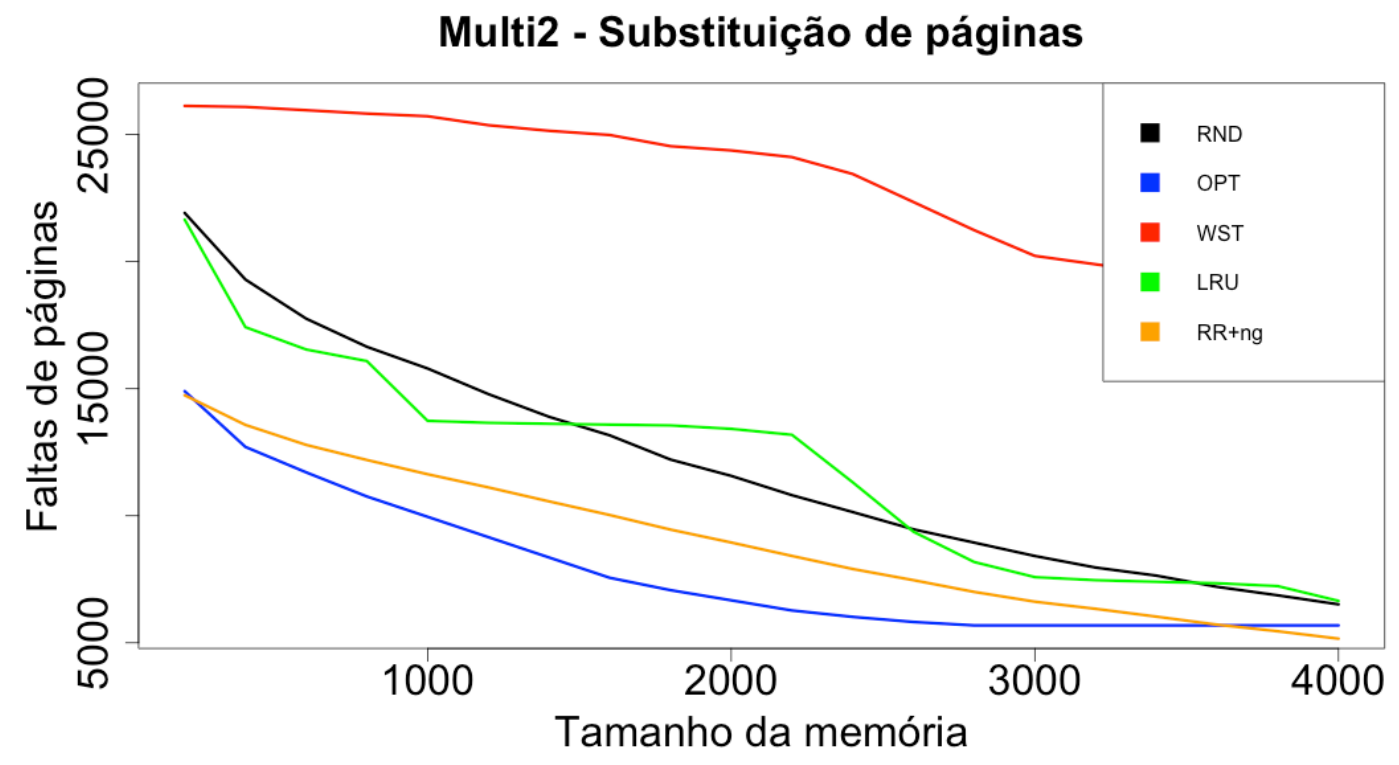

Fonte: Próprio Autor (2015)

A análise do perfil de frequência de acessos às páginas do programa mostra que metade das referências é feita por apenas $6 \%$ do total de páginas. Conforme analisado no trace multi1, a informação de frequência, obtida pelo modelo dos n-gramas, proporciona menos faltas de páginas também neste caso. 
Todas as outras políticas analisadas são superadas pelo RR+ng em todos os tamanhos de memória, conforme Figura 27. O mesmo acontece com o algoritmo Ótimo, que é superado pelo RR+ng em memórias de tamanhos pequenos. A eficiência do $\mathrm{RR}+\mathrm{ng}$ em memórias de pequeno tamanho no trace multi2 é determinada pelo fato do algoritmo não encontrar a página da busca antecipada e trazê-la para a memória. Esse comportamento pode trazer muitos benefícios a sistemas que utilizam controle mais rígido de memória para aplicações, ou sistemas de gerenciamento de memória que compartilhem um conjunto mínimo de páginas por processo, como, por exemplo, sistemas que adotam uma política de gerenciamento de memória local.

Quanto mais memória disponível, maior a probabilidade da página da busca antecipada já estar na memória. Com isso, as poucas vezes em que se executa a busca antecipada, ela ocorre em uma mudança de working set. Tais resultados mostram que o $\mathrm{RR}+\mathrm{ng}$ é bem adequado para sistemas com política de memória global.

Figura 28: Gráfico de falta de páginas do trace multi3.

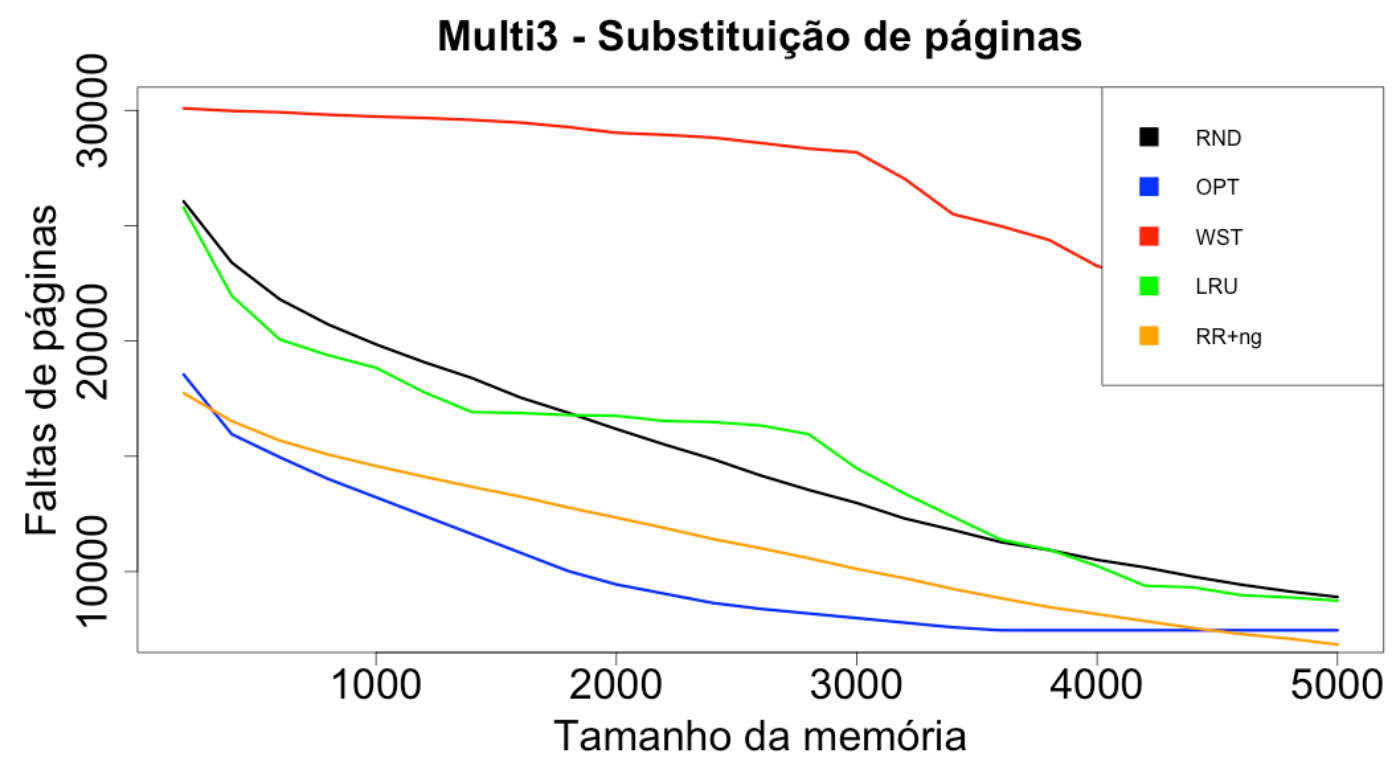

Fonte: Próprio Autor (2015) 
Dos traces utilizados na análise, o que contém o maior nível de multiprogramação é o trace multi3. São diversos padrões de acessos intercalados entre os quatro programas usados. Como não existe uma uniformidade da localidade temporal, páginas que serão acessadas em um futuro próximo são descartadas prematuramente. Para essa sequência de referências o LRU não é bom, porém o RR+ng recupera essas páginas que foram descartadas prematuramente e supera o desempenho do LRU e o aleatório, visualizado na Figura 28.

Assim como os traces multi1 e multi2, o RR+ng também supera o algoritmo OPT nas memórias de pequeno tamanho no trace multi3. O RR+ng se aproxima do RND em memórias de maior tamanho. Isso acontece pelo fato do $R R+n g$ fazer menos pré-paginação.

Caso nesse ponto o algoritmo criado tenha obtido o desempenho desejado, não é preciso aprofundar a análise. A análise de faltas de páginas somente mostra informações resumidas que comparamos com outras políticas. Caso o desempenho esperado não tenha sido obtido, é necessário usar outra métrica, para que possamos entender o que acontece durante a execução e por qual motivo. Sendo assim, como os resultados obtidos aqui com a métrica de número de faltas de página não mostraram detalhes do seu desempenho, na próxima seção apresenta-se uma análise de desempenho dos algoritmos usando a métrica de QUALIDADE.

\subsubsection{Avaliação usando a métrica de QUALIDADE}

Esta seção apresenta uma análise de desempenho para comparação dos algoritmos OPT, RND, LRU e RR+ng usando a métrica de QUALIDADE. Os resultados experimentais incluem tanto os valores médios (Tabela 7) quanto os valores instantâneos da QUALIDADE ao longo da execução de cada caso 
de teste (trace).

Figura 29: Gráfico de QUALIDADE do OPT para 300 páginas no trace multi1

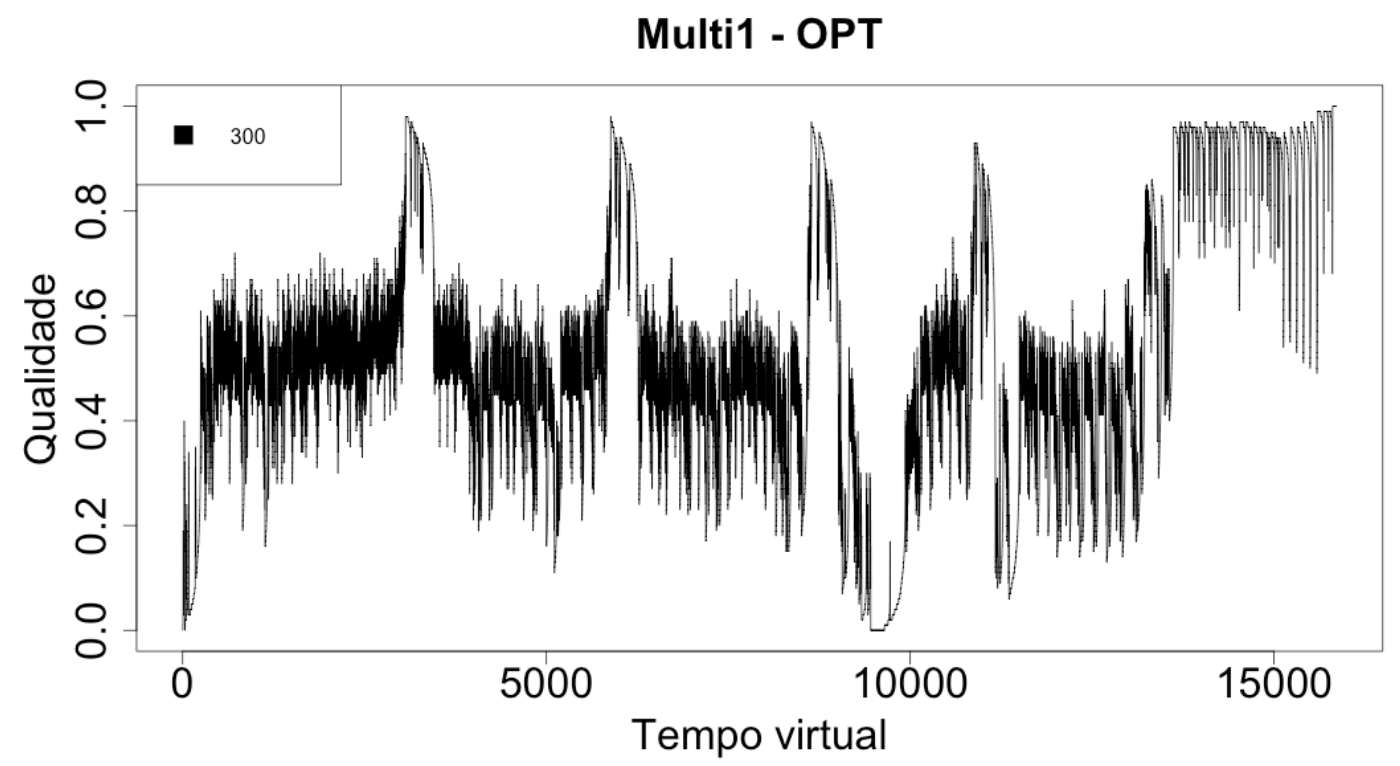

Fonte: Próprio Autor (2015)

Figura 30: Gráfico de QUALIDADE do LRU para 300 páginas no trace multi1

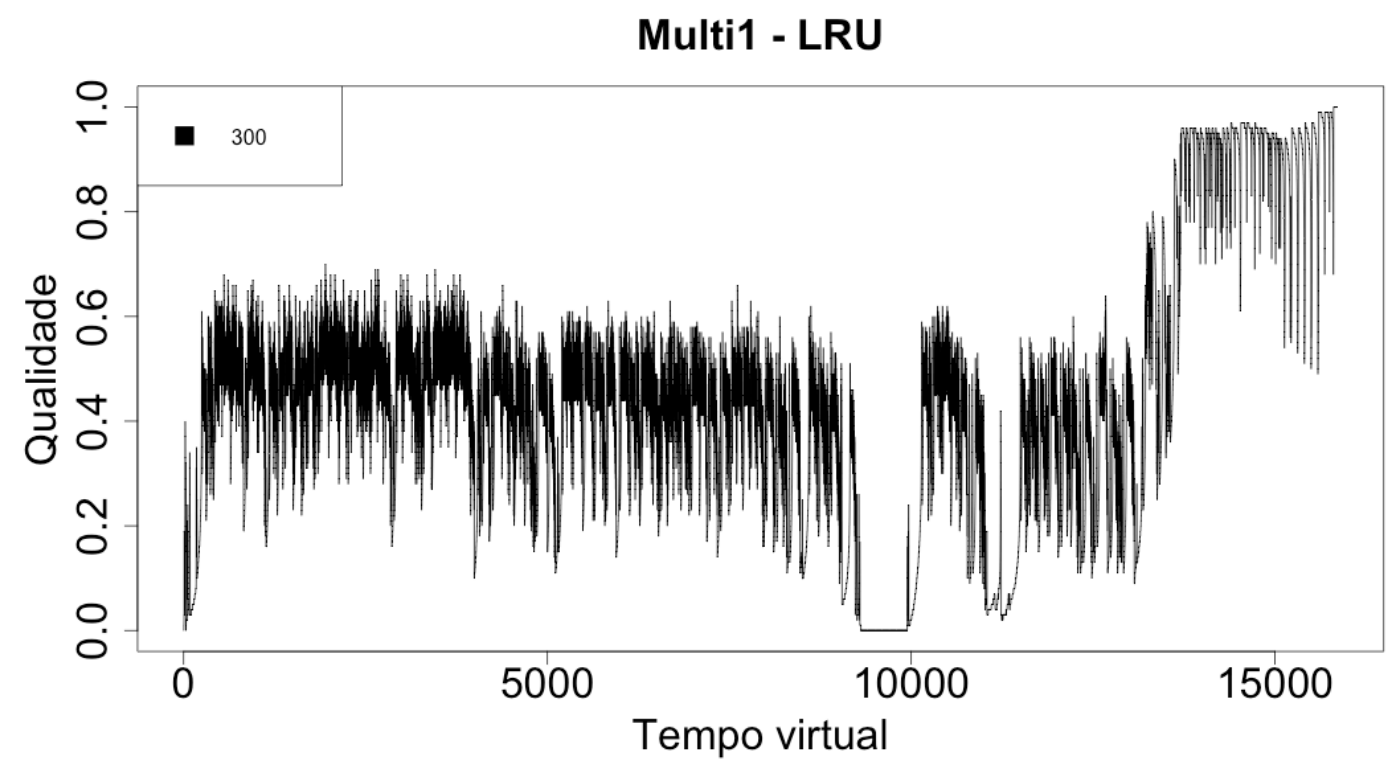

Fonte: Próprio Autor (2015)

Multi1: 
Tabela 7: QUALIDADE média para cada caso de teste

\begin{tabular}{|c|c|c|c|c|}
\hline Trace & T. da memória & Algoritmo & qm médio & F. de páginas \\
\hline \multirow[t]{8}{*}{ Multi1 } & 300 & OPT & $50,76 \%$ & 7.336 \\
\hline & & LRU & $44,42 \%$ & 8.786 \\
\hline & & $R R+n g$ & $53,56 \%$ & 6.767 \\
\hline & & RND & $37,03 \%$ & 10.197 \\
\hline & 1400 & OPT & $81,18 \%$ & 2.936 \\
\hline & & LRU & $55,39 \%$ & 8.161 \\
\hline & & $\mathrm{RR}+\mathrm{ng}$ & $71,34 \%$ & 3.814 \\
\hline & & RND & $69,46 \%$ & 5.113 \\
\hline \multirow[t]{8}{*}{ Multi2 } & 200 & OPT & $42,90 \%$ & 14.900 \\
\hline & & LRU & $19,65 \%$ & 21.652 \\
\hline & & $\mathrm{RR}+\mathrm{ng}$ & $44,78 \%$ & 14.741 \\
\hline & & RND & $17,63 \%$ & 21.915 \\
\hline & 2000 & OPT & $74,39 \%$ & 6.671 \\
\hline & & LRU & $51,57 \%$ & 13.419 \\
\hline & & $R R+n g$ & $66,56 \%$ & 8.946 \\
\hline & & RND & $56,62 \%$ & 11.568 \\
\hline \multirow[t]{8}{*}{ Multi3 } & 200 & OPT & $37,96 \%$ & 18.544 \\
\hline & & LRU & $15,37 \%$ & 25.782 \\
\hline & & $\mathrm{RR}+\mathrm{ng}$ & $43,67 \%$ & 17.734 \\
\hline & & RND & $14,27 \%$ & 26.051 \\
\hline & 2800 & OPT & $72,72 \%$ & 8.183 \\
\hline & & LRU & $50,37 \%$ & 15.958 \\
\hline & & $\mathrm{RR}+\mathrm{ng}$ & $63,82 \%$ & 10.580 \\
\hline & & RND & $55,54 \%$ & 13.541 \\
\hline
\end{tabular}


Figura 31: Gráfico de QUALIDADE do RND para 300 páginas no trace multi1

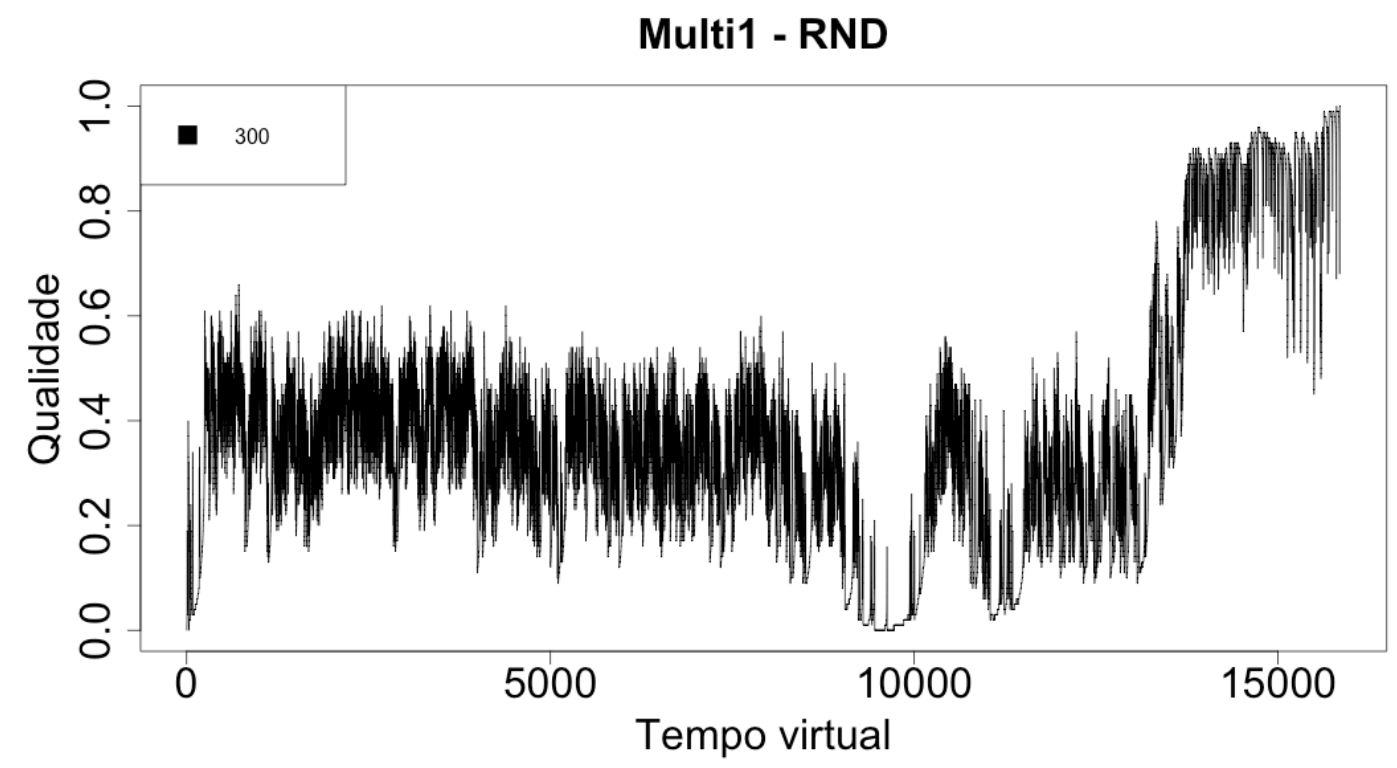

Fonte: Próprio Autor (2015)

Figura 32: Gráfico de QUALIDADE do RR+ng para 300 páginas no trace multi1

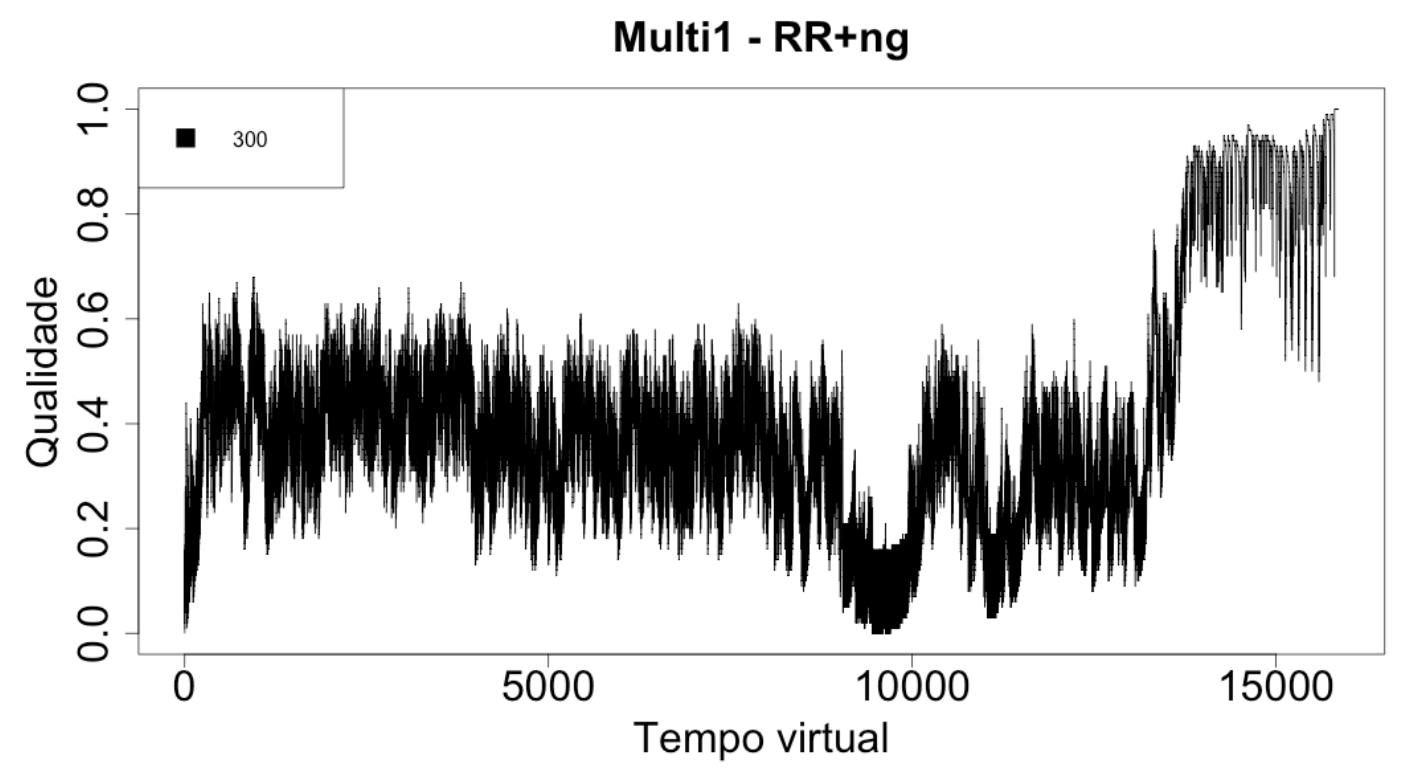

Fonte: Próprio Autor (2015)

Para análise dos resultados obtidos com o trace multi1, foram escolhidos os tamanhos de memória de 300 e 1400 páginas. O motivo da escolha foram 
Figura 33: Zoom do gráfico de QUALIDADE do RR+ng e OPT para 300 páginas no trace multi1

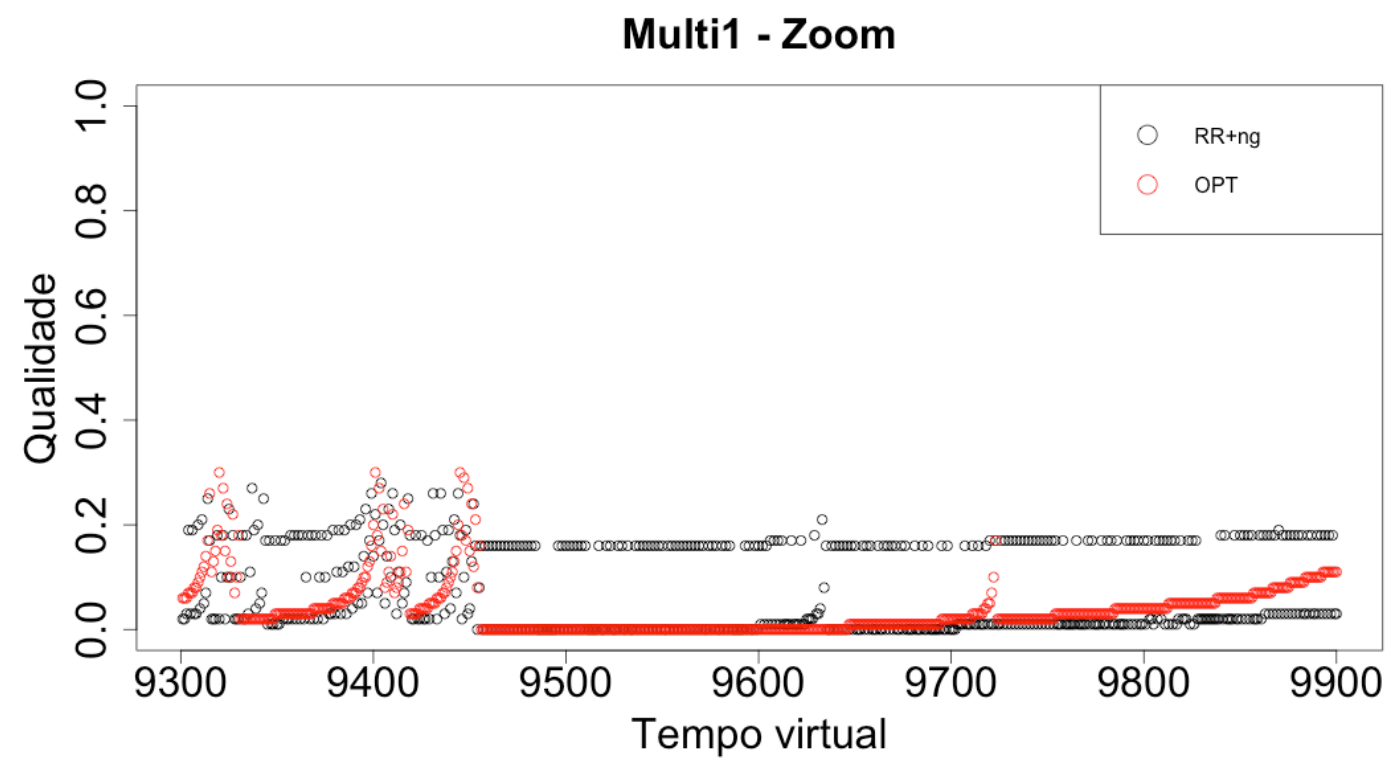

Fonte: Próprio Autor (2015)

os desempenhos do RR+ng observados com a métrica de número de faltas de página com relação a política OPT, conforme apresentados na Figura 26. O tamanho de memória com 300 páginas obteve o melhor desempenho comparativo do $\mathrm{R} R+n g$ observados com a métrica de número de faltas de página, e o tamanho de 1400 páginas, o pior.

Segundo a tabela 7, as médias de QUALIDADE foram 53,56\%, 50,76\%, $44,42 \%$ e $37,03 \%$, respectivamente, para os algoritmos RR+ng, OPT, LRU e RND, para uma memória com 300 páginas. Os valores de faltas de páginas acompanham de forma inversa a métrica de QUALIDADE. As Figuras 29, 30 , 31 e 32 apresentam gráficos com os valores instantâneos da QUALIDADE ao longo da execução do trace multi1 para cada um dos algoritmos. Esses gráficos mostram o valor da QUALIDADE do conteúdo da memória a cada instante de tempo virtual. A variação dos valores pode ser explicada pela mudança nos padrões de acesso à memória durante a execução dos programas e pelo 
comportamento de cada algoritmo a cada uma destas mudanças.

É possível notar quatro picos maiores que $90 \%$ na região intermediária do gráfico da Figura 29 para o OPT e aproximadamente 20 vales menores antes do grande vale próximo do tempo virtual 10.000. Pode-se verificar também que o gráfico de QUALIDADE tem informações sobre a execução do algoritmo e o padrão de acesso implicitamente. O grande vale por volta do tempo virtual de 9.000 e 10.000 nos revela algumas informações importantes. Primeiro, existe uma forte mudança de localidade que faz o algoritmo OPT atingir $0 \%$ de qualidade, ou seja, nenhuma página que está no momento na memória será acessada no futuro próximo. Em segundo lugar, outra informação que podese identificar no gráfico são os pontos em que existe mudança de working set. E em terceiro, os picos do algoritmo OPT que indicam o momento em que $o$ working set está na memória é bem utilizado. Através dessas informações obtidas pelo gráficos de QUALIDADE, pode-se redefinir, em uma segunda iteração do método, as informações que podem auxiliar as técnicas previamente estabelecidas na confecção do RR+ng.

O RR+ng supera o OPT em 3,56\% de QUALIDADE e o pior desempenho foi do RND que perde para o OPT em 13,46\%. Apesar do gráfico de QUALIDADE do RR+ng da Figura 32 apresentar menos picos acima de $60 \%$ que o OPT, ele é mais denso e mais próximo da média, assim, contendo também menos pontos nos vales. Um ponto interessante para comparação do OPT com o RR+ng é no intervalo de tempo virtual entre 9.000 e 10.000, em que o OPT mantém o vale próximo a zero de QUALIDADE, enquanto o RR+ng mantém próximo a $20 \%$. A Figura 32 apresenta um detalhamento neste intervalo. Pode-se claramente observar que a QUALIDADE do algoritmo $R R+n g$ é maior que a do OPT na maioria dos pontos.

Para as simulações do multi1 com 1400 páginas de tamanho, de acordo 
Figura 34: Gráfico de QUALIDADE do OPT para 1400 páginas no trace multi1

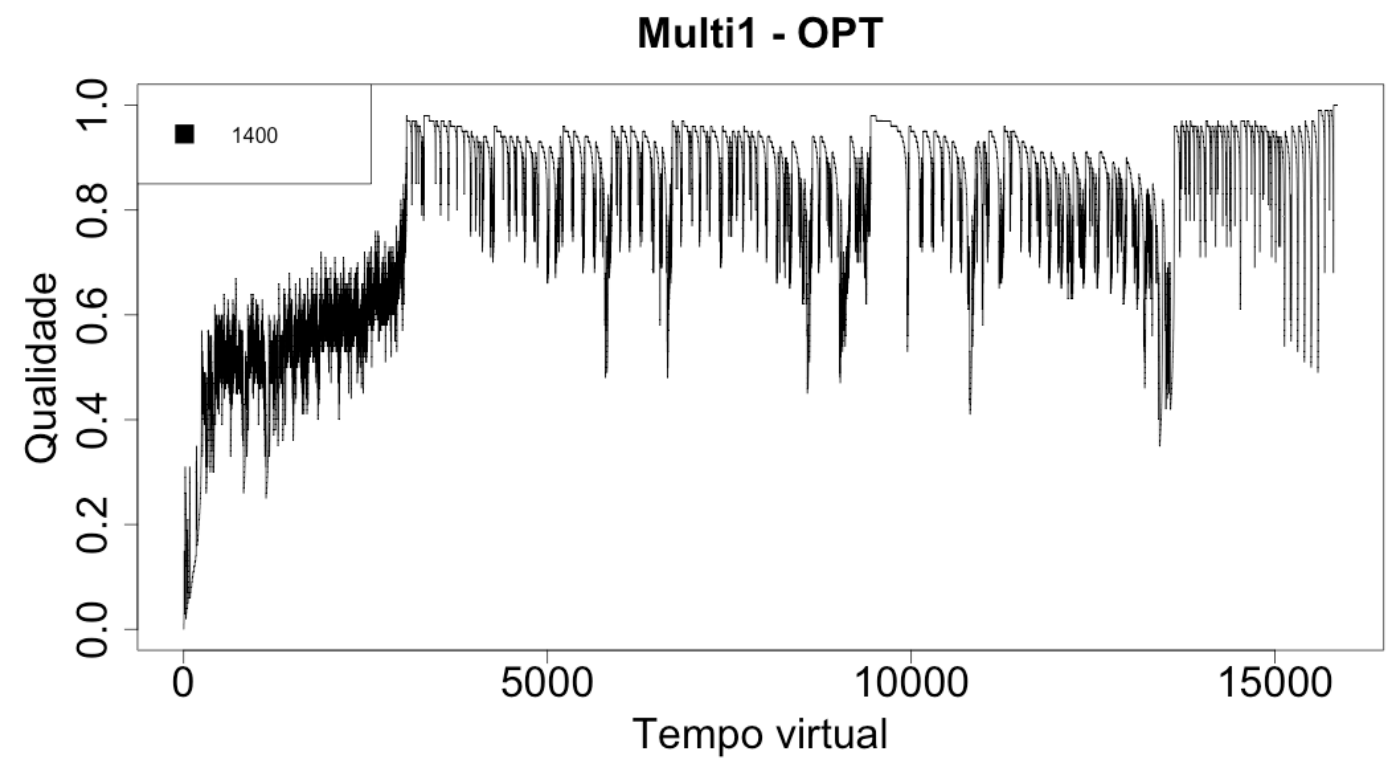

Fonte: Próprio Autor (2015)

Figura 35: Gráfico de QUALIDADE do LRU para 1400 páginas no trace multi1

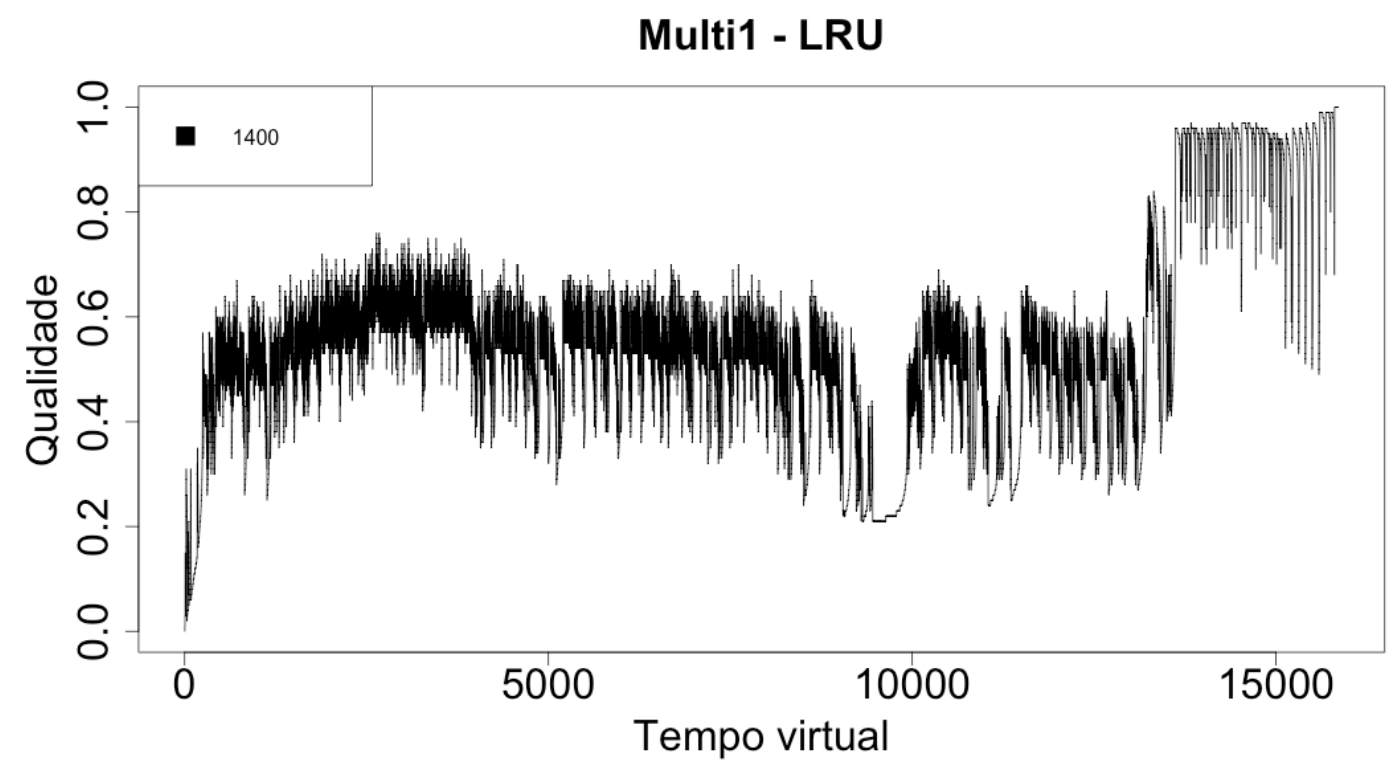

Fonte: Próprio Autor (2015)

com a tabela 7, as médias de QUALIDADE foram $81,18 \%, 71,34 \%, 69,46 \%$ e $55,39 \%$, respectivamente, para os algoritmos OPT, RR+ng, RND e LRU. Os 
Figura 36: Gráfico de QUALIDADE do RND para 1400 páginas no trace multi1

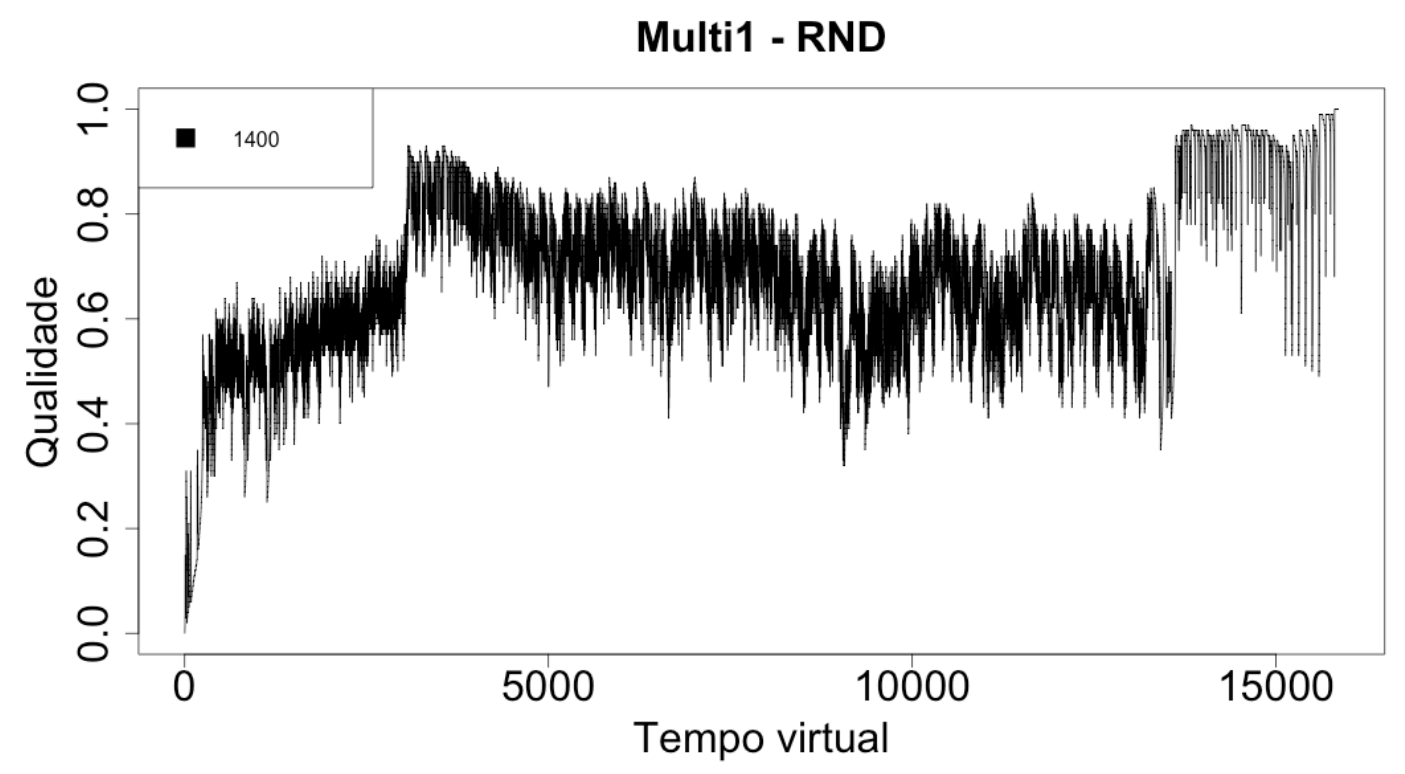

Fonte: Próprio Autor (2015)

Figura 37: Gráfico de QUALIDADE do RR+ng para 1400 páginas no trace multi1

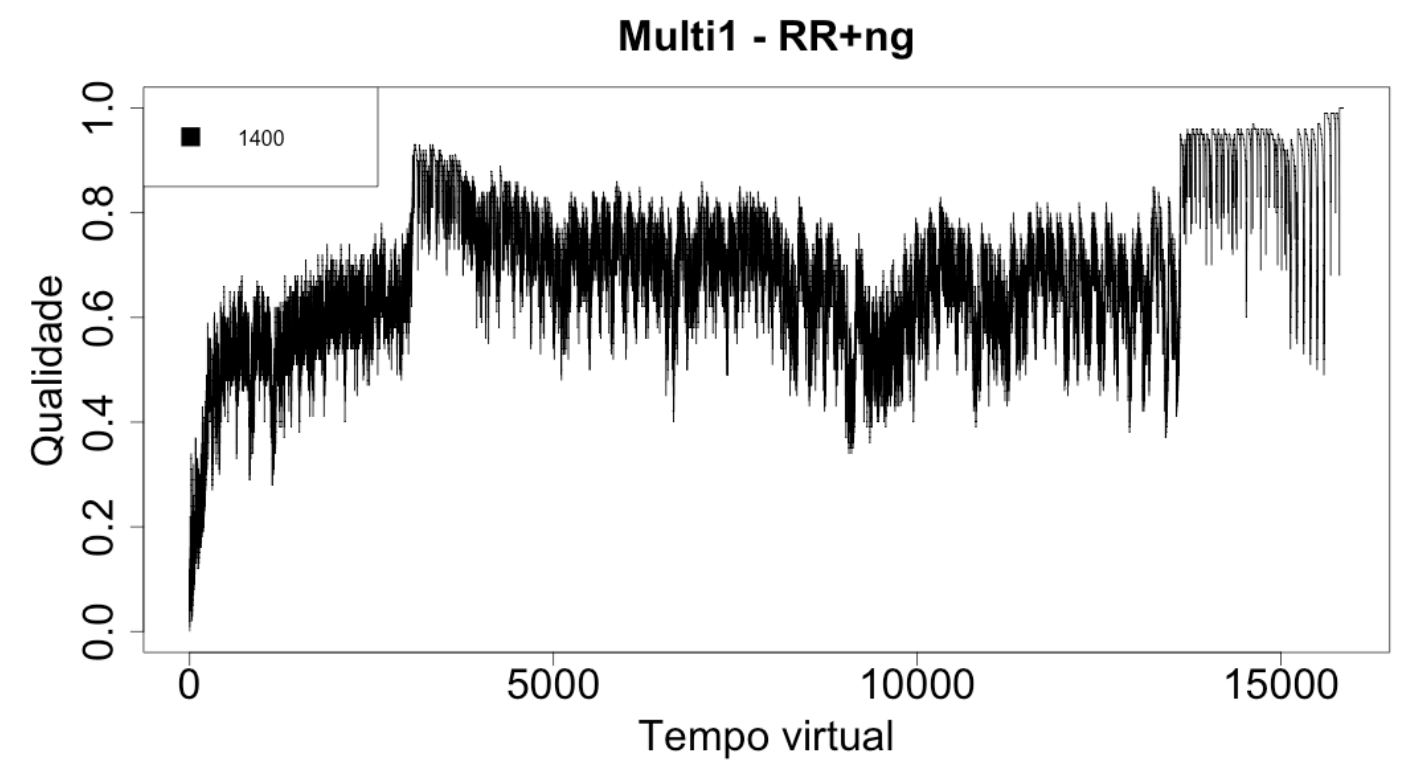

Fonte: Próprio Autor (2015)

valores de faltas de páginas também acompanham de forma inversa a métrica de QUALIDADE. Nas Figuras 34, 35, 36 e 37 encontram-se os gráficos de 
QUALIDADE da execução do trace multi1 para cada um dos algoritmos com memória de capacidade de 1400 páginas. É possível verificar uma grande melhora se compararmos com os gráficos com memória de 300 páginas para todos os algoritmos. Este resultado, embora já esperado, corrobora na validação da métrica de QUALIDADE com relação à medida do desempenho dos algoritmos estudados.

Podemos ver que o gráfico de QUALIDADE tem informações sobre a execução do algoritmo e o padrão de acesso implicitamente, porém menos marcado comparando com as memórias de pequeno tamanho. Só é possível observar o vale por volta do tempo virtual de 9.000 e 10.000 no execução do trace com o LRU, mas ainda é possível ver a mudança de localidade nos outros gráficos. Quanto maior a memória, mais páginas dos programas permanecem na memória principal, consequentemente, menor será a probabilidade de ocorrer uma falta de páginas o que eleva a QUALIDADE medida e dificulta a visualização das mudanças de working set.

Nesse caso o OPT supera o RR+ng em 9,84\% de QUALIDADE e o pior desempenho continua sendo do LRU que perde para o OPT em $25,79 \%$. O resultado é muito bom, visto que foi escolhido o tamanho de memória em que o RR+ng tem pior desempenho em comparação com o OPT e dele não se distancia mais que $10 \%$. É interessante notar que o $R R+n g$ se aproxima mais da política aleatória (RND) com memória maiores. A explicação para esse comportamento vem do fato do $\mathrm{RR}+\mathrm{ng}$ ser um algoritmo híbrido com relação à estratégia de busca (sob demanda e pré-paginação). Ele não usa a prépaginação caso a página contida no hash já esteja na memória. Como a possibilidade de estar na memória é maior com o aumento do total de páginas na RAM, o RR+ng executa menos operações de pré-paginação. Sem a prépaginação, o RR+ng tem o mesmo comportamento que o RND. Com relação 
ao gráfico de QUALIDADE do RND, na Figura 36, pode-se verificar que é bem mais parecida com o gráfico na Figura 37.

Figura 38: Gráfico de QUALIDADE do OPT para 200 páginas no trace multi2

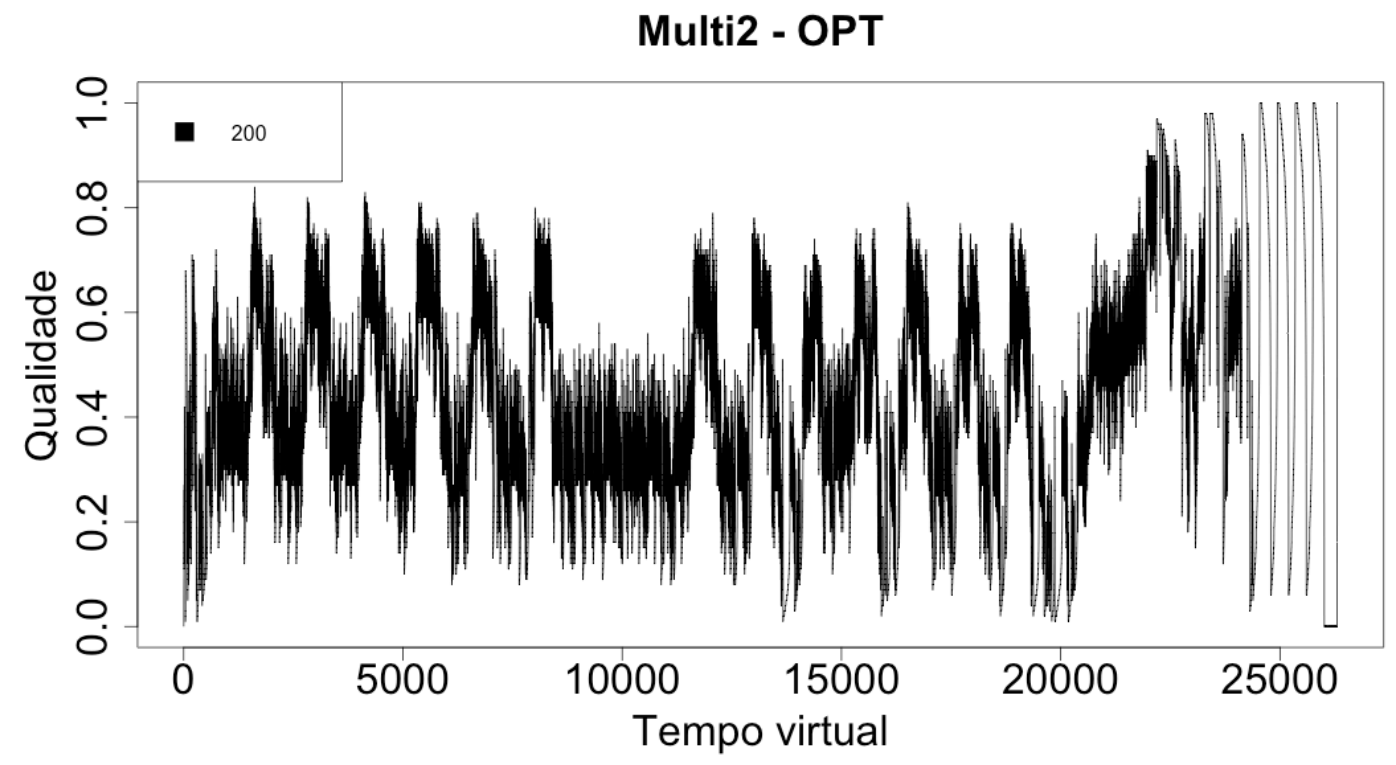

Fonte: Próprio Autor (2015)

Figura 39: Gráfico de QUALIDADE do LRU para 200 páginas no trace multi2

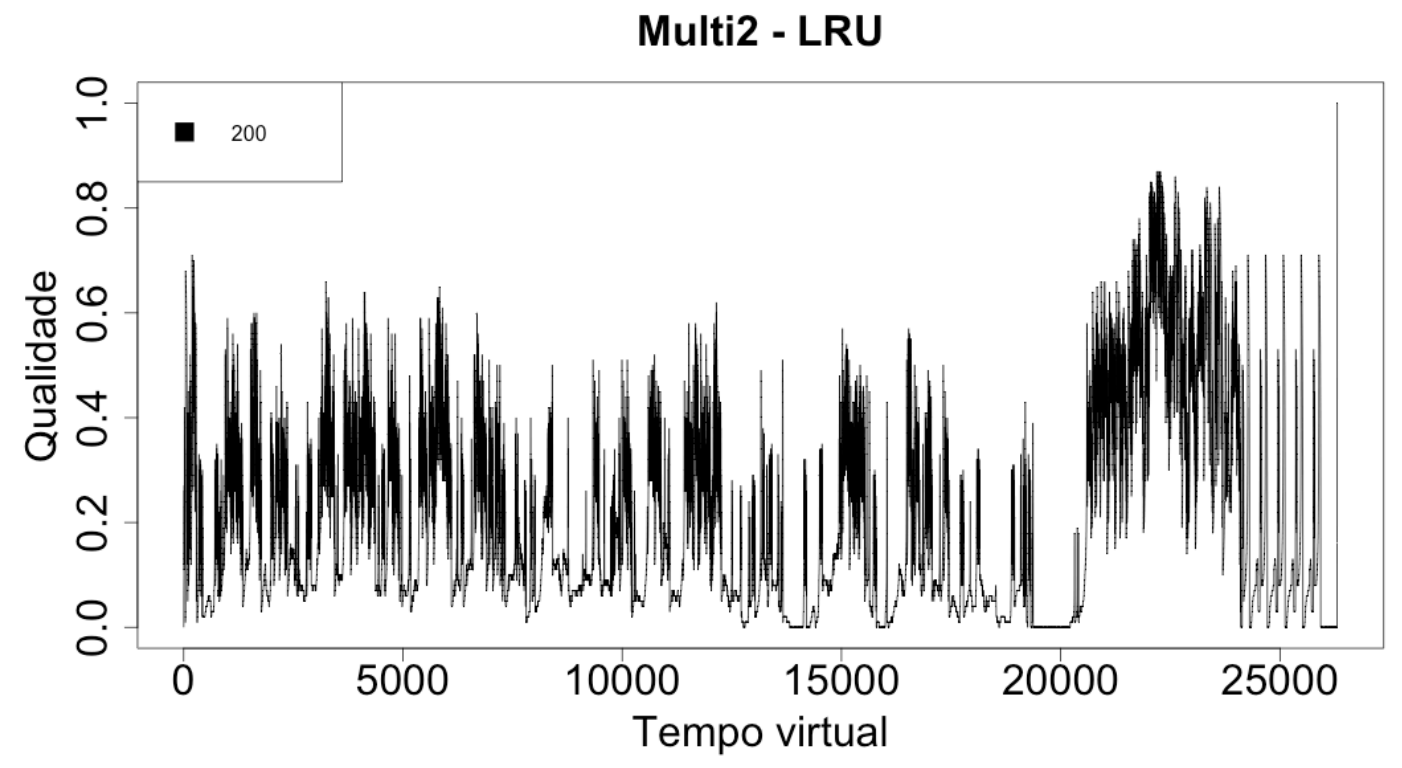

Fonte: Próprio Autor (2015) 
Figura 40: Gráfico de QUALIDADE do RND para 200 páginas no trace multi2

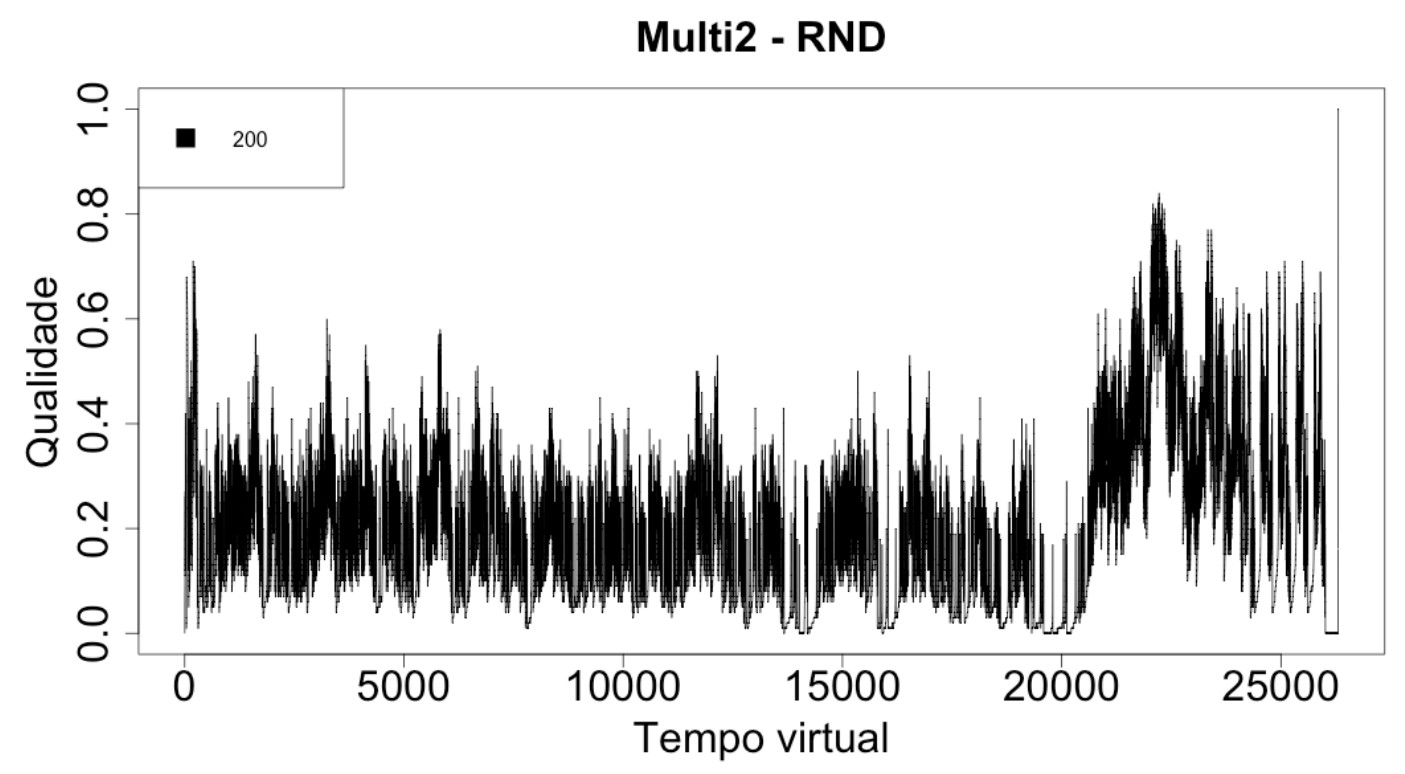

Fonte: Próprio Autor (2015)

Figura 41: Gráfico de QUALIDADE do RR+ng para 200 páginas no trace multi2

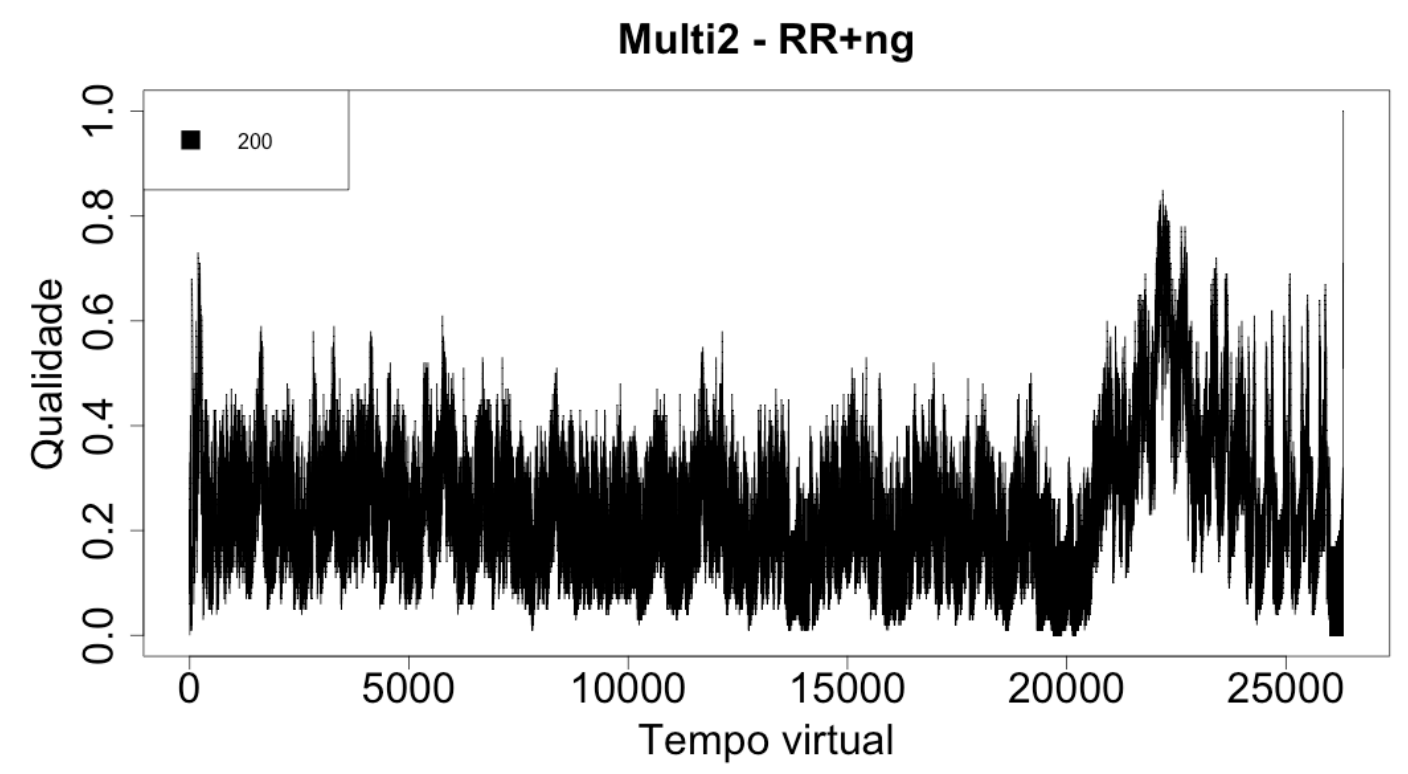

Fonte: Próprio Autor (2015)

\section{Multi2:}

Para análise do trace multi2 foram escolhidos os tamanhos de memórias 
de 200 e 2000 páginas. A escolha desses tamanhos foi feita tendo como base $o$ gráfico de faltas de página da Figura 27. O RR+ng apresentou melhor desempenho que o OPT para o tamanho de memória com 200 páginas. A principal diferença entre o trace multi1 com relação ao multi2 é o aumento do nível de multiprogramação com a inclusão do programa postgres conforme descrito na Tabela 2 do capítulo 2 .

Da Tabela 7, temos que as médias de QUALIDADE foram $44,78 \%, 42,90 \%$, $19,65 \%$ e 17,63\%, respectivamente, para os algoritmos RR+ng, OPT, LRU e RND. Da mesma forma que no multi1, os valores de faltas de páginas acompanham de forma inversa a métrica de QUALIDADE e a ordem de desempenho dos algoritmos também foi mantida. Nas Figuras 38, 39, 40 e 41 temos os gráficos de QUALIDADE da execução do trace multi2 para cada um dos algoritmos com memória de capacidade de 200 páginas. É possível notar nesse trace, especialmente no gráfico do OPT, uma grande quantidade de picos seguidos de vales em toda a execução do programa. Isso pode ser explicado pela existência de mais working sets e mais mudanças entre working sets no trace multi2.

Como no multi1, também é possível verificar que o gráfico de QUALIDADE do trace multi2 tem informações sobre a execução dos programas que compõem o trace e o padrão de acesso implicitamente. O gráfico da política ótima (OPT) seria a melhor alternativa para avaliar informações importantes, pois as mudanças entre pico e vale são mais acentuadas. Entre os tempos virtuais 1.000 e 20.000 pode-se ver 13 grandes picos com 13 vales intercalados. Se compararmos com o mapa de acesso do multi2, na Figura 43, esses picos e vales estão relacionados com os loopings que não aparecem no mapa de acesso do multi1 na Figura 42. Pode-se, então, ver a mudança de localidade prejudicando a qualidade da configuração da memória. Através das informa- 
ções obtidas no gráfico de QUALIDADE, pode-se, em uma segunda iteração do método, redefinir as informações que podem auxiliar as técnicas previamente estabelecidas na confecção do RR+ng, levando em conta também os exatos momento em que a execução apresenta baixo desempenho.

Figura 42: Gráfico do mapa de acesso trace multi1

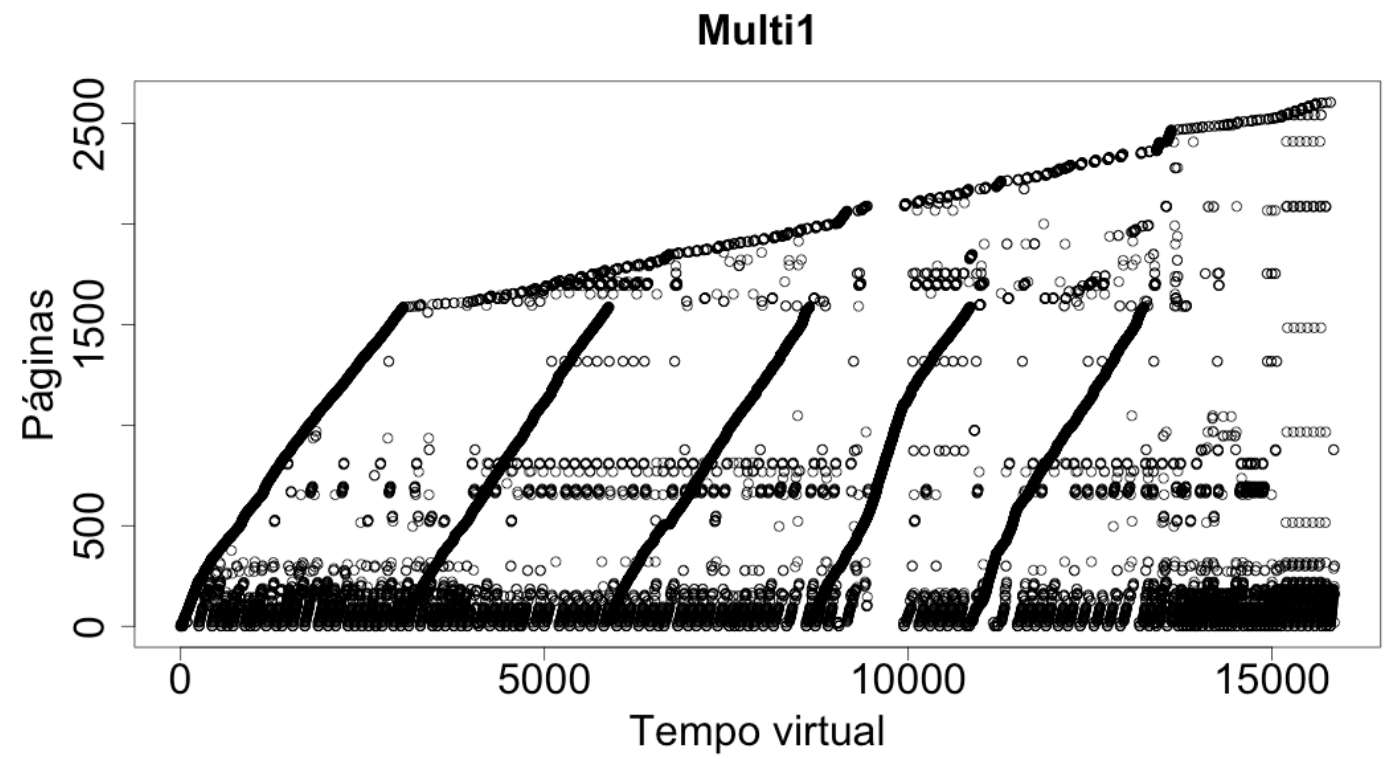

Fonte: Próprio Autor (2015)

O algoritmo RR+ng supera o OPT em 1,88\% de QUALIDADE e o pior desempenho foi novamente do RND que perde para o OPT em $27,15 \%$. No multi2, a estratégia do RR+ng para a escolha da página de busca antecipada baseado em bigramas tem desempenho menor com o aumento do nível de multiprogramação. Mesmo assim, o RR+ng obteve um resultado que não pode ser obtido utilizando um algoritmo tradicional de substituição de páginas. Com relação ao gráfico de QUALIDADE do RND na Figura 40, pode-se verificar que o formato é bem parecido com o gráfico na Figura 41 do $R R+n g$ pela utilização do algoritmo aleatório de substituição de páginas utilizados em ambos os algoritmos.

As simulações do multi2 com 2000 páginas de tamanho, segundo a ta- 
Figura 43: Gráfico do mapa de acesso trace multi2

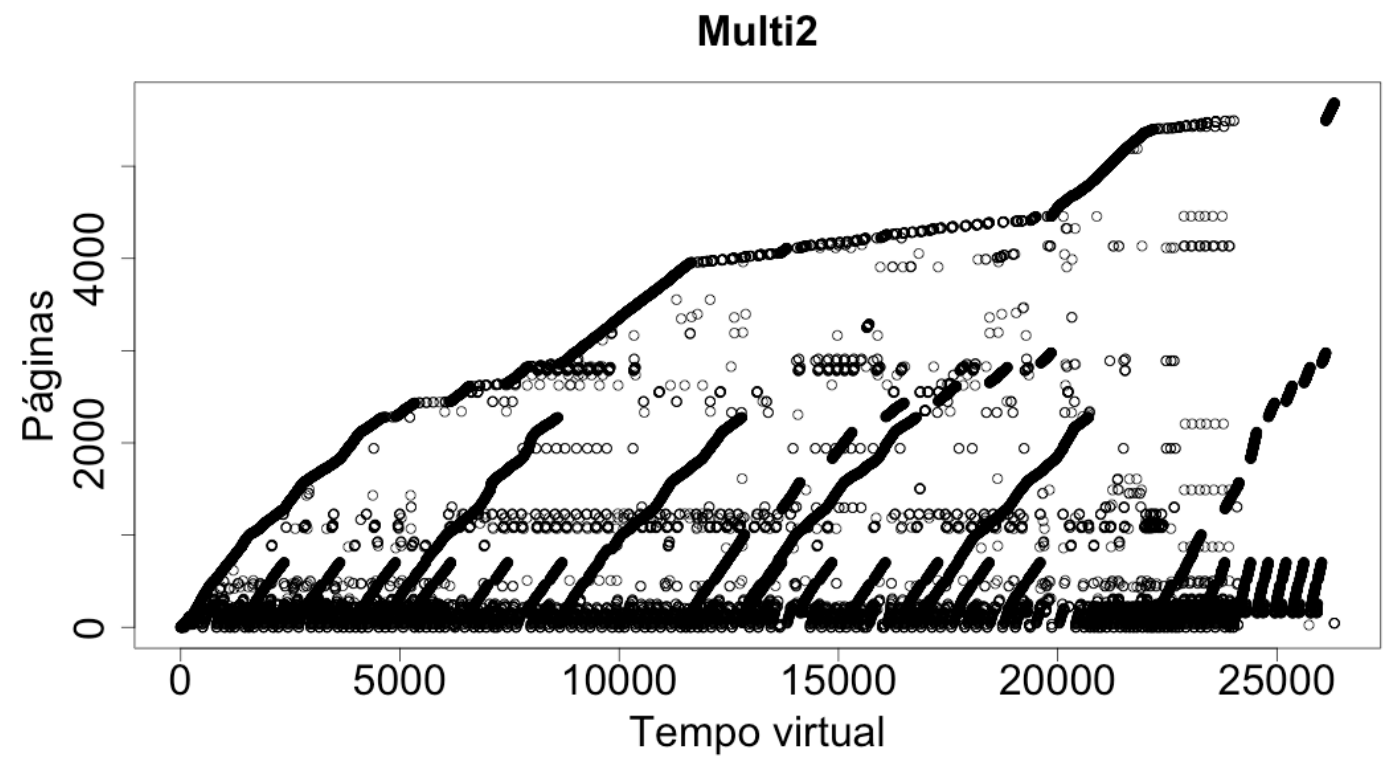

Fonte: Próprio Autor (2015)

Figura 44: Gráfico de QUALIDADE do OPT para 2000 páginas no trace multi2

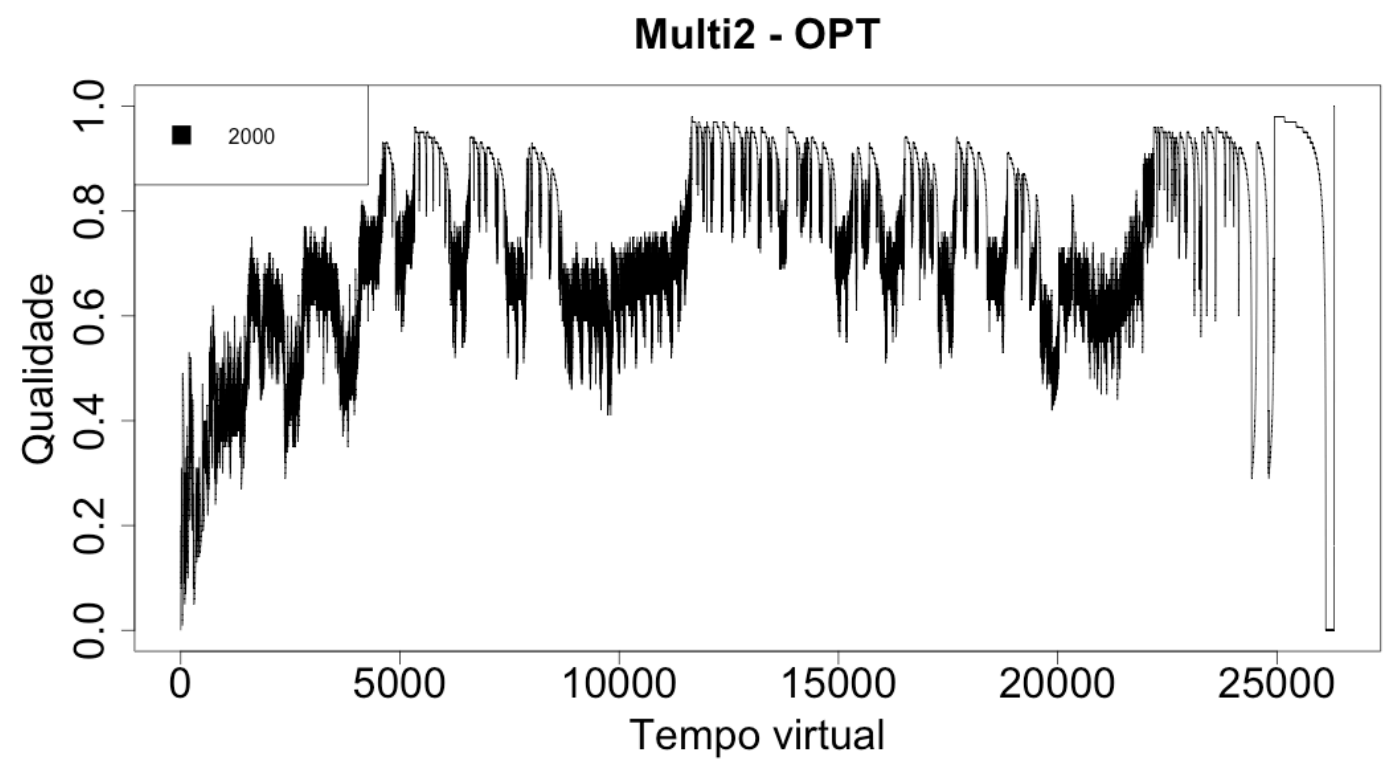

Fonte: Próprio Autor (2015)

bela 7, apresentaram as seguintes médias de QUALIDADE: 74,39\%, 66,56\%, $56,62 \%$ e $51,57 \%$, respectivamente, para os algoritmos OPT, RR+ng, RND 
Figura 45: Gráfico de QUALIDADE do LRU para 2000 páginas no trace multi2

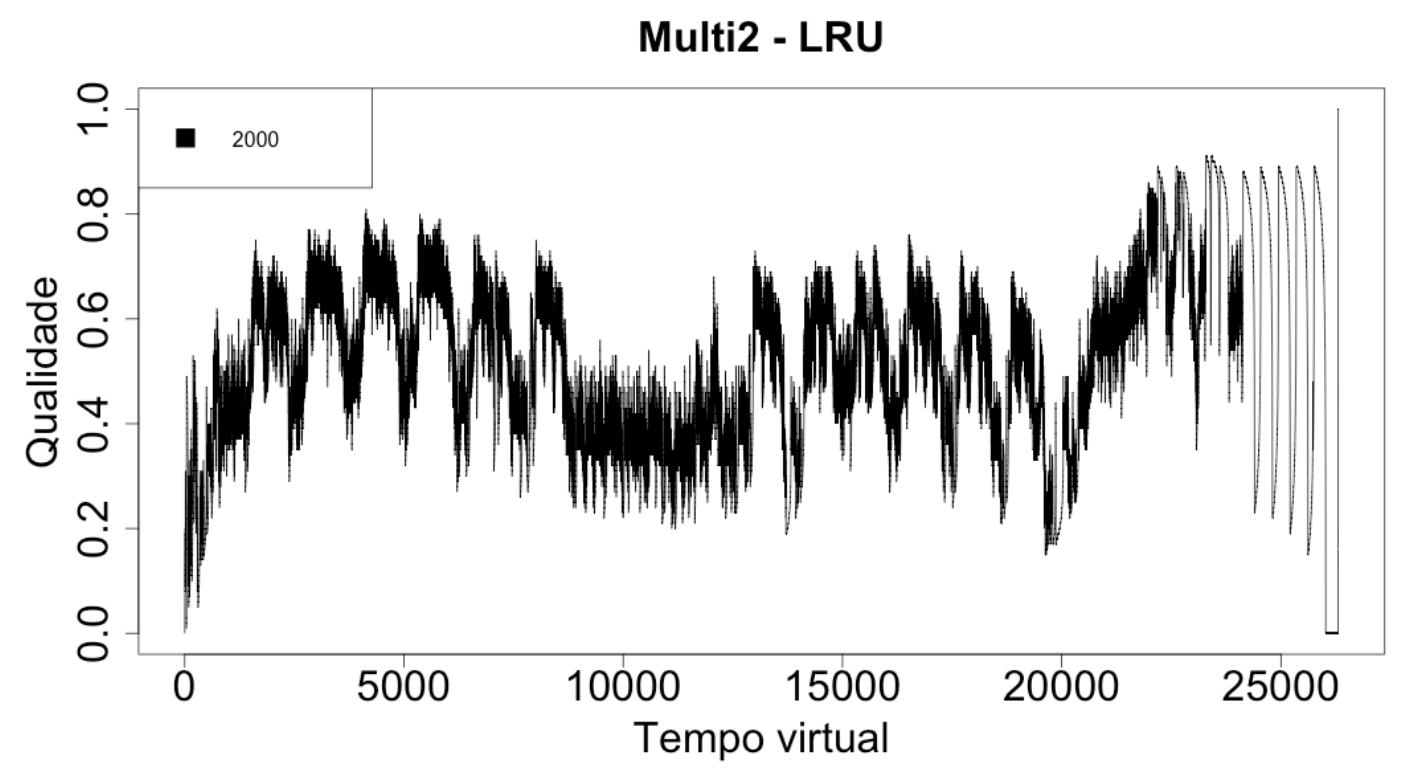

Fonte: Próprio Autor (2015)

Figura 46: Gráfico de QUALIDADE do RND para 2000 páginas no trace multi2

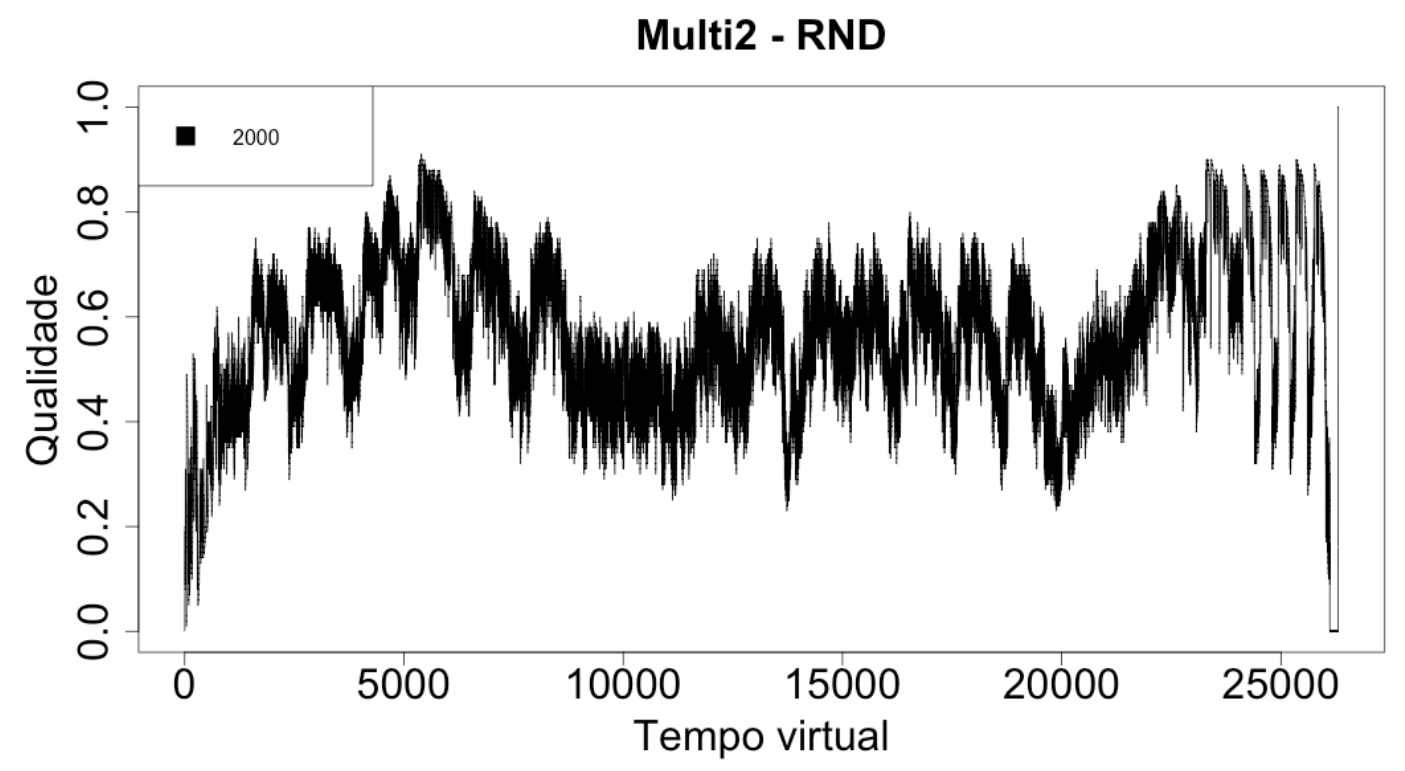

Fonte: Próprio Autor (2015)

e LRU. Novamente, os valores de faltas de páginas acompanham de forma inversa a métrica de QUALIDADE. As Figuras 44, 45, 46 e 47 mostram os 
Figura 47: Gráfico de QUALIDADE do RR+ng para 2000 páginas no trace multi2

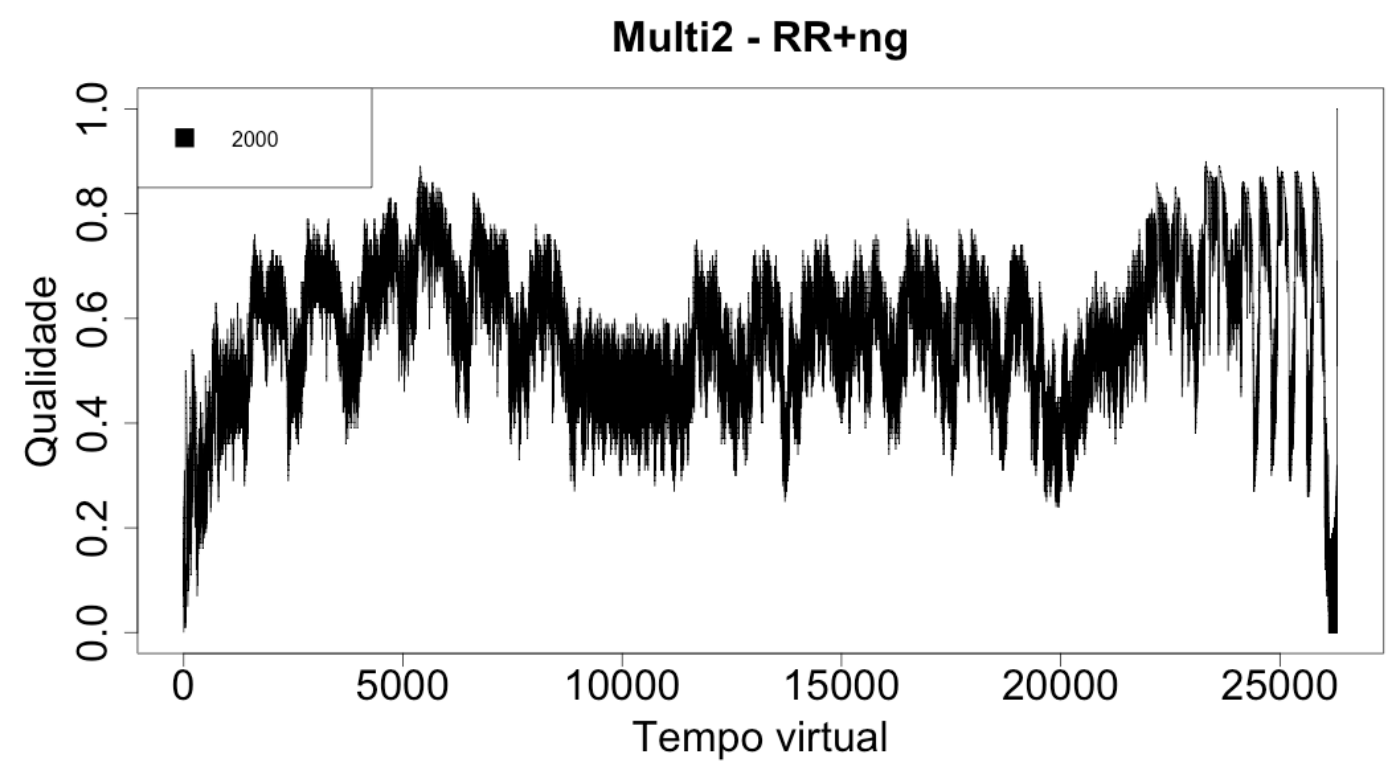

Fonte: Próprio Autor (2015)

gráficos de QUALIDADE pelo tempo virtual para trace multi2 com memória de tamanho 2000 páginas. Podemos mais uma vez verificar uma melhora se compararmos com os gráficos com memória de 200 páginas para todos os algorítimos.

O gráfico de QUALIDADE mostra informações sobre toda a execução do programa e seu padrão de acesso implicitamente. De forma contrária aos gráficos anteriores, destacam-se dois pontos em que a QUALIDADE se mantém por volta de $65 \%$ durante algum tempo entre 8.000 e 10.000. Também aparece quando a quantidade de memória é 200 páginas, mas o destaque se dá pelo fato dos picos e vales serem menores. Quanto maior a memória, mais páginas dos programas permanecem nela, consequentemente, menor será a probabilidade de ocorrer falta de páginas, o que eleva a QUALIDADE e dificulta a visualização das mudanças no working set.

O algoritmo OPT supera o RR+ng em 7,83\% de QUALIDADE e o pior de- 
sempenho continua sendo do LRU que perde para o OPT em $22,82 \%$. O resultado é melhor em comparação com o multi1, visto que foi escolhido o tamanho de memória que o RR+ng tem pior desempenho em comparação com o OPT e a ele não se distancia mais que $8 \%$. Tanto o $R R+n g$ quanto o LRU se aproximaram mais do OPT no pior caso. Novamente o RR+ng se aproxima mais da política aleatório (RND) com memória maiores. Com relação ao gráfico de QUALIDADE do RND na Figura 46, pode-se verificar que é bem mais parecida com o gráfico na Figura 47.

Figura 48: Gráfico de QUALIDADE do OPT para 200 páginas no trace multi3

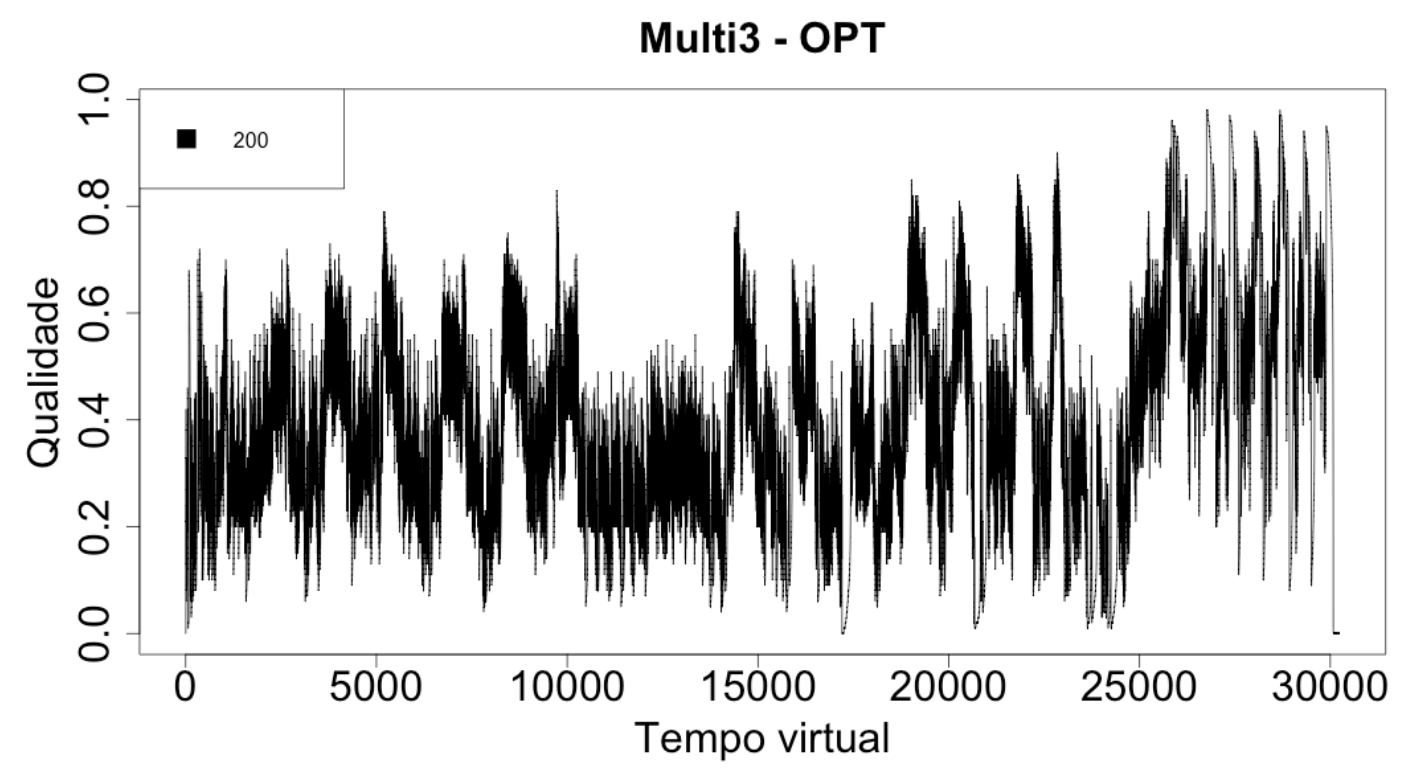

Fonte: Próprio Autor (2015)

\section{Multi3:}

Ao analisar o trace multi3 foram escolhidos os tamanhos de memórias de 200 e 2800. A razão da escolha foi a mesma dos traces anteriores: o desempenho obtido com relação à política OPT que observamos no gráfico de faltas de página da Figura 28. De forma similar as análises do multi1 e multi2, o tamanho de memória com 200 páginas obteve o maior desempenho comparativo em relação ao $\mathrm{RR}+\mathrm{ng}$ e o tamanho de 2800 páginas, o pior. A diferença entre 
Figura 49: Gráfico de QUALIDADE do LRU para 200 páginas no trace multi3

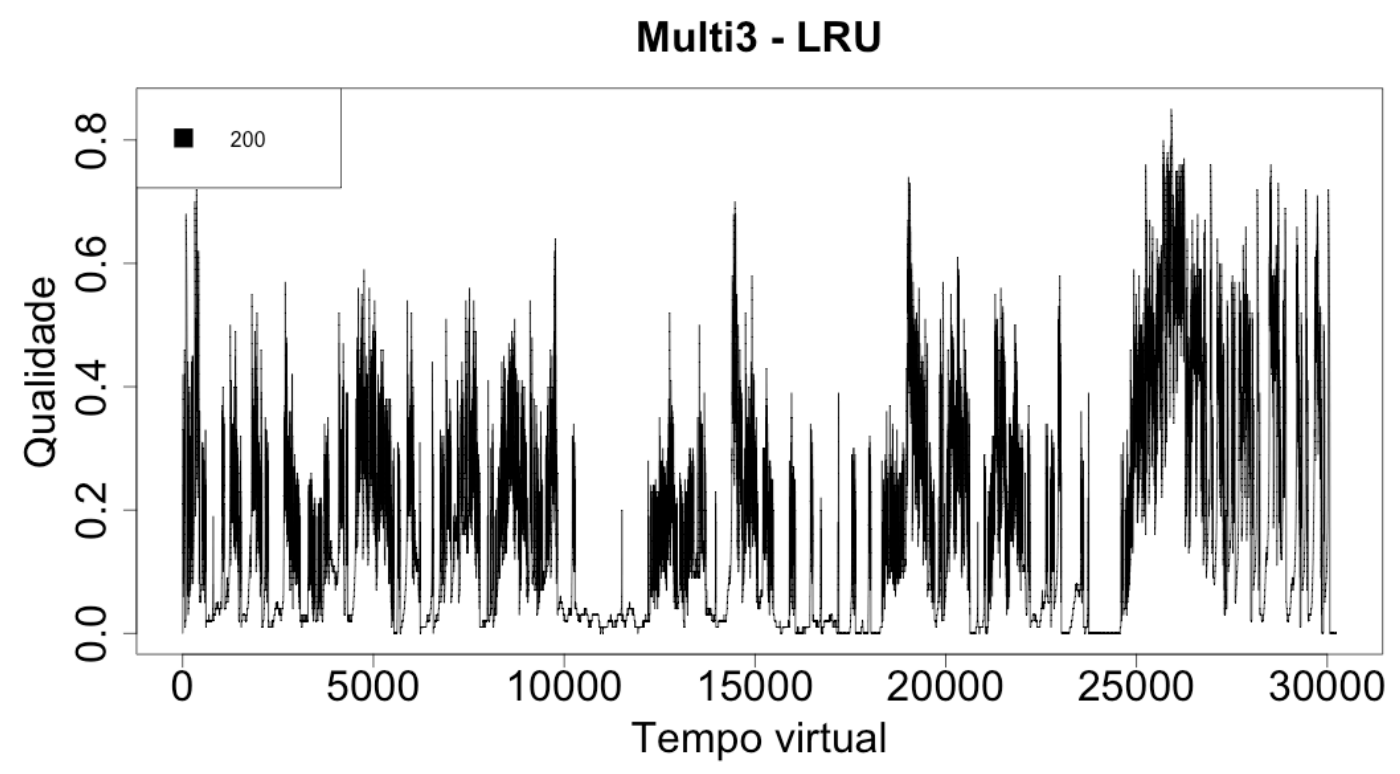

Fonte: Próprio Autor (2015)

Figura 50: Gráfico de QUALIDADE do RND para 200 páginas no trace multi3

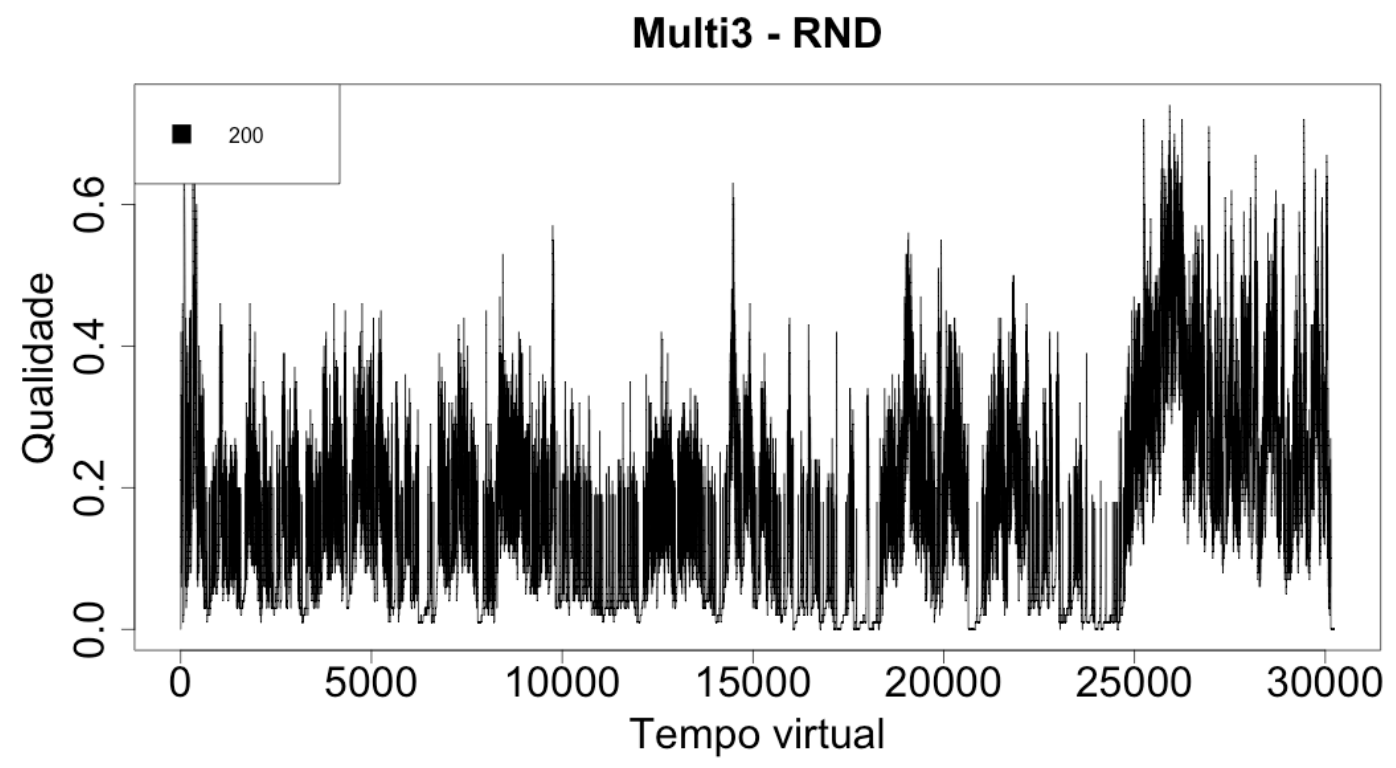

Fonte: Próprio Autor (2015)

o trace multi2 e multi3 é o aumento da multiprogramação, com a inclusão de novos programas, o gnuplot e o glimpse. 
Figura 51: Gráfico de QUALIDADE do RR+ng para 200 páginas no trace multi3

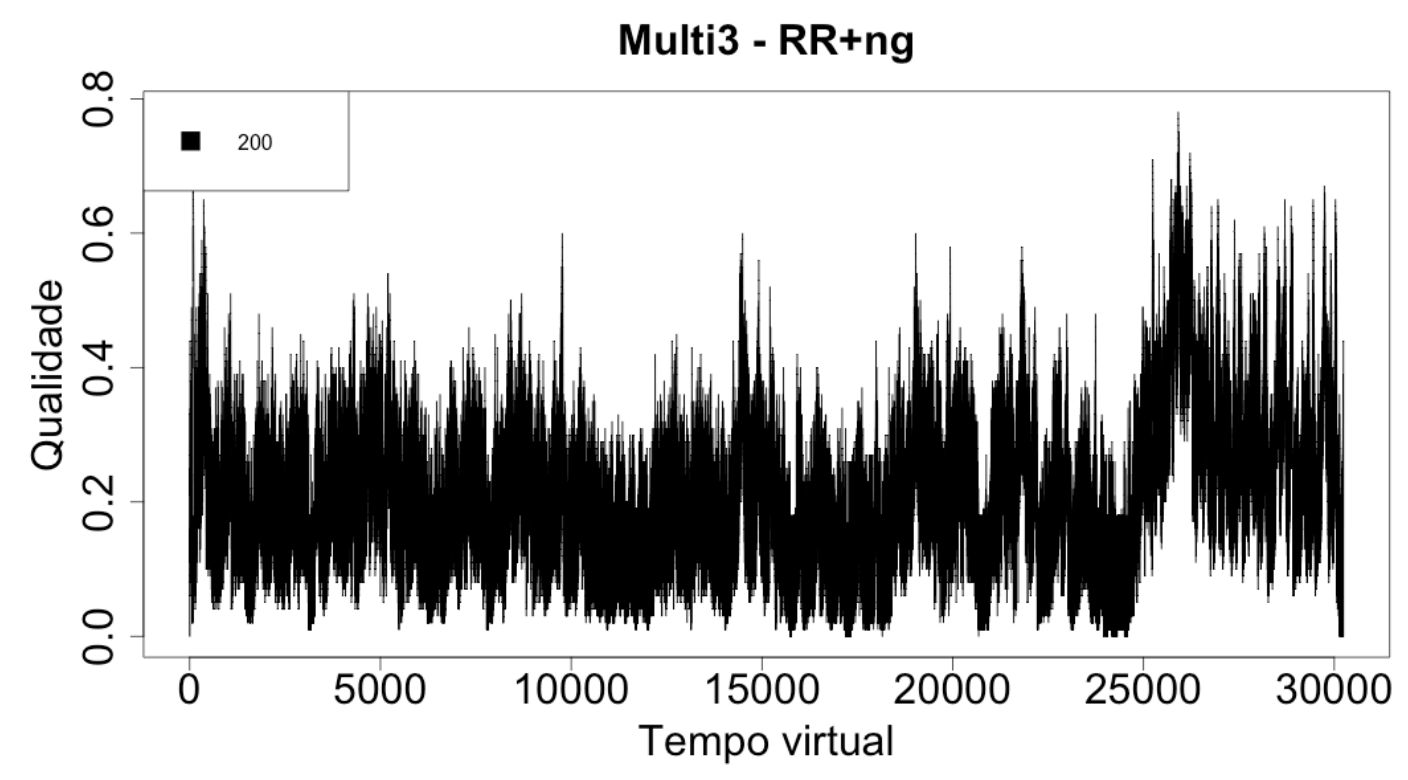

Fonte: Próprio Autor (2015)

Como podemos observar na Tabela 7, as médias de QUALIDADE para a memória de 200 páginas foram $43,67 \%, 37,96 \%, 15,37 \%$ e 14,27\%, respectivamente, para os algoritmos RR+ng, OPT, LRU e RND. Como no multi1 e multi2, os valores de faltas de páginas acompanham de forma inversa a métrica de QUALIDADE e a ordem de desempenho dos algoritmos novamente foi mantida. Nas Figuras 48, 49, 50 e 51, apresentam-se gráficos com os valores instantâneos da QUALIDADE ao longo da execução do trace multi3 para cada um dos algoritmos.

É possível verificar similar comportamento, no multi1 e multi2, o gráfico de QUALIDADE do trace multi3 também tem informações sobre o padrão de acesso dos programas. Na comparação entre os algoritmos, o RR+ng supera o OPT em $5,71 \%$ de QUALIDADE e o pior desempenho foi do RND que perde para o OPT em $23,69 \%$.

A execução do multi3 com memória de 2800 páginas apresentou, de 
Figura 52: Gráfico de QUALIDADE do OPT para 2800 páginas no trace multi3

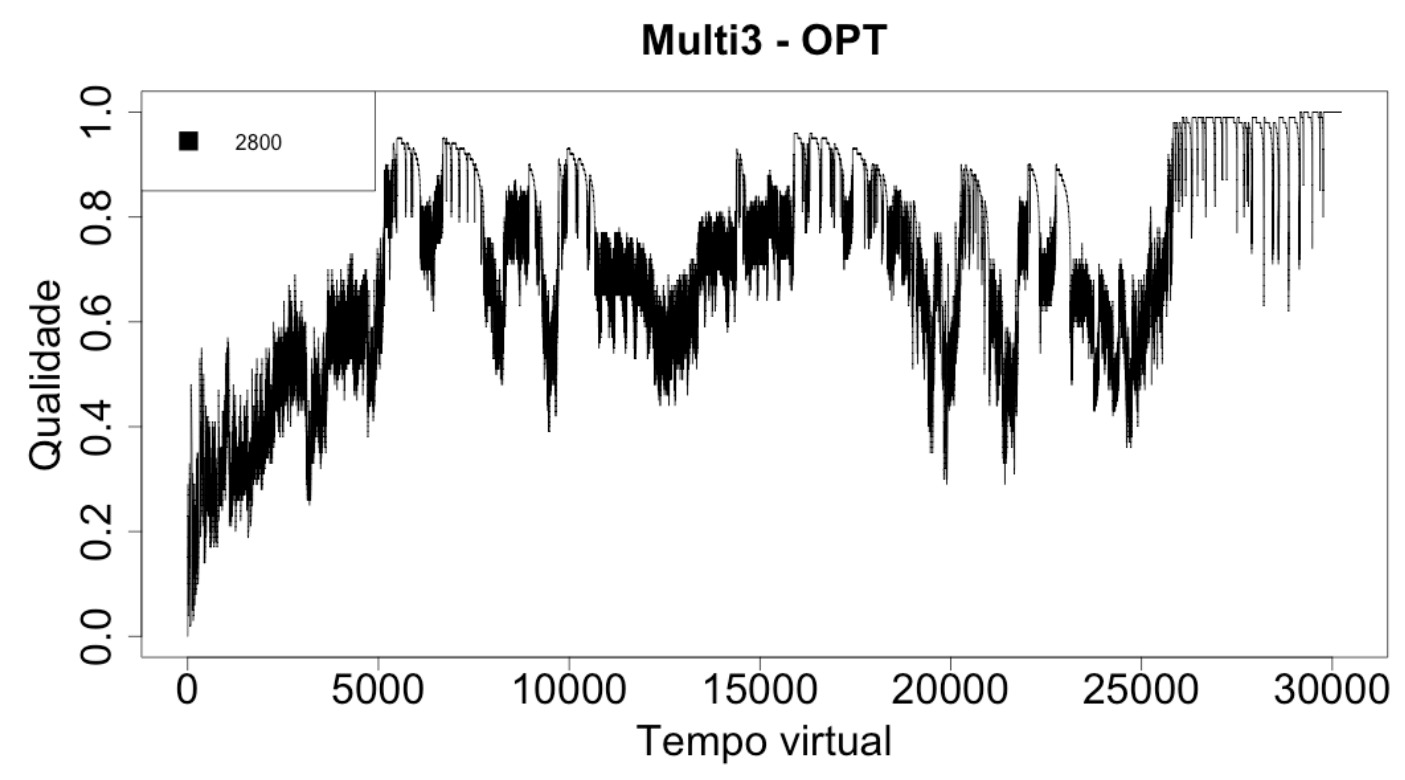

Fonte: Próprio Autor (2015)

Figura 53: Gráfico de QUALIDADE do LRU para 2800 páginas no trace multi3

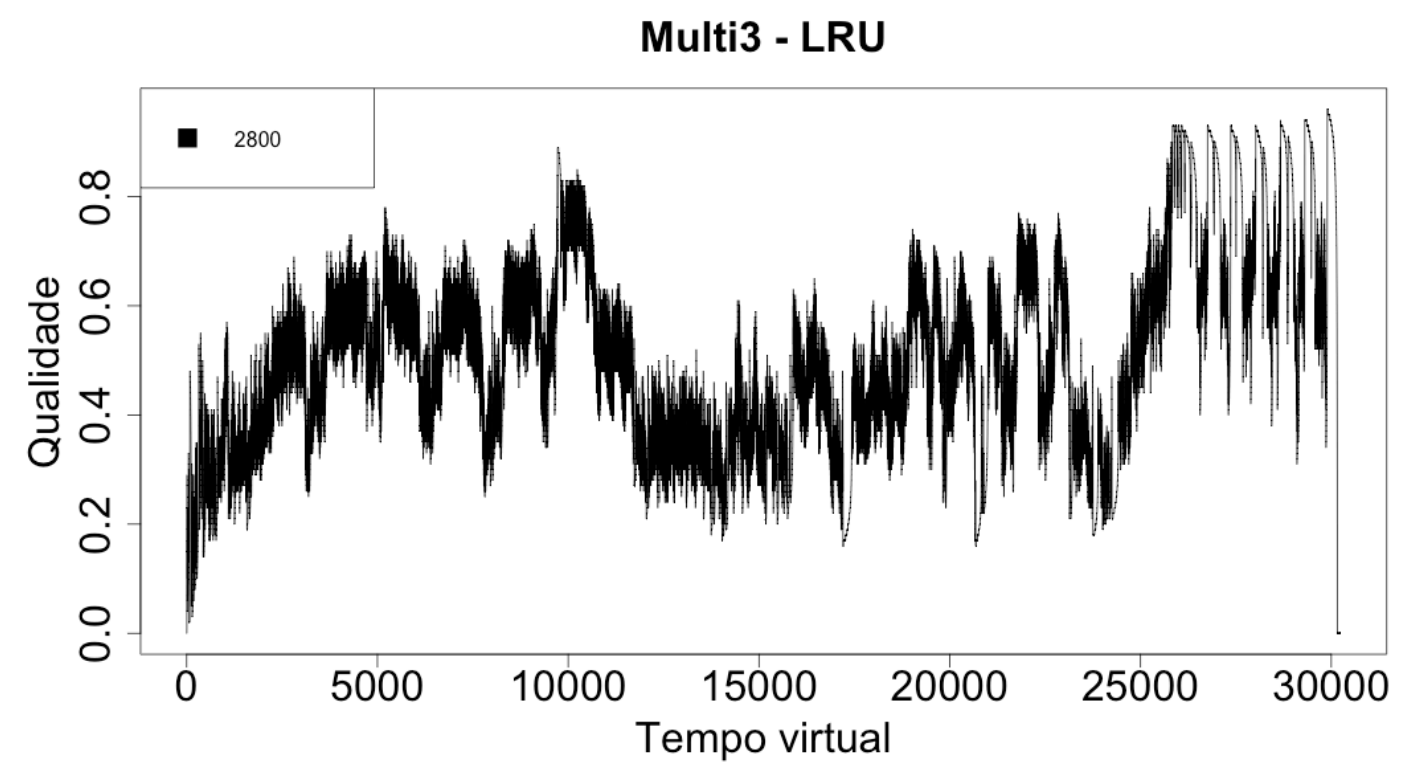

Fonte: Próprio Autor (2015)

acordo com a Tabela 7, as médias de QUALIDADE iguais a $72,72 \%, 63,82 \%$, $55,54 \%$ e $50,37 \%$, respectivamente, para os algoritmos OPT, RR+ng, RND 
Figura 54: Gráfico de QUALIDADE do RND para 2800 páginas no trace multi3

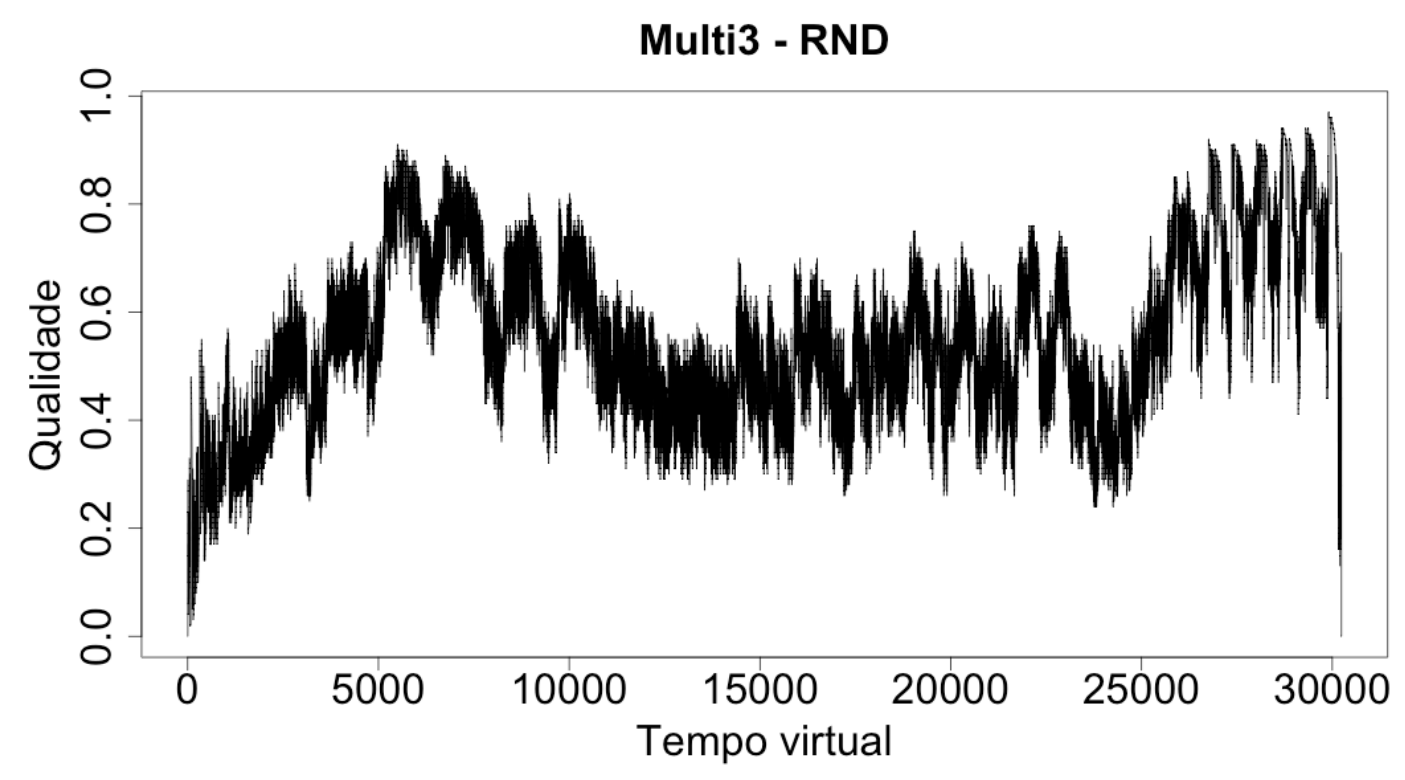

Fonte: Próprio Autor (2015)

Figura 55: Gráfico de QUALIDADE do RR+ng para 2800 páginas no trace multi3

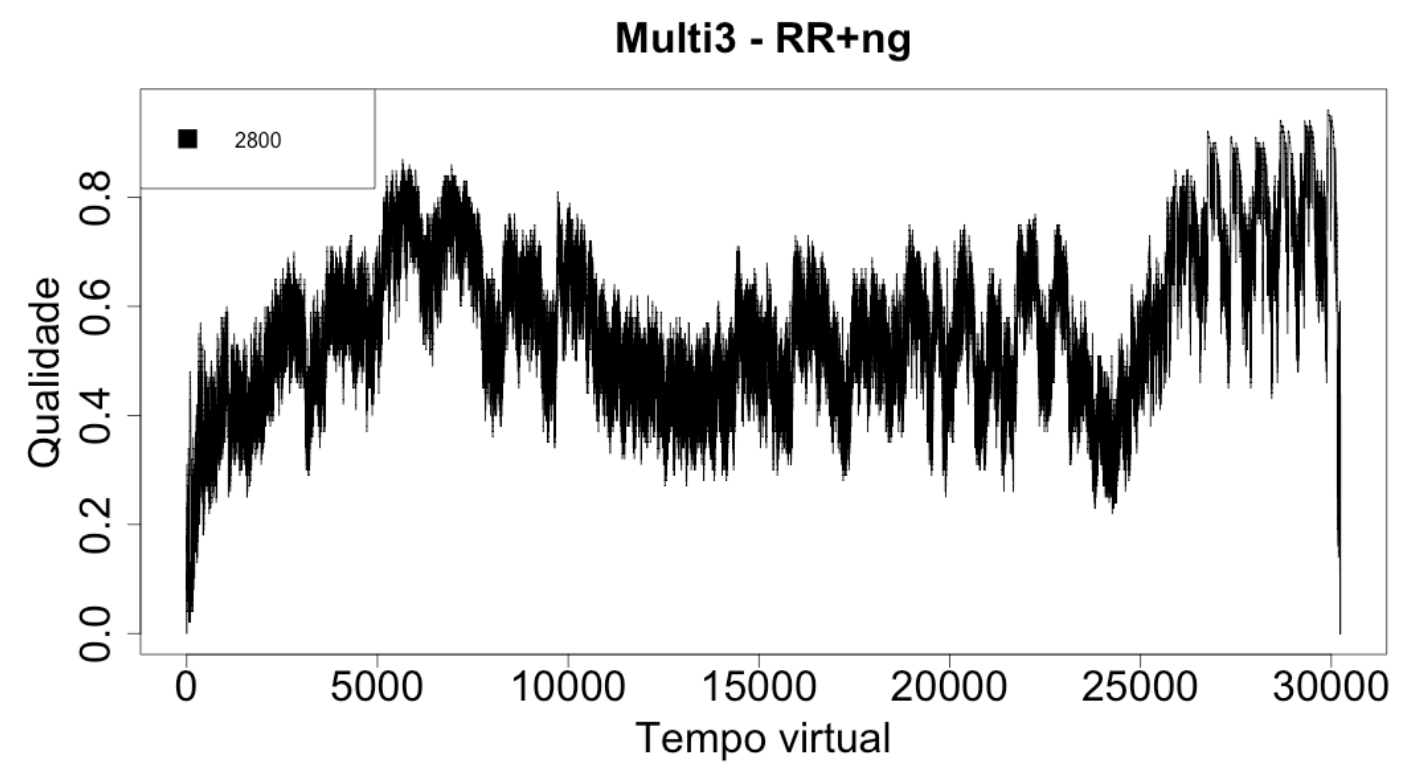

Fonte: Próprio Autor (2015)

e LRU. Nas Figuras 52, 53, 54 e 55, apresentam-se gráficos com os valores instantâneos da QUALIDADE ao longo da execução do trace multi3 para cada 
um dos algoritmos com memória de capacidade de 2800 páginas. Pode-se verificar melhora se compararmos com os gráficos com memória de tamanho menor para todos os algoritmos. O mesmo acontece com os traces multi1 e multi2. O OPT supera o RR+ng em $8,90 \%$ de QUALIDADE e o pior desempenho é do LRU, que perde para o OPT em 22,35\%.

Finalizada a avaliação, cabe agora terminar o processo de criação do novo algoritmo ou executar mais uma rodada do método. Caso opte-se por reavaliar as técnica e informações utilizadas, é possível substituí-las, ou mantê-las e adicionar mais técnicas e informações. Tudo isso depende do fato de o desempenho ter sido considerado satisfatório ou não.

\subsubsection{Verificação do desempenho esperado}

O desempenho esperado deve ser definido com base nos objetivos do projeto do novo algoritmo. A métrica de verificação do desempenho pode ser, por exemplo, baseada na métrica de QUALIDADE. Nesse caso, poderia ser definida uma média de QUALIDADE compatível com os requisitos do projeto. Outra possibilidade é atribuir uma média comparativa. Por exemplo, a respeito do $R R+n g$, o desempenho esperado no pior caso foi especificado para ser no máximo $8 \%$ pior que o algoritmo ótimo sob demanda, em termos de QUALIDADE.

Caso o algoritmo não atinja o desempenho esperado, como neste caso, é possível voltar ao primeiro passo e escolher técnicas e informações complementares, assim recomeçando a confecção do novo algoritmo. Não é garantida a melhora do algoritmo na nova iteração, pois pode ser que o primeiro algoritmo seja o melhor entre as próximas $n$ iterações. Por esse motivo é interessante definir um número máximo de iterações. 
O RR+ng não atingiu o desempenho esperado porque no pior caso, em comparação com o ótimo, obteve no máximo 9,84\% menos QUALIDADE. Na próxima seção executa-se a segunda iteração na tentativa de obter o resultado esperado.

\subsection{Criação do algoritmo RRlock+ng (segunda iteração)}

O algoritmo RR+ng não atingiu satisfatoriamente o desempenho esperado que foi definido para, no pior caso, ser no máximo $8 \%$ pior que o algoritmo ótimo sob demanda, em termos de QUALIDADE. Faz-se, então, necessária uma segunda iteração do método, pois a gerência de memória requer maior desempenho. O RRlock+ng foi criado na segunda iteração do método sistêmico proposto baseado no conceito de qualidade. Os mesmos aspectos priorizados na construção do $\mathrm{RR}+\mathrm{ng}$ foram também priorizados na obtenção do RRlock+ng. Nesta seção mostra-se a concepção do novo algoritmo, RRlock+ng, passo a passo.

Como na primeira iteração do método, as técnicas para busca e posicionamento são definidas. A primeira tarefa da segunda iteração é verificar se as técnicas escolhidas na primeira iteração serão compatíveis com as novas escolhidas aqui. Obteve-se bom desempenho na primeira iteração, então, a meIhor decisão é manter as técnicas de paginação sob demanda e pré-paginação para a política de busca, e incluir uma técnica de posicionamento. Sabe-se que o RR+ng adotou a política aleatória para posicionamento. O novo algoritmo RRlock+ng usa a técnica de lock de páginas para posicionamento. Esta técnica mantém a página na memória por um período de tempo, por esse motivo ela é considerada uma técnica de posicionamento temporal de páginas. 
Cabe agora avaliar as informações que foram definidas na primeira iteração. Como obteve-se resultado positivo com o apoio das informações definidas, não foram feitas alterações nas informações de apoio. Como em PIANTOLA; MIDORIKAWA 2008, utiliza-se a informação de frequência de páginas e o profiling para auxiliar a técnica de posicionamento lock. O RRlock+ng utiliza o mesmo tipo de n-grama para auxiliar a pré-paginação, descrito na primeira iteração, porém agora as informações obtidas em tempo de execução são adicionadas também no profile.

Na primeira iteração a diretriz especificada no método sistêmico foi seguida, desta forma foi definida a política aleatória para substituição de páginas. O motivo dessa escolha foi mostrar que para escolher qual a página a ser removida da memória, pode ser adotado um algoritmo simples, com baixa sobrecarga e mesmo assim obter bom desempenho. Isso foi possível pelo uso do conceito de qualidade e vai ser mantido na segunda iteração na concepção do RRlock+ng. Após finalizada as escolhas da primeira parte do método, constrói-se então o algoritmo.

O algoritmo RRlock+ng mantém a estrutura do RR+ng com a adição da técnica de travamento de páginas (lock) e a informação de frequência apoiada por profiling. O Algoritmo 2, a seguir, apresenta o pseudocódigo do RRlock+ng. As alterações decorrentes da modificação são referenciadas nas linhas 5-6, 11-12 e 14. A linha 5 verifica se a página referenciada encontra-se no profile e a linha 6 atribui o valor 1 ao flag PG_locked, o mesmo acontece nas linhas 11 e 12. Já a linha 14 é responsável pela criação e manutenção do profile. 


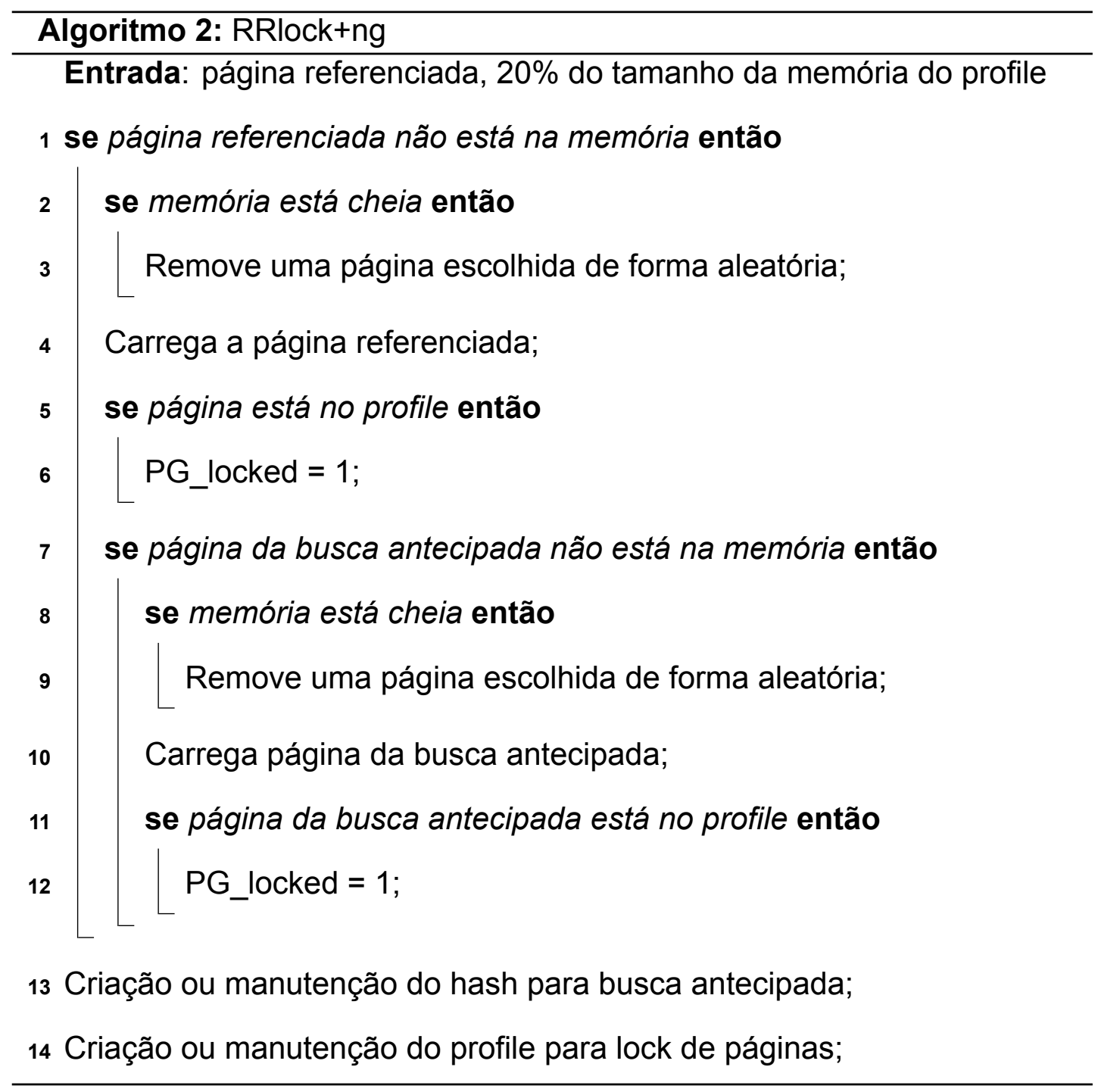

Segundo Piantola e Midorikawa (2008), poucas páginas do programa são responsáveis pela maior parte das referências. Na primeira execução do algoritmo de gerência de memória, cria-se um profile com as páginas mais acessadas. A partir da segunda execução é possível reservar $20 \%$ da memória para guardar as páginas com maior frequência que estão no profile. As páginas do profile que entrarem na memória ficam em lock até o final da execução do programa. 


\subsection{Avaliação do algoritmo RRlock+ng}

Nesta seção, apresentam-se as análises comparativa, usando gráficos de falta de páginas, e analise utilizando a métrica de QUALIDADE.

Foram escolhidas as políticas: OPT e RR+ng, para melhor visualização e foco nas mudanças e mantidos os mesmos traces: multi1, multi2 e multi3. 0 apêndice A contém gráficos de faltas de páginas com outros traces de diferentes aplicações.

Como analisado na primeira iteração, metade dos acessos, no multi1, são realizados por $7,5 \%$ das páginas. A informação de frequência de acessos, obtida pelo profiling, proporciona menos faltas de páginas. O RRlock+ng supera o RR+ng em todos os tamanhos de memória e em todos os três traces, verificado nas figuras: 56, 57 e 58. O motivo é a adição do profile com a informação das páginas acessadas mais frequentemente.

Figura 56: Gráfico de falta de páginas do trace multi1.

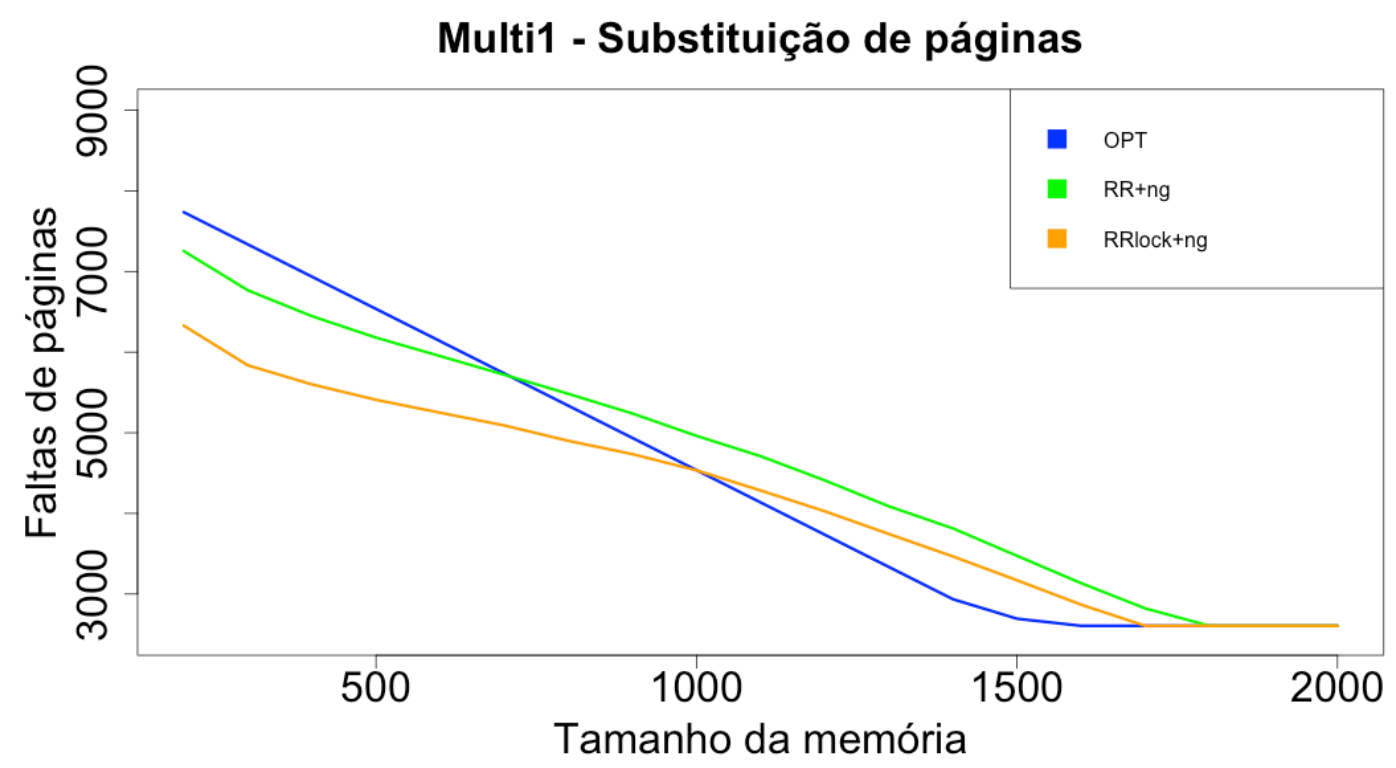

Fonte: Próprio Autor (2015) 
Figura 57: Gráfico de falta de páginas do trace multi2.

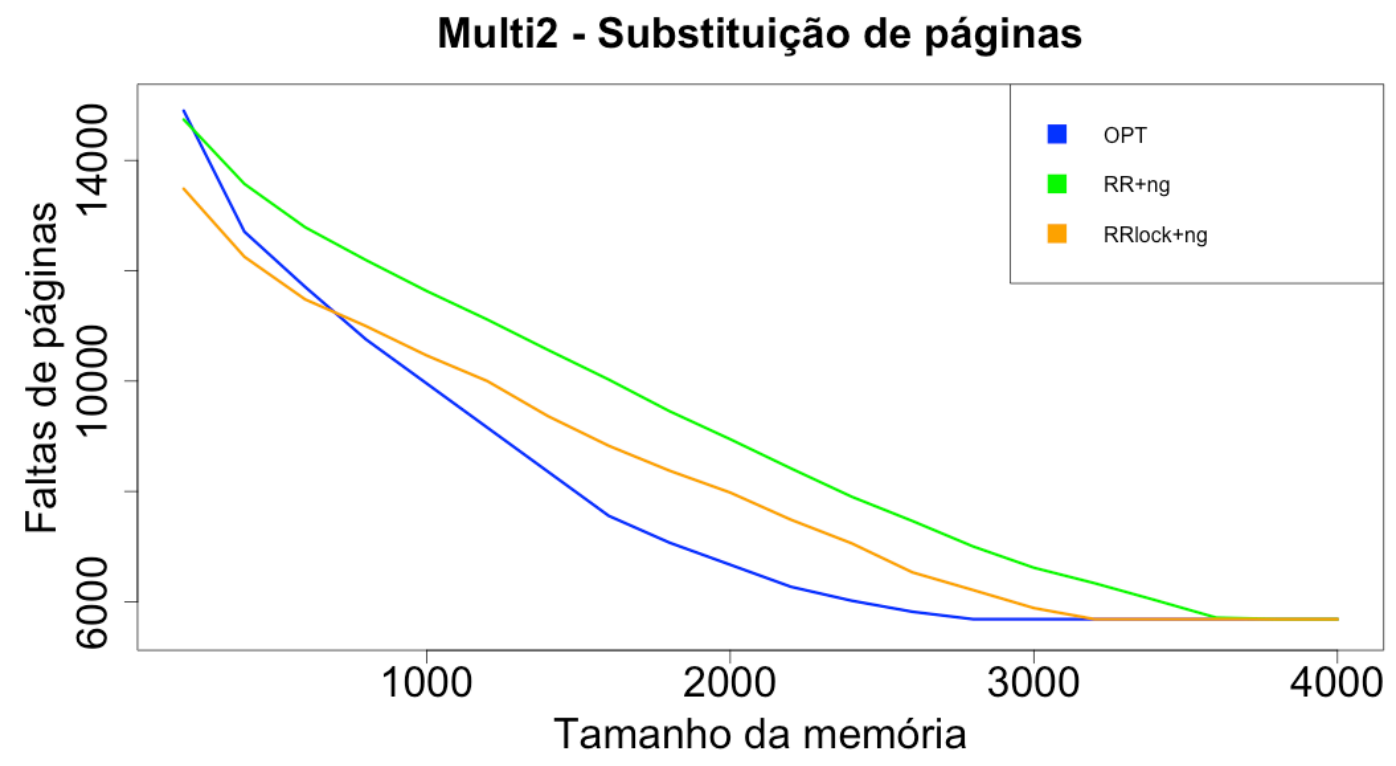

Fonte: Próprio Autor (2015)

Figura 58: Gráfico de falta de páginas do trace multi3.

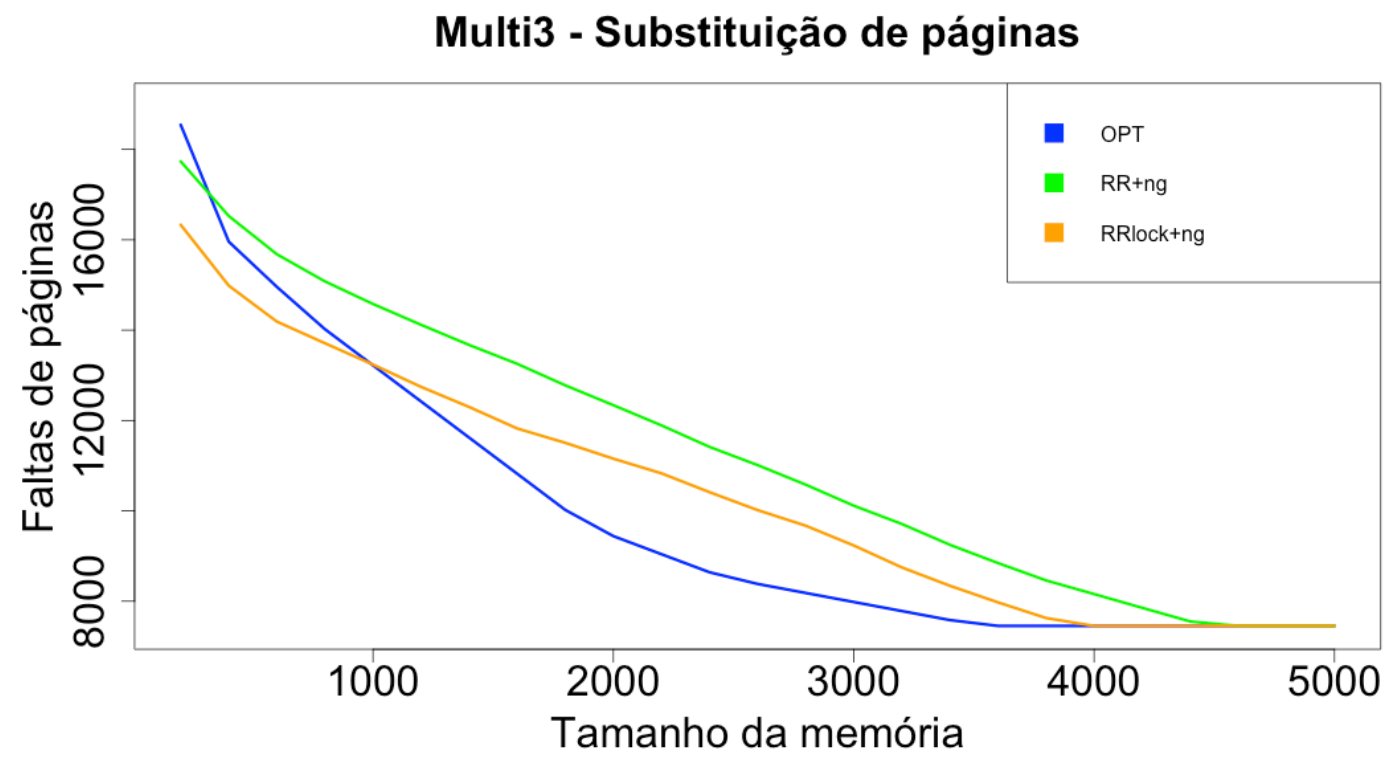

Fonte: Próprio Autor (2015)

O algoritmo RRlock+ng também supera o algoritmo OPT nos tamanhos menores de memória. Desta forma, no multi1, memórias menores que 1000 
páginas, já no multi2 menores que 800 páginas e por fim, no multi3, tamanhos de páginas menores que 1000. Isso, devido a utilização do técnica de lock.

Pode-se observar também que, como o RR+ng é o algoritmo base do RRlock+ng, a curva no gráfico permanece similar entre eles. Nos gráficos das Figuras 56, 57 e 58, as linhas representadas por eles permanecem quase paralelas.

O ganho médio de desempenho em relação ao $R R+n g$ é respectivamente para o multi1, multi2 e multi3: $10,41 \%, 11,09 \%$ e $9,64 \%$. O que é considerado expressivo para esse contexto.

\section{Análise da QUALIDADE dos traces multi1, multi2 e multi3}

Para análise de QUALIDADE dos resultados obtidos com o trace multi1, multi2 e multi3, foram escolhidos os mesmos tamanhos de memória da primeira iteração. Obteve-se melhor desempenho em tamanho de memória pequenas para o RRlock+ng, o qual é um resultado parecido da iteração anterior para o RR+ng, porém melhor. Os gráficos de QUALIDADES para a analise estão no apêndice $A$.

A Tabela 8 apresenta as médias de QUALIDADE para o OPT e RRlock+ng com os mesmos tamanhos de memoria da iteração anterior. As médias de QUALIDADE foram $60,52 \%, 48,81 \%$ e $47,16 \%$, respectivamente, para o algoritmo RRlock+ng, para memórias pequenas nos traces multi1, multi2 e multi3. Os valores de faltas de páginas são proporcionais de forma inversa a métrica de QUALIDADE.

O desempenho esperado no pior caso foi especificado para ser no máximo 8\% pior que o algoritmo ótimo, em relação a métrica de QUALIDADE. Portanto o RRlock+ng atingiu o desempenho alvo porque no pior caso, em relação ao algoritmo ótimo, obteve no máximo 3,35\% mais QUALIDADE. O resultado foi 
Tabela 8: QUALIDADE média para cada caso de teste do RRlock+ng

\begin{tabular}{ccccc}
\hline Trace & T. da memória & Algoritmo & qm médio & F. de páginas \\
\hline \hline Multi1 & \multirow{2}{*}{300} & OPT & $50,76 \%$ & 7.336 \\
& & RRlock+ng & $60,52 \%$ & 5.834 \\
\hline \multirow{2}{*}{1400} & OPT & $81,18 \%$ & 2.936 \\
& & RRlock+ng & $77,04 \%$ & 3.517 \\
\hline \multirow{2}{*}{ Multi2 } & \multirow{2}{*}{200} & OPT & $42,90 \%$ & 14.900 \\
& \multirow{2}{*}{2000} & RRlock+ng & $48,81 \%$ & 13.453 \\
\hline \multirow{2}{*}{ Multi3 } & \multirow{2}{*}{200} & OPT & $74,39 \%$ & 6.671 \\
& & RRlock+ng & $73,88 \%$ & 7.958 \\
\hline \multirow{3}{*}{2800} & OPT & $37,96 \%$ & 18.544 \\
& & RRlock+ng & $47,16 \%$ & 16.381 \\
\hline & OPT & $72,72 \%$ & 8.183 \\
& & RRLock+ng & $70,20 \%$ & 9.609 \\
\hline
\end{tabular}

positivo, isso quer dizer que, em média o RRlock+ng é 3,35\% melhor que o ótimo sob demanda.

\subsection{Considerações sobre a aplicação do método e dos algoritmos}

O desempenho esperado foi atingido, porém mais uma iteração teve que ser feita para melhorar o RR+ng criando um novo algoritmo. Na segunda iteração do método sistêmico incluiu-se a técnica de profiling, como foi adotado em (MIDORIKAWA; PIANTOLA; CASSETTARI, 2008), deixando assim o código mais rápido e com maior precisão desde o início de sua execução. Com isso, poderíamos remover a função de manutenção do hash na linha 13 em Algoritmo 
2.

Pode-se concluir que o método foi bem sucedido com a obtenção do RRlock+ng, que é um algoritmo que apresentou um bom desempenho, e, para alguns tamanhos de memória, até mesmo melhor que o algoritmo ótimo sob demanda. Além disso, a métrica de QUALIDADE refletiu o desempenho dos algoritmos analisados, pois a sua média apresentou forte correlação inversa com a métrica de número de falta de páginas. Por fim, os gráficos de QUALIDADE revelaram ser úteis para analisar os traces e retirar propriedades como padrão de acesso e mudança de localidade, especialmente quando analisados os gráficos da política OPT.

Os resultados obtidos, com ambos os algoritmos, mostram que tratar o problema da gerência da memória, consumindo recursos computacionais determinando quais páginas devem estar na memória em um determinado instante de tempo ao invés de quais devem deixá-la, pode ser uma possível solução. 


\section{CONCLUSÕES}

O objetivo desse trabalho foi propor uma forma eficiente de gerenciar a memória com a composição de técnicas de busca, posicionamento e substituição de páginas. Foi possível verificar que o uso do conceito de qualidade garante uma gerência eficiente, gerando melhor desempenho do sistema, menos faltas de páginas, menor tempo de execução ou maior nível de multiprogramação.

O objetivo foi alcançado através da aplicação do conceito de qualidade da configuração da memória principal, a concepção e a criação de um método para construir algoritmos de gerência de memória que utilize esse conceito e a definição da métrica de QUALIDADE para analisar e comparar o desempenho dos algoritmos de gerência de memória. O método criado com base no conceito de qualidade do conteúdo da memória gera algoritmos em que o foco principal é manter ou buscar páginas que serão referenciadas em um futuro próximo.

O trabalho apresentou a reanálise dos principais trabalhos que tinham como objetivo aumentar o desempenho da gerência de memória, tornando possível retirar novas conclusões e ideias sobre quais fatores influenciam de maneira positiva e quais os fatores que são secundários com relação ao desempenho do sistema de memória. A partir deste estudo foi determinado o conceito de qualidade e a métrica para medi-la. Aplicando tal conceito, foi formulado um método sistêmico de construção de algoritmos de gerência de 
memória. Realizou-se uma aplicação do método, criando-se então, o algoritmo RR+ng e em uma segunda iteração, o RRlock+ng. A métrica da QUALIDADE foi aplicada na fase final do método, mostrando-se adequada para realizar as análises.

Os resultados obtidos mostram que a hipótese de tratar o problema da gerência da memória, consumindo recursos computacionais determinando quais páginas devem estar na memória em um determinado instante de tempo ao invés de quais devem deixá-la, mostrou-se válida e parece promissora.

\subsection{Contribuições}

A contribuição mais significativa foi mostrar a importância da configuração da memória principal, ou seja, que é relevante que em um determinado instante de tempo, as páginas que serão referenciadas em um futuro próximo estejam na memória, para que o sistema fique mais tempo sem faltas de páginas, obtendo, consequentemente, melhor desempenho. Portanto, a política de substituição de páginas deixa de ser o único objeto dos esforços para a solução do problema de desempenho e os algoritmos de busca e posicionamento como também técnicas complementares ganham valor. Neste contexto, se verifica a importância do conceito de qualidade do conteúdo de memória, conforme definido neste trabalho.

Uma outra contribuição foi o método para construção de algoritmos que tem como base o uso do conceito da qualidade do conteúdo da memória principal. Tal método proporciona uma forma de obter um algoritmo com foco na qualidade que tem maiores chances de obter melhor desempenho na gerência de memória.

A definição de uma métrica que usa recência e frequência de acessos à 
memória para medir a qualidade da memória principal é uma contribuição para a área de análise de políticas de gerência de memória. Essa métrica é essencial para comparação das técnicas e informações utilizadas em um sistema de gerenciamento de memória virtual paginada, na busca de melhor desempenho nas execuções de programas.

A técnica de pré-paginação é analisada como alternativa de busca para se obter uma configuração de memória com boa qualidade. Um resultado interessante é que, nos experimentos, o RR+ng e o RRlock+ng superam o algoritmo Ótimo (OPT) em memórias de tamanho pequeno. Pode-se tirar duas conclusões: a primeira é que todo algoritmo de gerência de memória que utiliza substituição sob demanda pura é limitado ao Ótimo. A segunda é que algoritmos com busca antecipada podem ultrapassar esse limite imposto por aqueles sob demanda pura.

Outra contribuição interessante se refere à boa atuação do RR+ng e do RRlock+ng em memórias de tamanho pequeno, pois isso faz com que o algoritmo proposto apresente vantagens em sistemas de memória com gerência local, que distribuem poucas páginas para cada um dos processos, ou em um sistema embarcado.

Por fim, mas não menos importante, é que os próprios algoritmos de gerência de memória paginada RR+ng e RRlock+ng obtiveram desempenho perto do algoritmo Ótimo sob demanda e em algumas simulações o superaram.

\subsection{Trabalhos futuros}

Alguns experimentos complementares podem ser desenvolvidos para dar continuidade a este trabalho. Uma sugestão a considerar é utilizar a métrica de QUALIDADE em outros contextos de gerência de memória como, por exemplo, 
auxiliar a alocação de memória em hipervisores ou monitores de máquinas virtuais.

Além do uso da métrica de QUALIDADE em outros contexto, o método sistêmico de criação de algoritmos de gerência de memória pode ser aplicado em outras partes do sistema operacional, como por exemplo, na gerência do cache de blocos de disco do sistema de arquivos ou, até mesmo, na gerência do cache do navegador WEB.

Apesar do contexto do trabalho apresentar o conceito de qualidade em sistemas de memória virtual paginada, ele pode ser aproveitado em vários níveis da hierarquia de memória. Também pode ser adaptado para outros módulos dos sistemas operacionais que não a gerência de memória.

Usando o método sistêmico de construção de algoritmos de gerência de memória, novos algoritmos poderiam ser criados.

Outra sugestão a considerar é criar algoritmos com a técnica de superpaging utilizando o hardware impulse aplicando o método proposto da tese. O uso das superpages para substituir ou tornar a pré-paginação e o uso dos n-gramas menos custosos. Da mesma forma, pode ser analisado o uso do conceito de qualidade para aproveitar a ideia da política de substituição de páginas far em uma gerência de memória robusta. 


\section{REFERÊNCIAS}

AEROFLEX GAISLER. Quad Core LEON4 SPARC V8 Processor - Data Sheet and Users Manual. [S.I.], 2011. LEON4- NGMP-DRAFT.

AGRAWAL, K.; BENDER, M. A.; FINEMAN, J. T. The worst page-replacement policy. In: Fun with Algorithms. [S.I.]: Springer Berlin Heidelberg, 2007, (Lecture Notes in Computer Science, v. 4475). p. 135-145.

ARM HOLDINGS. ARM. Cortex-R4 and Cortex-R4F Technical Reference Manual. [S.I.], 2006.

BAYLIS, M. H. J.; FLETCHER, D. G.; HOWARTH, D. J. Paging studies made on the i.c.t. atlas computer. IFIP Congress, p. 831-837, ago. 1968.

BELADY, L. A. A study of replacement algorithms for a virtual-storage computer. IBM System Journal, IBM Corp., Riverton, NJ, USA, v. 5, n. 2, p. 78-101, jun. 1966.

BELADY, L. A.; KUEHNER, C. J. Dynamic space-sharing in computer systems. j-CACM, v. 12, n. 5, p. 282-288, maio 1969.

BURKS, A. W.; GOLDSTINE, H. H.; NEUMANN, J. von. Perspectives on the computer revolution. In: PYLYSHYN, Z. W.; BANNON, L. J. (Ed.). Norwood, NJ, USA: Ablex Publishing Corp., 1989. cap. Preliminary Discussion of the Logical Design of an Electronic Computing Instrument (1946), p. 39-48.

CASSETTARI, H.; MIDORIKAWA, E. T. Algoritmo adaptativo de substituição de páginas LRU-WAR: Exploração do modelo LRU com detecção de acessos sequenciais. In: Anais do Workshop de Sistemas Operacionais (I WSO - XXIV Congresso da Sociedade Brasileira de Computação). Salvador, BA: SBC, 2004. p. 25-35.

CASSETTARI, H. H. Análise da localidade de programas e desenvolvimento de algoritmos adaptativos para substituição de páginas. Tese (Mestrado) Escola Politécnica da Universidade de São Paulo, 2004.

CASSETTARI, H. H.; MIDORIKAWA, E. T. Caracterização de cargas de trabalho em estudos sobre gerência de memória virtual. In: Anais do Workshop em Desempenho de Sistemas Computacionais e de Comunicação. Salvador, BA: SBC, 2004. (III WPerformance), p. CD-ROM.

$\mathrm{CHOI}$, J. et al. An implementation study of a detection-based adaptive block replacement scheme. In: Proceedings of the Annual Conference on USENIX 
Annual Technical Conference. Berkeley, CA, USA: USENIX Association, 1999. (ATEC '99), p. 18-18.

. Towards application/file-level characterization of block references: A case for fine-grained buffer management. SIGMETRICS Performance Evaluation Review, ACM, New York, NY, USA, v. 28, n. 1, p. 286-295, jun. 2000.

DAHLGREN, F. et al. Sequential hardware prefetching in shared-memory multiprocessors. IEEE Transactions on Parallel and Distributed Systems, p. 733-746, 1995.

DASHTI, M. et al. Traffic management: A holistic approach to memory placement on NUMA systems. SIGARCH Comput. Archit. News, ACM, v. 41, n. 1, p. 381-394, mar. 2013.

DEITEL, H. M.; DEITEL, P. J.; CHOFFNES, D. R. Operating Systems'. Upper Saddle River, NJ: Prentice-Hall, 2005.

DENNING, P. J. Working sets past and present. IEEE Trans. Softw. Eng., IEEE Press, Piscataway, NJ, USA, v. 6, n. 1, p. 64-84, jan. 1980.

DENNING, P. J.; SCHWARTZ, S. C. Properties of the working-set model. Communications ACM, ACM, v. 15, n. 3, p. 191-198, mar. 1972.

FIAT, A.; ROSEN, Z. Experimental studies of access graph based heuristics: Beating the Iru standard? In: Proceedings of the $8^{\text {th }}$ Annual ACM-SIAM Symposium on Discrete Algorithms. New Orleans, USA: ACM, 1997. p. 63-72.

GANAPATHY, N.; SCHIMMEL, C. General purpose operating system support for multiple page sizes. In: Proceedings of the Annual Conference on USENIX Annual Technical Conference. Berkeley, USA: USENIX Association, 1998. (ATEC '98), p. 8-8.

GEROFI, B. et al. Cmcp: A novel page replacement policy for system level hierarchical memory management on many-cores. In: Proceedings of the 23rd International Symposium on High-performance Parallel and Distributed Computing. New York, NY, USA: ACM, 2014. (HPDC '14), p. 73-84.

GLASS, G.; CAO, P. Adaptive page replacement based on memory reference behavior. SIGMETRICS Performance Evaluation Review, ACM, New York, NY, USA, v. 25, n. 1, p. 115-126, jun. 1997.

GORMAN, M.; HEALY, P. Performance characteristics of explicit superpage support. Lecture Notes in Computer Science, v. 6161, p. 293-310, 2012.

HATFIELD, D. J.; GERALD, J. Program restructuring for virtual memory. IBM Systems Journal, v. 10, n. 3, p. 168-192, 1971. 
INTEL. Profile-Guided Optimizations Overview. 2008. Internet. Disponível em: http://www .intel.com/software/products/compilers/docs/flin/main for/mergedprojects/optaps_for/common/optaps_pgo_ovw.htm. Acesso em: 16/03/2008.

JIA, Q. et al. Supercloud: Opportunities and challenges. SIGOPS Oper. Syst. Rev., ACM, New York, NY, USA, v. 49, n. 1, p. 137-141, jan. 2015.

JIANG, S.; ZHANG, X. LIRS: An efficient low inter-reference recency set replacement policy to improve buffer cache performance. SIGMETRICS Perform. Eval. Rev., ACM, v. 30, n. 1, p. 31-42, jun. 2002.

JURAFSKY, D.; MARTIN, J. H. Speech and Language Processing: An Introduction to Natural Language Processing. New Jersey, USA: Prentice Hall, 2008.

KANRAR, S.; MANDAL, N. K. Dynamic page replacement at the cache memory for the video on demand server. In: Advanced Computing, Networking and Informatics - Volume 2. [S.I.]: Springer International Publishing, 2014, (Smart Innovation, Systems and Technologies, v. 28). p. 461-469.

KIM, H.; RAJKUMAR, R. Memory reservation and shared page management for real-time systems. Journal of Systems Architecture, Elsevier, v. 60, n. 2, p. 165-178, fev. 2014.

$\mathrm{KIM}$, J. M. et al. A low-overhead high-performance unified buffer management scheme that exploits sequential and looping references. In: Proceedings of the 4th Conference on Symposium on Operating System Design \& Implementation - Volume 4. Berkeley, CA, USA: USENIX Association, 2000. (OSDI'00), p. 119-134.

KNOPP, K. Theory and Applications of Infinite Series. New York, USA: Publishing Co., 1921.

KOBBE, S.; BAUER, L.; HENKEL, J. Adaptive on-the-fly application performance modeling for many cores. In: Proceedings of the 2015 Design, Automation \& Test in Europe Conference \& Exhibition. San Jose, CA, USA: EDA Consortium, 2015. (DATE '15), p. 730-735.

LEE, D. et al. LRFU: a spectrum of policies that subsumes the least recently used and least frequently used policies. IEEE Transactions on Computers, IEEE, v. 50, n. 12, p. 1352-1361, dez. 2001.

LI, B. et al. Exploiting semantics of virtual memory to improve the efficiency of the on-chip memory system. Lecture Notes in Computer Science, Euro-Par 2012 Parallel Processing, v. 7484, p. 232-245, 2012.

MAHAPATRA, N. R.; VENKATRAO, B. The processor-memory bottleneck: Problems and solutions. Crossroads, ACM, New York, NY, USA, v. 5, n. 3es, abr. 1999. 
MANNING, C. D.; SCHÜTZE, H. Foundations of Statistical Natural Language Processing. Cambridge, UK: The MIT Press, 1999.

MARKATOS, E. P. Visualizing working sets. SIGOPS Operating System Review, ACM, New York, NY, USA, v. 31, n. 4, p. 3-11, out. 1997.

MCDOUGALL, R. Supporting Multiple Page Sizes in the Solaris Operating System. [S.I.], 2004. Also published in FIPS 186-2.

MEGIDDO, N.; MODHA, D. S. ARC: a self-tuning, low overhead replacement cache. In: Proceedings of the $2^{\text {nd }}$ USENIX Conference on File and Storage Technologies. San Francisco, USA: USENIX Association, 2003. (FAST '03), p. $115-130$.

MIDORIKAWA, E. T.; PIANTOLA, R. L.; CASSETTARI, H. H. Influência das técnicas e informações no auxílio de políticas adaptativas de substituição de páginas. In: Anais do IV Workshop de Sistemas Operacionais. Rio de Janeiro, Brasil: SBC, 2007. (WSO '07), p. 1979-1990.

. On adaptive replacement based on Iru with working area restriction algorithm. SIGOPS Operating System Review, ACM, v. 42, n. 6, p. 81-92, out. 2008.

NAVARRO, J. et al. Practical, transparent operating system support for superpages. In: Proceedings of the $5^{\text {th }}$ Symposium on Operating Systems Design and implementation. New York, USA: ACM, 2002. (OSDI '02), p. 89-104.

PETERSON, J. L.; NORMAN, T. A. Buddy systems. Commun. ACM, ACM, New York, NY, USA, v. 20, n. 6, p. 421-431, jun. 1977.

PHALKE, V. Modeling and Managing Program References in a Memory Hierarchy. Tese (Doutorado) — Rutgers University, 1995.

PIANTOLA, R. L. Uso de técnicas e informações em algoritmos adaptativos para substituição de páginas. Tese (Mestrado) — Universidade de São Paulo, 2010.

PIANTOLA, R. L.; MIDORIKAWA, E. T. Ajustando o LRU-WAR para uma política de gerência de memória global. In: Anais do V Workshop de Sistemas Operacionais. Belém, PA: SBC, 2008. (WSO '08), p. 115-130.

. Uso de técnicas e informções para potencializar políticas de substituição em sistemas de memória virtual. In: Anais do VI Workshop de Sistemas Operacionais. Bento Gonçalves, RS: SBC, 2009. (WSO '09), p. 1979-1990.

. Influência das técnicas e informações no auxílio de políticas adaptativas de substituição de páginas. In: Anais do VII Workshop de Sistemas Operacionais. Belo Horizonte, MG: SBC, 2010. (WSO '10), p. 1979-1990. 
Qualidade da configuracão da memória para a política de substituiccão de páginas Iru. In: Escola Regional de Alto Desempenho. S, SP: [s.n.], 2014. (ERAD-SP), p. 76-80.

Main memory configuration quality for random page replacement policy. In: Proceedings of the 9th International Conference on Computer Engineering and Applications. Dubai, EAU: WSEAS Press, 2015. (CEA '15), p. 76-80.

QIU, S.; REDDY, A. Exploiting superpages in a nonvolatile memory file system. In: 2012 IEEE 28th Symposium on Mass Storage Systems and Technologies (MSST). San Diego, USA: IEEE, 2012. p. 1-5.

ROMER, T. Using Virtual Memory to Improve Cache and TLB Performance. Tese (Doutorado) - University of Washington, 1998.

SABEGHIL, M.; YAGHMAEE, M. H. Using fuzzy logic to improve cache replacement decisions. International Journal of Computer Science and Network Security, IJCSNS, Seoul, v. 6, n. 3A, p. 182-188, mar. 2006.

SHAIK, R.; PASHA, M. M. An efficient algorithm and a generic approach to reduce page fault rate and access time costs. In: Emerging ICT for Bridging the Future - Proceedings of the 49th Annual Convention of the Computer Society of India (CSI) Volume 1. [S.I.]: Springer International Publishing, 2015, (Advances in Intelligent Systems and Computing, v. 337). p. 513-523.

SHANNON, C. E. Game playing machines. Journal of the Franklin Institute, Elsevier, v. 260, n. 6, p. 447-453, dez. 1955.

SILBERSCHATZ, A.; GALVIN, P. B.; GAGNE, G. Operating System Concepts. 8th. ed. [S.I.]: Wiley Publishing, 2008.

SLEATOR, D. D.; TARJAN, R. E. Amortized efficiency of list update and paging rules. Communications of the ACM, ACM, New York, NY, USA, v. 28, n. 2, p. 202-208, fev. 1985.

SMARAGDAKIS, Y.; KAPLAN, S.; WILSON, P. EELRU: simple and effective adaptive page replacement. SIGMETRICS Perform. Eval. Rev., ACM, v. 27, n. 1, p. 122-133, maio 1999.

SMITH, A. J. Sequential program prefetching in memory hierarchies. Computer, v. 11, n. 12, p. 7-21, dez. 1978.

STILKERICH, I. et al. Team up: Cooperative memory management in embedded systems. In: Compilers, Architecture and Synthesis for Embedded Systems CASES, 2014 International Conference on. Uttar Pradesh, India: IEEE, 2014. p. 1-10.

SUBRAMANIAN, I. et al. Implementation of multiple pagesize support in hp-ux. In: Proceedings of the Annual Conference on USENIX Annual Technical Conference. Berkeley, USA: USENIX Association, 1998. (ATEC '98), p. 9-9. 
TRIVEDI, K. S. Prepaging and applications to array algorithms. IEEE Transactions on Computers, C-25, n. 9, p. 915-921, set. 1976.

UHLIG, R. A.; MUDGE, T. N. Trace-driven memory simulation: a survey. ACM Computing Surveys, ACM, v. 29, n. 2, p. 128-170, jun. 1997.

WEISBERG, P.; WISEMAN, Y. Using 4KB page size for virtual memory is obsolete. In: Information Reuse \& Integration. Las Vegas, USA: IEEE, 2009. (IRI '09), p. 262-265.

ZHANG, L. et al. The impulse memory controller. IEEE Transactions on Computers, IEEE Computer Society, v. 50, n. 11, p. 1117-1132, nov. 2001. 


\section{APÊNDICE A - GRÁFICOS ADICIONAIS PARA A ANÁLISE DOS ALGORITMOS}

Neste apêndice encontram-se os gráficos de falta de páginas para outros traces na Figura 59. O pacote de traces LIRS foi utilizado pelos autores do algoritmo LIRS (JIANG; ZHANG, 2002). O qual inclui: o 2_Pools, um programa sintético concebido pelos autores do LIRS; os traces do programas: CPP, CS, GLI, PS (CHOI et al., 1999; $\mathrm{CHOI}$ et al., 2000); multi1, multi2, multi3 (KIM et al., 2000); e Sprite (LEE et al., 2001). Esses programas estão descritos na Tabela 9.

Os gráficos de QUALIDADE da segunda iteração do método do capítulo 5, também estão neste apêndice, representados pelas Figuras 60, 61, 62, 63, 64 e 65. 
Figura 59: Gráfico de falta de páginas por tamanhos de memória dos traces do pacote Lirs. Legenda: LRU(rosa), WST(vermelho), OPT(azul), RND(preto), RR+ng(verde) e RRlock+ng(laranja)

(a)

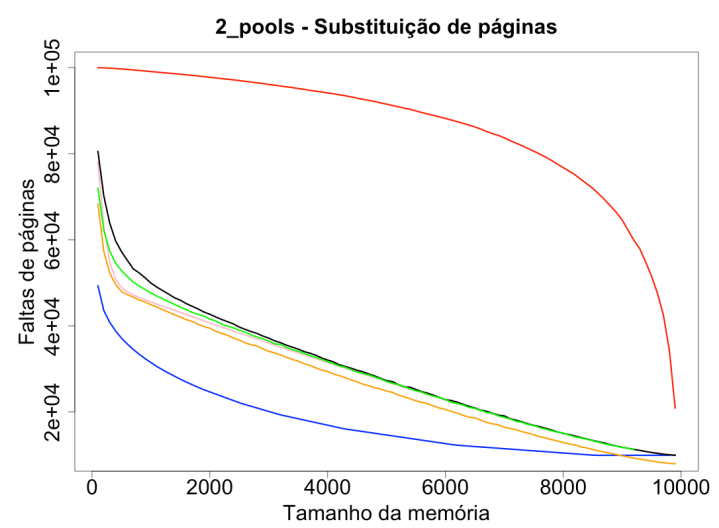

(c)

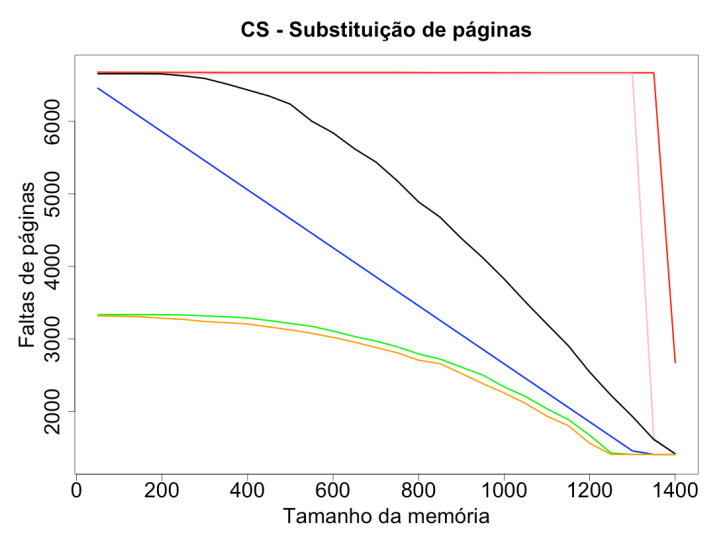

(e)

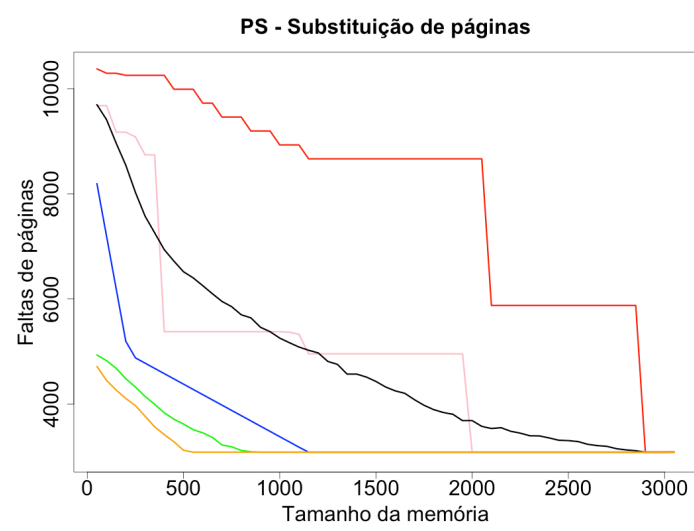

(b)

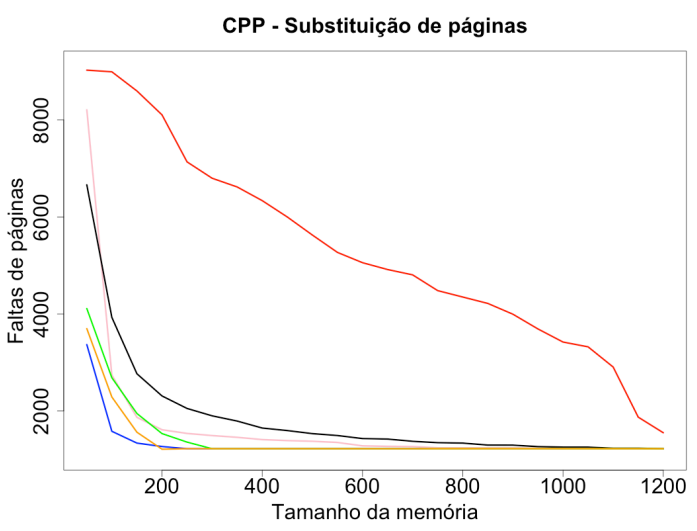

(d)

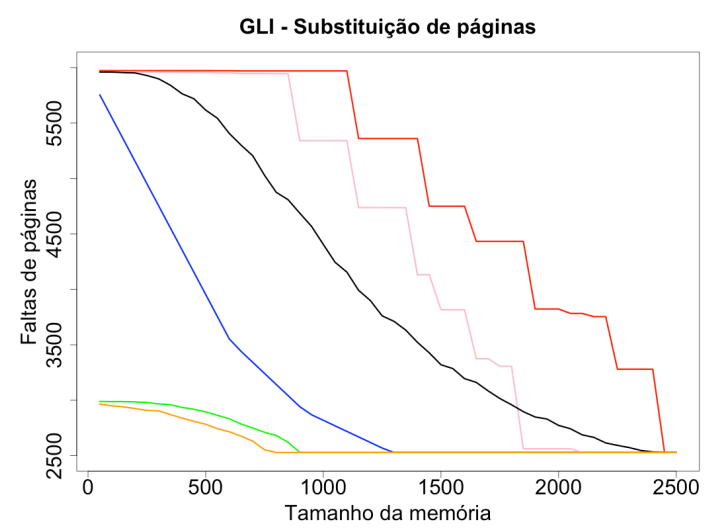

(f)

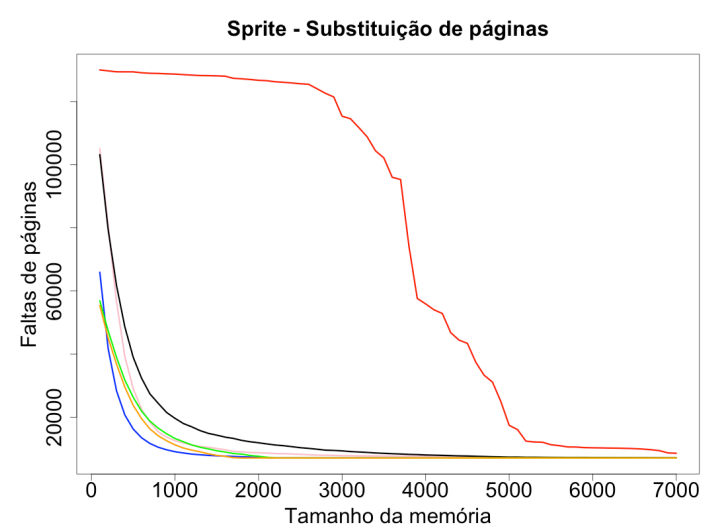

Fonte: Próprio Autor (2015) 
Tabela 9: Descrição dos traces do pacote Lirs

\begin{tabular}{|c|c|c|}
\hline Trace & Descrição & Total de páginas \\
\hline 2_Pools & $\begin{array}{l}\text { Simulador sintético com acessos aleatórios } \\
\text { em páginas com probabilidades de referên- } \\
\text { cia distintas. }\end{array}$ & 9939 \\
\hline CPP & $\begin{array}{l}\text { Pré-processador do projeto GNU para com- } \\
\text { pilação de programas em linguagem C. }\end{array}$ & 1223 \\
\hline CS & $\begin{array}{l}\text { Cscope, utilitário para analise códigos fonte } \\
\text { de programas em C. }\end{array}$ & 1409 \\
\hline GLI & Glimpse, utilitário para procura de texto. & 2529 \\
\hline PS & $\begin{array}{l}\text { Postgres, operações de consulta na banco } \\
\text { de dados relacional. }\end{array}$ & 3083 \\
\hline Sprite & $\begin{array}{l}\text { Proveniente do sistema de arquivos de } \\
\text { rede Sprite. Contém requisições a um ser- } \\
\text { vidor de arquivos a partir de várias esta- } \\
\text { ções de trabalho cliente em um período de } \\
\text { dois dias. }\end{array}$ & 7075 \\
\hline
\end{tabular}


Figura 60: Gráfico de QUALIDADE do RRlock+ng para 300 páginas no trace multi1

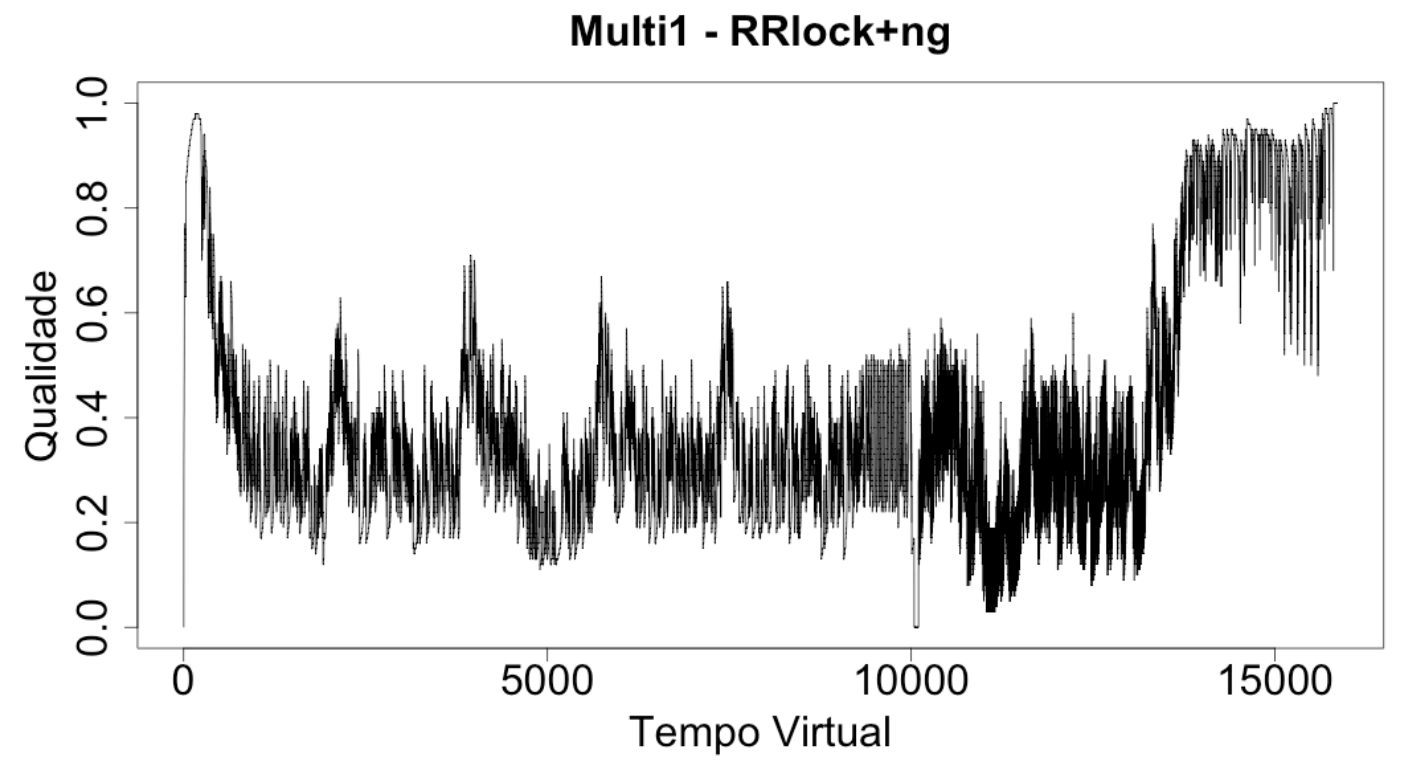

Fonte: Próprio Autor (2015)

Figura 61: Gráfico de QUALIDADE do RRlock+ng para 1400 páginas no trace multi1

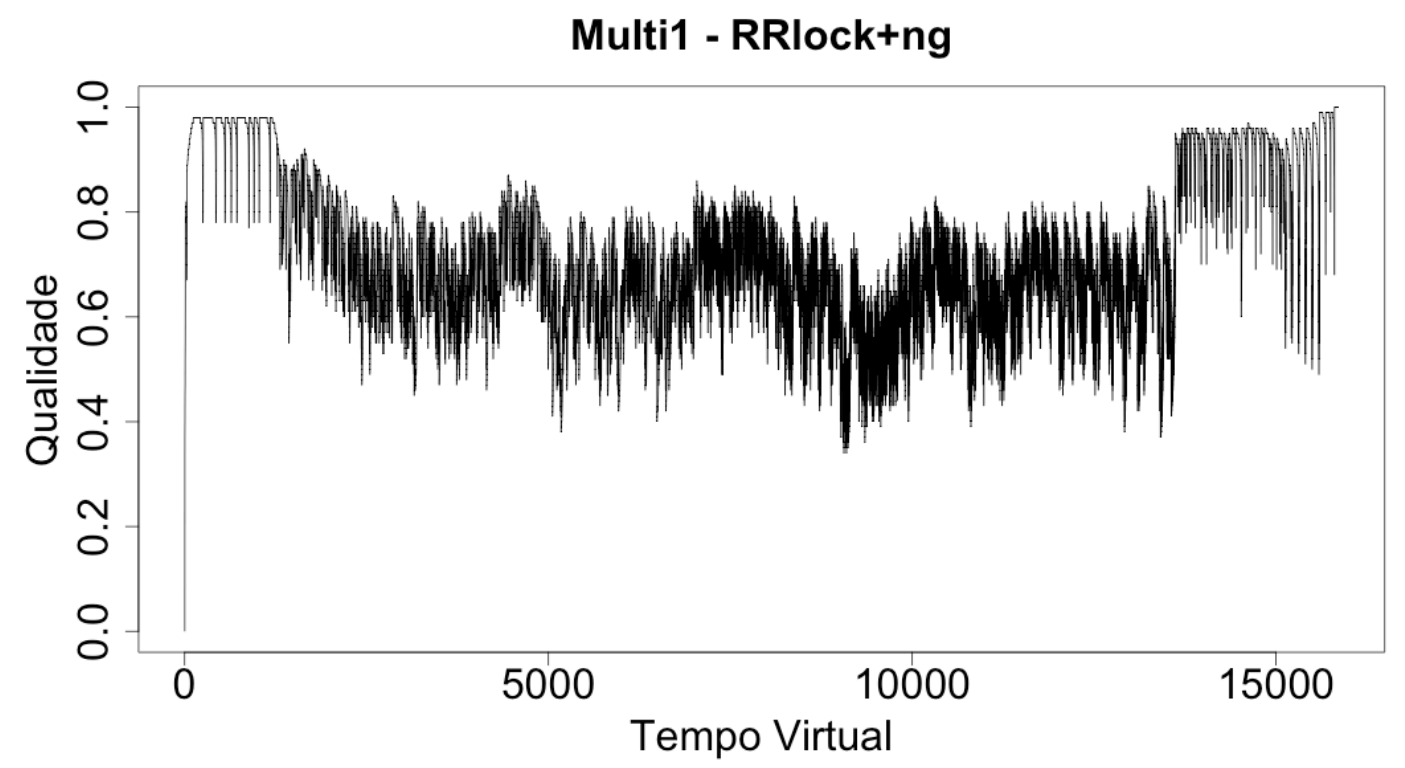

Fonte: Próprio Autor (2015) 
Figura 62: Gráfico de QUALIDADE do RRlock+ng para 200 páginas no trace multi2

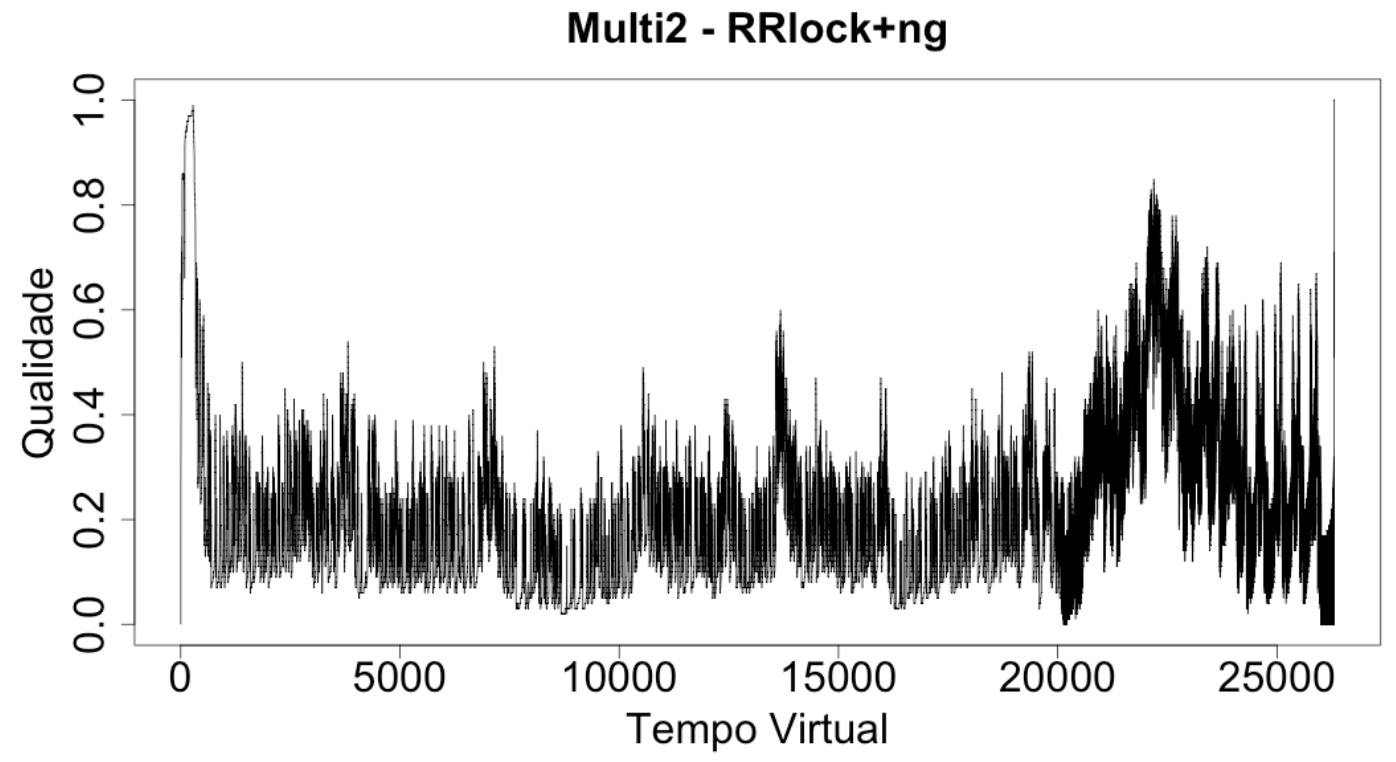

Fonte: Próprio Autor (2015)

Figura 63: Gráfico de QUALIDADE do RRlock+ng para 2000 páginas no trace multi2

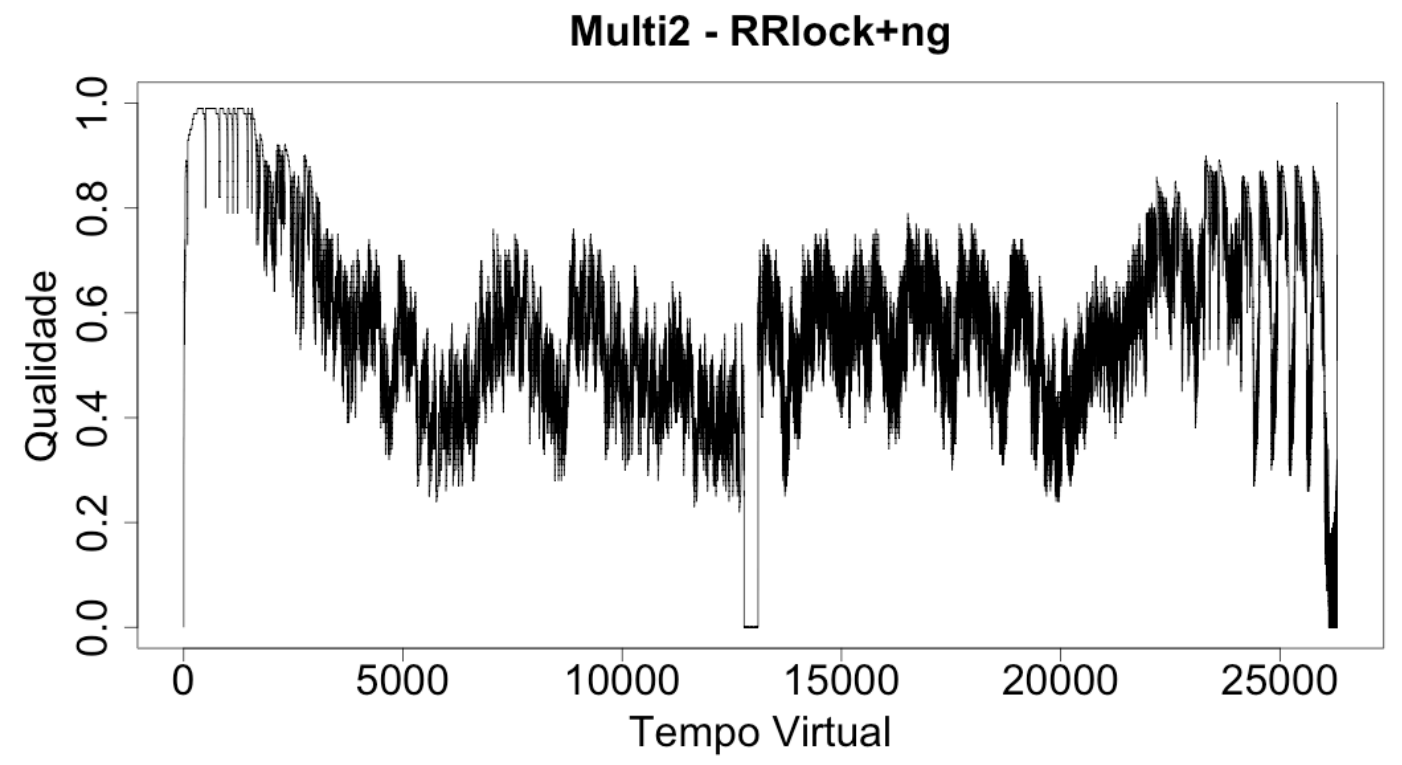

Fonte: Próprio Autor (2015) 
Figura 64: Gráfico de QUALIDADE do RRlock+ng para 200 páginas no trace multi3

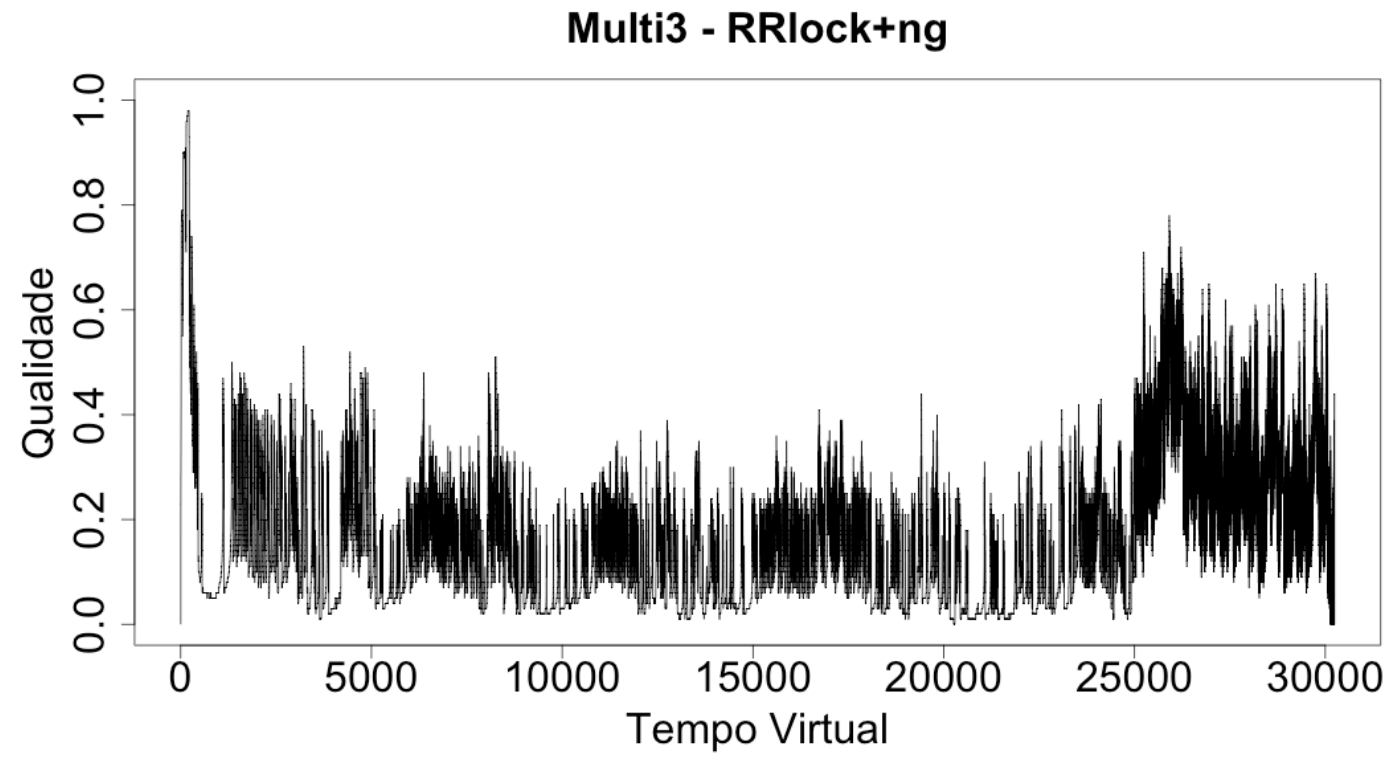

Fonte: Próprio Autor (2015)

Figura 65: Gráfico de QUALIDADE do RRlock+ng para 2800 páginas no trace multi3

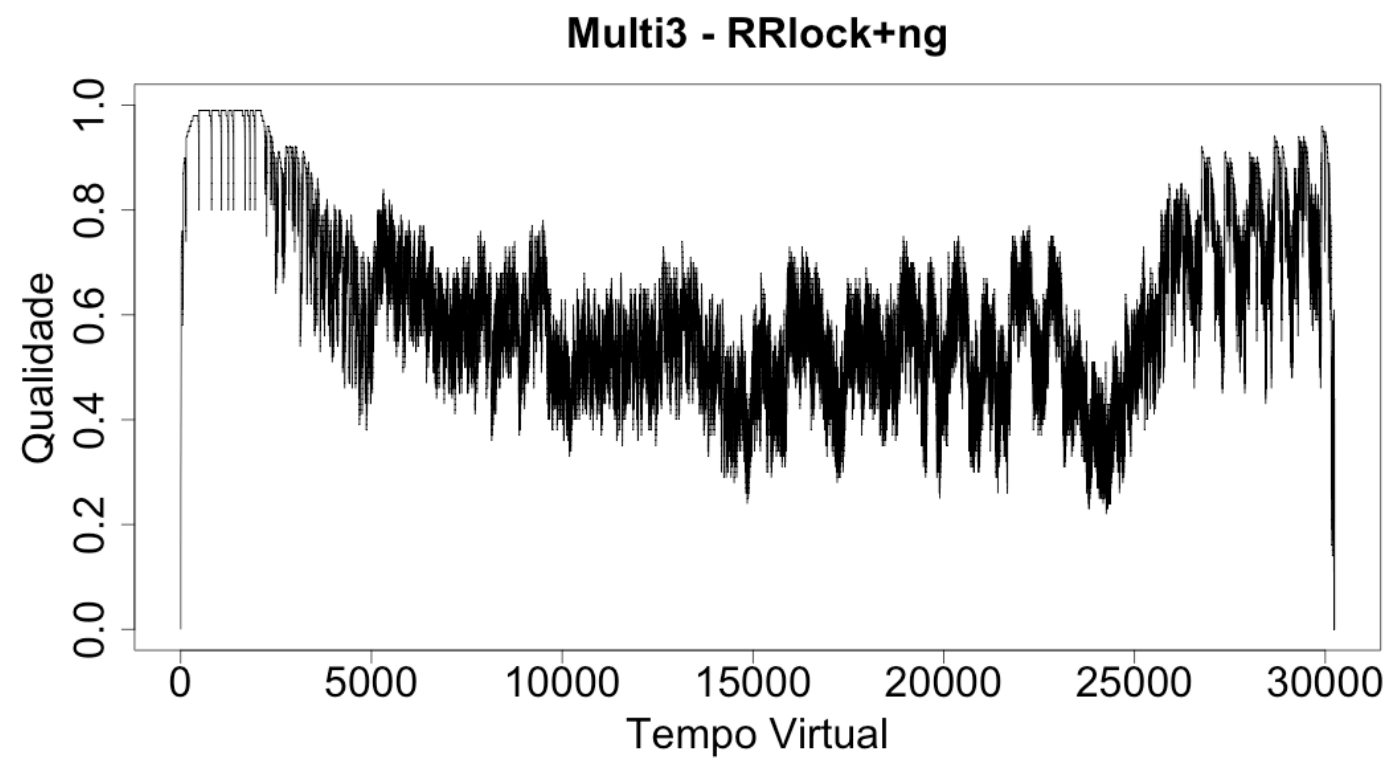

Fonte: Próprio Autor (2015) 